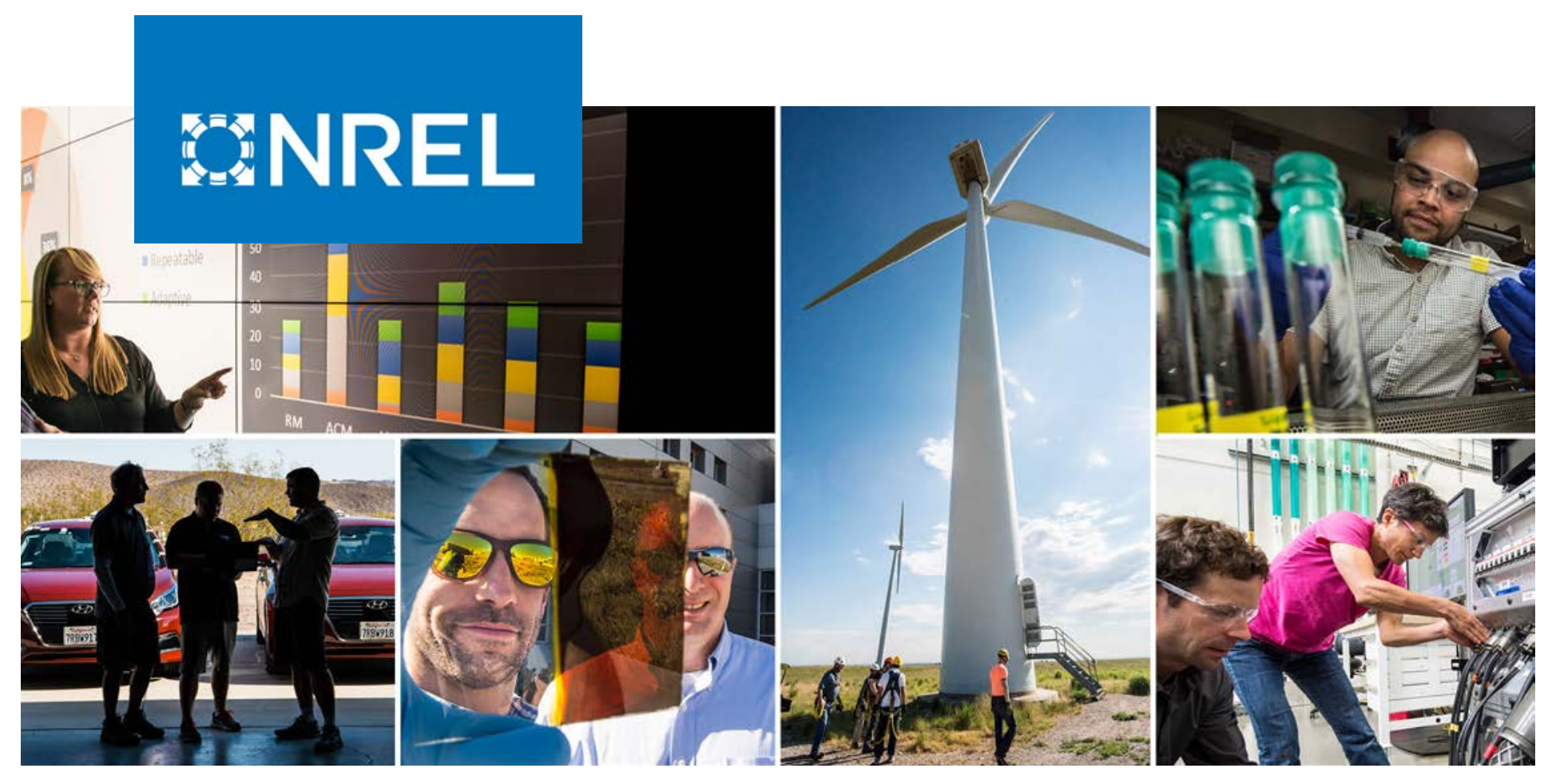

\title{
Acciona Power Plant Hydrogen Mitigation Project
}

\author{
Greg Glatzmaier
}

National Renewable Energy Laboratory

NREL is a national laboratory of the U.S. Department of Energy

Office of Energy Efficiency \& Renewable Energy

Operated by the Alliance for Sustainable Energy, LLC

This report is available at no cost from the National Renewable Energy Laboratory (NREL) at www.nrel.gov/publications.

\section{Technical Report}

NREL/TP-5500-73168

April 2020 


\title{
FANRL
}

\section{Acciona Power Plant Hydrogen Mitigation Project}

\author{
Greg Glatzmaier
}

National Renewable Energy Laboratory

\section{Suggested Citation}

Glatzmaier, Greg. 2020. Acciona Power Plant Hydrogen Mitigation Project. Golden, CO: National Renewable Energy Laboratory. NREL/TP-5500-73168.

https://www.nrel.gov/docs/fy20osti/73168.pdf.

NREL is a national laboratory of the U.S. Department of Energy Office of Energy Efficiency \& Renewable Energy Operated by the Alliance for Sustainable Energy, LLC

This report is available at no cost from the National Renewable Energy Laboratory (NREL) at www.nrel.gov/publications.

Contract No. DE-AC36-08GO28308
Technical Report NREL/ TP-5500-73168 April 2020

National Renewable Energy Laboratory 15013 Denver West Parkway Golden, CO 80401 303-275-3000 • www.nrel.gov 


\section{NOTICE}

This work was authored by the National Renewable Energy Laboratory, operated by Alliance for Sustainable Energy, LLC, for the U.S. Department of Energy (DOE) under Contract No. DE-AC36-08GO28308. Funding provided by U.S. Department of Energy Office of Energy Efficiency and Renewable Energy, Solar Energy Technologies Office. The views expressed herein do not necessarily represent the views of the DOE or the U.S. Government.

This report is available at no cost from the National Renewable Energy Laboratory (NREL) at www.nrel.gov/publications.

U.S. Department of Energy (DOE) reports produced after 1991 and a growing number of pre-1991 documents are available free via www.OSTI.gov.

Cover Photos by Dennis Schroeder: (clockwise, left to right) NREL 51934, NREL 45897, NREL 42160, NREL 45891, NREL 48097, NREL 46526.

NREL prints on paper that contains recycled content. 


$\begin{array}{ll}\text { Project Title: } & \text { Acciona Power Plant Hydrogen Mitigation Project } \\ \text { Project Period: } & 06 / 01 / 15-9 / 30 / 18 \\ \text { Submission Date: } & 12 / 17 / 18 \\ \text { Recipient: } & \text { National Renewable Energy Laboratory } \\ \text { Address: } & \begin{array}{l}15013 \text { Denver West Parkway } \\ \text { Golden, CO 80401 }\end{array} \\ \text { Award Number: } & \text { DE-AC36-086028308 } \\ \text { Project Team: } & \begin{array}{l}\text { National Renewable Energy Laboratory } \\ \text { Acciona Solar Power Inc. }\end{array} \\ \text { Principal Investigator: } & \begin{array}{l}\text { Greg Glatzmaier } \\ \text { Senior Engineer }\end{array} \\ & \begin{array}{l}\text { Phone: 303-384-7470 } \\ \text { Email: greg.glatzmaier@nrel.gov }\end{array} \\ \text { DOE Tech Manager: } & \text { Rajgopal Vijaykumar } \\ \text { DOE Project Officer: } & \text { Christine Bing }\end{array}$




\section{Table of Contents}

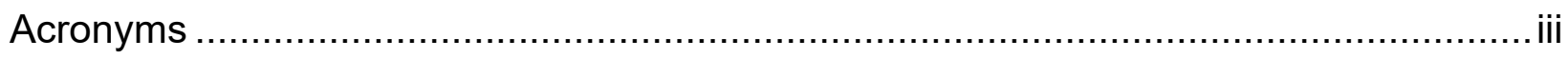

Evaluation criteria \& milestone status...........................................................................

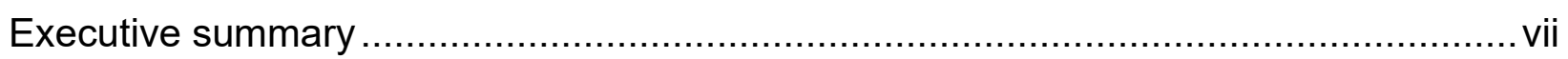

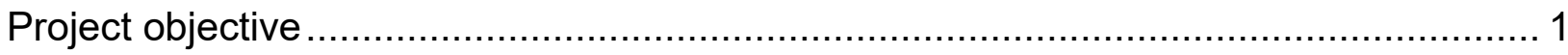

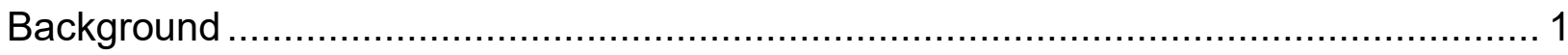

Parabolic trough power plant design and operation...................................... 1

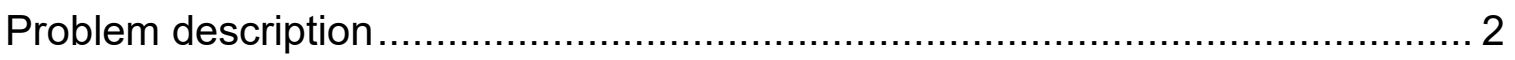

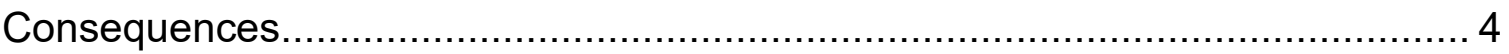

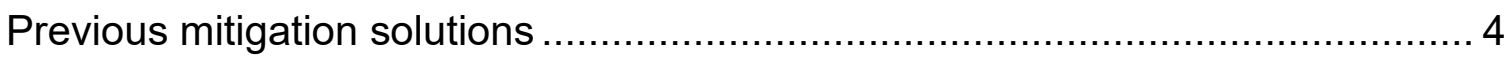

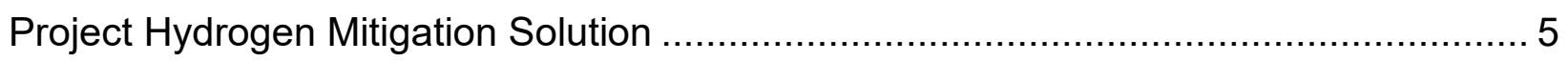

NREL and Acciona Solar Power initial discussions ....................................... 5

Measuring hydrogen levels in the expansion tank ........................................... 6

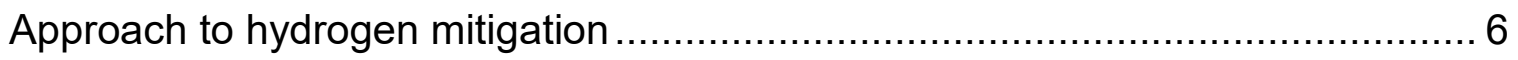

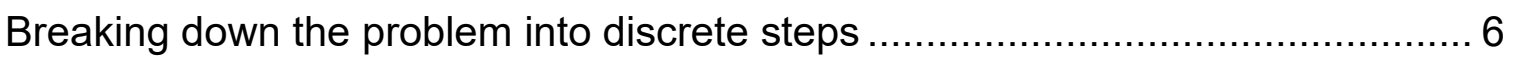

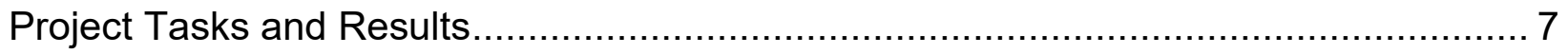

Sensor development - design and experiments ........................................ 7

Sensor development - modeling transient response .................................... 14

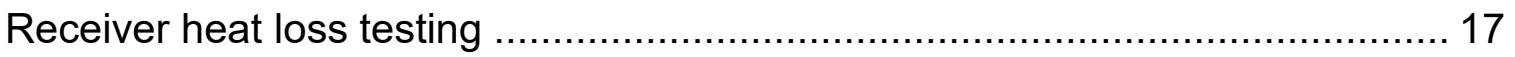

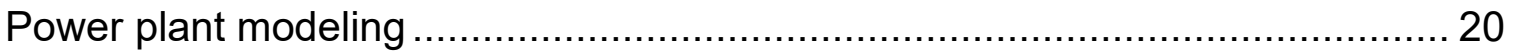

Modeling results for NSO power plant with no hydrogen extraction .................. 27

Modeling results for NSO power plant with hydrogen extraction ...................... 29

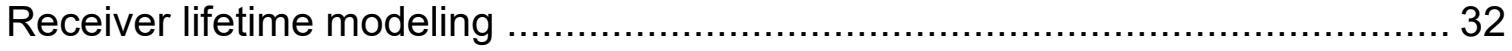

Expansion tank model development ........................................................... 33

Estimating diffusion coefficients of hydrogen in heat transfer fluid .................... 36

Diffusion coefficient of hydrogen in head space gas..................................... 36

Diffusion coefficient of hydrogen in heat transfer liquid ................................. 37

Mass transfer model of hydrogen diffusion using diffused aeration ................... 37

Modeling of mass transfer at surface liquid-gas interface................................ 38

Modeling of mass transfer at the bubbles' liquid-gas interface ......................... 39

Combining bubble and surface mass transfer ............................................ 40

Nevada Solar One expansion tank geometry and operating parameters .......... 40

Simulation results for Nevada Solar One parabolic trough power plant............. 41 
Expansion tank experimental work ........................................................... 43

Hydrogen/HTF interface properties measurements - experimental procedure .. 44

Hydrogen/HTF interface properties measurements - measurement results ...... 47

Mitigation process - development of integrated module................................. 50

Mitigation process - integrated module model development............................. 53

Mitigation process - steady-state model ............................................... 54

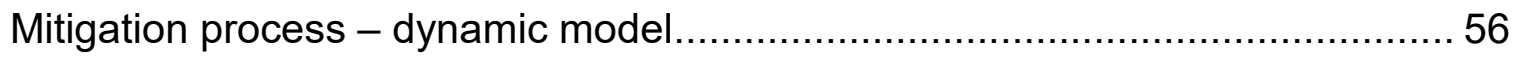

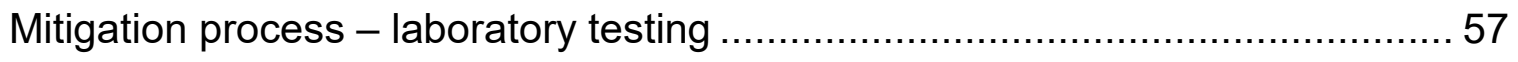

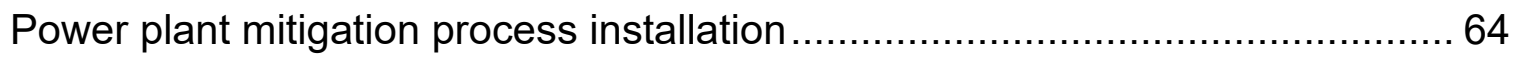

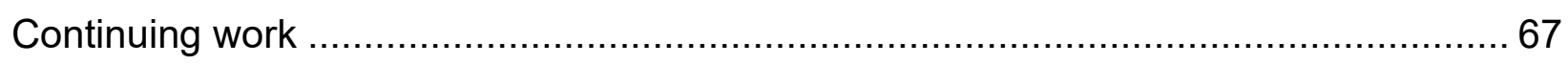

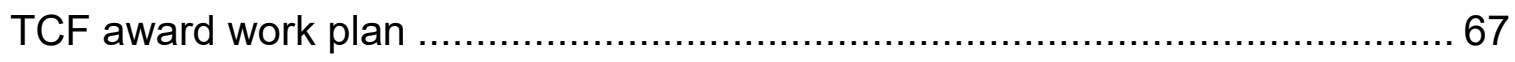

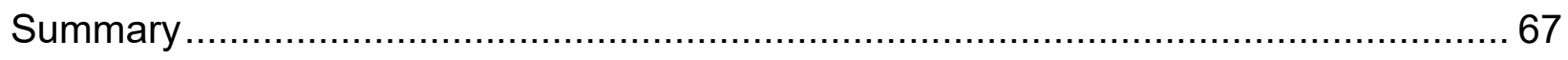

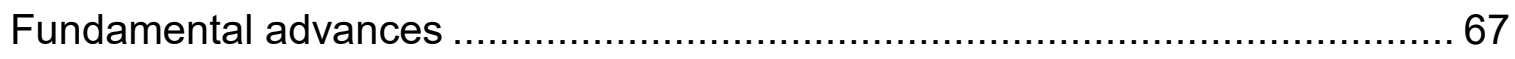

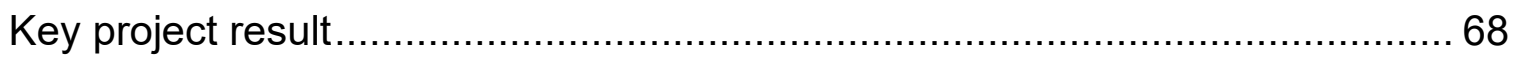

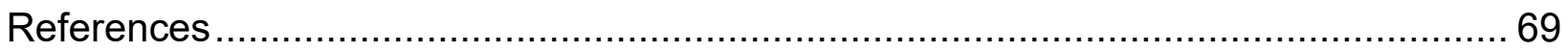


Acronyms

$\begin{array}{ll}\text { ASP } & \text { Acciona Solar Power, Inc. } \\ \text { BL } & \text { boundary layer } \\ \text { CRADA } & \text { Cooperative Research and Development Agreement } \\ \text { DOE } & \text { Department of Energy } \\ \text { FOA } & \text { Funding Opportunity Announcement } \\ \text { HTF } & \text { heat transfer fluid (Dowtherm A }{ }^{\text {TM }} \text { or Therminol VP-1 }{ }^{\text {TM}} \text { ) } \\ \text { HSG } & \text { headspace gas } \\ \text { NREL } & \text { National Renewable Energy Laboratory } \\ \text { NSO } & \text { Nevada Solar One } \\ \text { P\&ID } & \text { Piping \& Instrumentation Diagram } \\ \text { TCF } & \text { Technology Commercialization Fund } \\ \text { VOC } & \text { volatile organic compound }\end{array}$




\section{Executive Summary}

In 2014, Acciona Solar Power and the National Renewable Energy Laboratory initiated discussions to identify a method to solve a long-standing efficiency loss problem at parabolic trough power plants. Parabolic trough power plants begin to show lost thermal efficiency after six years of operation, due to the presence of trace concentrations of hydrogen in the heat transfer fluid that circulates in the power plant. Trace levels of hydrogen infiltrate the collector field receivers, increasing their heat loss, and decreasing the power plants' thermal efficiency. At the time, Acciona's Nevada Solar One power plant in Boulder City, Nevada was starting to show this efficiency loss.

After several discussions, APS and NREL agreed to a collaborative effort (CRADA) to develop and implement a method to reduce hydrogen levels in the circulating HTF at the NSO power plant. The project was planned as a three-year effort, and work started in June 2015. The CRADA's goal was to solve the long-standing lost efficiency problem caused by the buildup of hydrogen in the HTF, which significantly impacts the efficiency, electricity generation, and revenue from parabolic trough power plants.

Prior to the start of this project, NREL had conceived and patented [1] a general method to control hydrogen levels based on extracting hydrogen from the HTF that resides in the power plant expansion tanks. Project objectives were established based on this general approach. Specific objectives were to 1) develop a sensor that measures hydrogen levels in the power plant expansion tanks, 2) perform experiments to determine the impact of reducing hydrogen levels on the performance of the collector field receivers, 3 ) develop a model that predicts receiver lifetime as a function of receiver location in the collector field and dissolved hydrogen concentration in the HTF, 4) develop power plant models that predict hydrogen levels in the circulating HTF as a function of hydrogen extraction rates from the expansion tanks, and 5) design and demonstrate a method to extract hydrogen from the expansion tanks at a prescribe rate. The final project goal was to design, implement, and evaluate a full-scale hydrogen mitigation process at the NSO power plant.

During the first project year, we identified, developed, and demonstrated a sensor that measures hydrogen partial pressure in the headspace gas of the power plant expansion tanks $[2,3]$. Using this instrument, we performed several rounds of measurements of hydrogen partial pressure over the range of $1.3 \mathrm{mbar}$ to $0.0027 \mathrm{mbar}$ in hydrogen and nitrogen, and in mixtures of hydrogen, nitrogen, and the HTF components - biphenyl, and diphenylether. This work demonstrated the functionality of the method and established the measurement uncertainty to be $+/-20 \%$ for this partial pressure range.

We performed extended heat loss testing of an in-service receiver that was removed from the NSO collector field [4]. This testing showed that extended heating of the receiver at its nominal operating temperature caused hydrogen to reverse permeate out of the receiver annulus through the absorber. After heating for 120 days at an absorber temperature of $390^{\circ} \mathrm{C}$, measurements showed that hydrogen pressure in the annulus decreased from an initial value of 9.3 mbar to $1.3 \mathrm{mbar}$. This work clearly showed that hydrogen permeation into receiver can be reversed to improve receiver performance. 
We developed a power plant model [5] to 1) estimate steady-state hydrogen levels in all power plant components and subsystems that contain circulating HTF, and 2) determine the hydrogen extraction rate from the expansion tanks that is needed to reduce collector field hydrogen and maintain receiver performance. We developed a mass transfer model [6] for the expansion tanks that estimated rates of passive and enhanced hydrogen transfer across the HTF liquid/gas interface as a function of headspace gas hydrogen partial pressure.

Our power plant model determined that reducing dissolved hydrogen in the expansion tank HTF to a partial pressure of $0.3 \mathrm{mbar}$ in the headspace gas will maintain dissolved hydrogen concentration in the collector field to $0.09 \mathrm{ppm}$. Our receiver lifetime model estimated that maintaining the collector field hydrogen to $0.09 \mathrm{ppm}$ allows the collector field receivers to keep their original performance for the 30-year plant lifetime. Maintaining this hydrogen level requires a hydrogen extraction rate of $1.7 \cdot 10^{-4} \mathrm{moles} / \mathrm{s}$ from each expansion tank. This rate was the primary specification for the mitigation process design.

Our mass transfer model estimated hydrogen transfer rates across the liquid/gas interface in the expansion tank and showed that passive diffusion across the liquid/gas interface with moderate hydrogen partial pressures ( $\sim 0.5 \mathrm{mbar})$ in the headspace gas is likely sufficient to meet target rates around $1.7 \cdot 10^{-4} \mathrm{moles} / \mathrm{s}$. More aggressive extraction rates up to $2.0 \cdot 10^{-4}$ moles/s require either a diffused aeration system, which increases the liquid/gas interface area due to the bubbles created in the HTF, or a lower hydrogen partial pressure in the headspace gas (below $0.1 \mathrm{mbar}$ ), which increases the driving force for passive removal.

During the second year, we focused our effort to specify designs for the sensor and separation process unit that would be installed at the NSO power plant. We conceived an integrated process module that combined the hydrogen sensing and separating functions into a single unit. This advance greatly simplified the mitigation process design and installation. NREL submitted a patent application for the integrate sensor/separator module in 2017 [7].

We performed extensive modeling of the integrated module design to estimate its performance and to design laboratory experiments that would give us the information needed to proceed to the power plant installation design. We modeled the module's steady-state behavior, which corresponds to its separation mode, and its dynamic behavior, which corresponds to its sensor mode. We identified mass transfer resistances that were quantified and incorporated into both models to estimate hydrogen transfer rates under steady state and dynamic conditions.

We used our modeling results to design and fabricate a laboratory-scale integrated module and test system that was used to demonstrate both separating and sensor functions [8]. For the sensing mode, we measured the transient response as a function of total headspace gas pressure, hydrogen partial pressure, and headspace gas flowrate. The initial rate of the transient response gave us the steady-state hydrogen transfer rate, and the final pressure gave us the hydrogen partial pressure in the headspace gas. The response time needed for the integrated module (2-3 min.) was 
significantly less than the response time for the original sensor design (5-6 min.), and showed a significant advance in the performance of the sensor design. These experiments determined accuracy of partial pressure measurement to be $\pm 10 \%$, and the accuracy of the rate measurement to be $\pm 50 \%$.

For the separation mode, the key unknown variables for quantifying the transfer rate were the thicknesses of the hydrodynamic $\left(\delta_{H D}\right)$ and concentration $\left(\delta_{C}\right)$ boundary layers in the headspace gas flow. For turbulent flow, literature estimates of the thickness of these layers are $25 \mu \mathrm{m}-127 \mu \mathrm{m}$. Our experiments determined values for these thicknesses for the integrated module.

We designed and constructed an experiment to validate the numerical results obtained during the first year that predicted hydrogen mass transfer rates across the HTF liquid/gas interface in the expansion tank. Specifically, the mass transfer rate (and associated mass transfer coefficient), and Henry's law constant were determined experimentally as a function of pressure, temperature, and mixing. This experiment was a first-of-its-kind and was designed to provide transient data (mass transfer rate) and steady-state date (Henry's law constant) in a single run with high accuracy. All experimental data were documented [9].

During the third year, our work transitioned from primarily modeling and laboratory-scale experiments to the on-site installation at the NSO power plant. Work during the first two years was essentially performed at NREL. The start of the third year was marked by the transfer of effort from NREL to working with the NSO staff on a daily basis.

The workplan for the third year consisted of 1) specifying performance targets for the test-scale and full-scale processes at the power plant, 2) selecting the process location and piping configuration in the plant power block, 3) estimating installation costs for the processes, 4) specifying all equipment and components for the process, 5) evaluating safety and permitting requirements for pressure vessels and electrical equipment, 6 ) purchasing materials and equipment, 7) fabricating custom components, and 8) installing all equipment, piping, and instrumentation. When we reached the end of the period of performance for this project, NREL and NSO had made much progress towards the NSO installation, but the installation was only partially complete.

In August 2018, NREL was awarded Technology Commercialization Funds to continue this effort at the NSO power plant. The award funds this effort for an additional 17 months. During this time, NREL and NSO intend to complete the test- and full-scale installations of this mitigation process and evaluate their performances. 


\section{Project Objective}

This project was a cooperative effort (CRADA) between NREL and ASP. The project's goal was to solve a long-standing thermal efficiency loss and performance problem that significantly impacts the electricity output of parabolic trough power plants. The technical objectives were to develop a hydrogen mitigation process at NREL that reduces dissolved hydrogen in the circulating HTF of parabolic trough power plants, and to design, implement, and evaluate a hydrogen mitigation process at ASP's NSO power plant.

\section{Background}

Parabolic trough power plant design and operation

The parabolic trough power plant is a linear focus CSP plant that generates utilityscale electricity from sunlight. Figure 1 shows some of the basic power plant components, which include the collector field reflectors and receivers, steam generators, and HTF storage tanks - referred to as expansion tanks

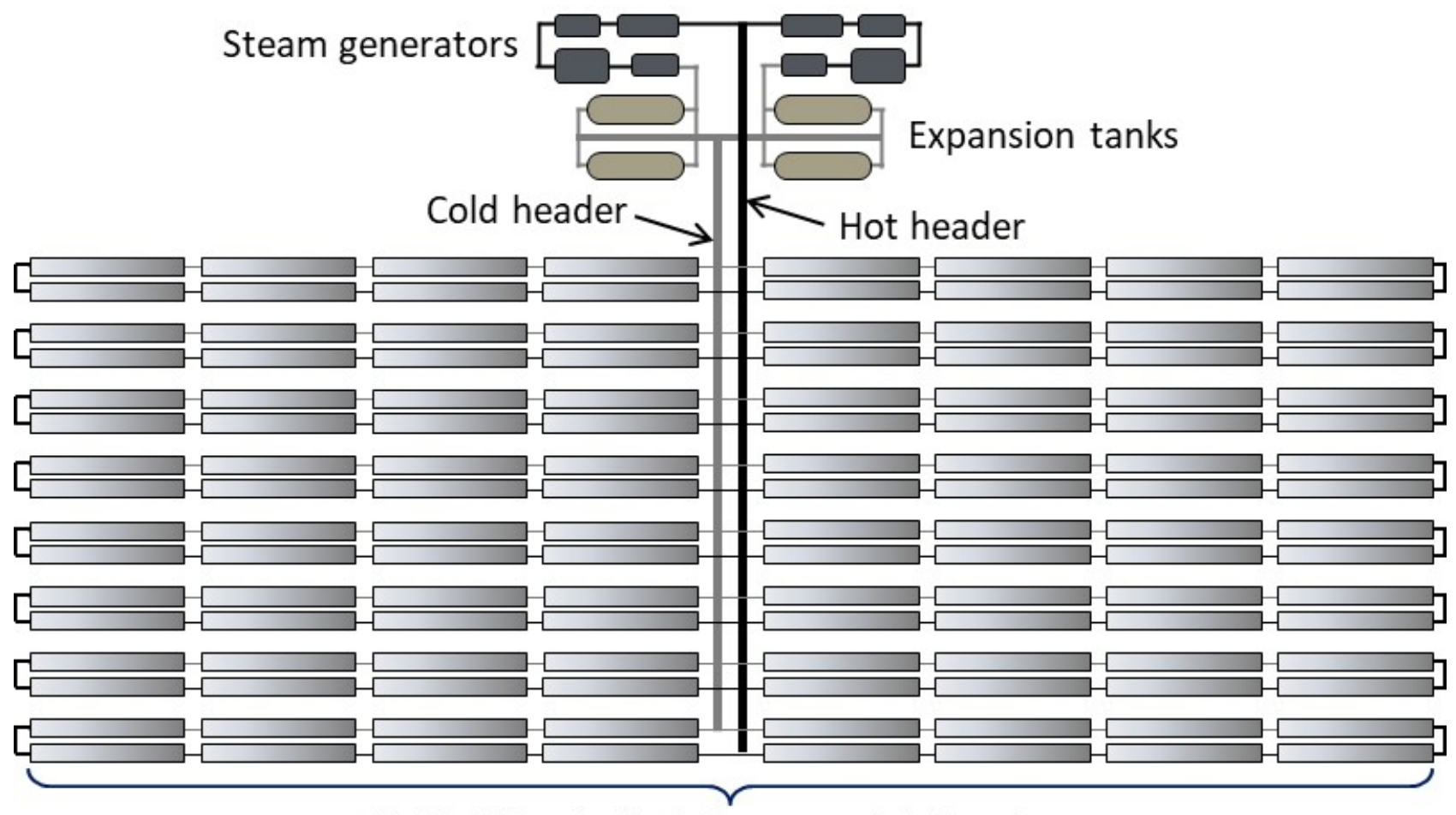

Field of Parabolic Reflectors with Receivers

Figure 1: Parabolic trough power plant components that contain the circulating HTF. 
The collector field consists of parabolic reflectors that concentrate and direct sunlight to receivers, which are located at their focal line as shown in Figure 2. The concentrated sunlight heats the HTF as it flows through the receivers. The HTF produces steam in the steam generators that power the turbine, and the turbine generates electricity for the electric power grid.

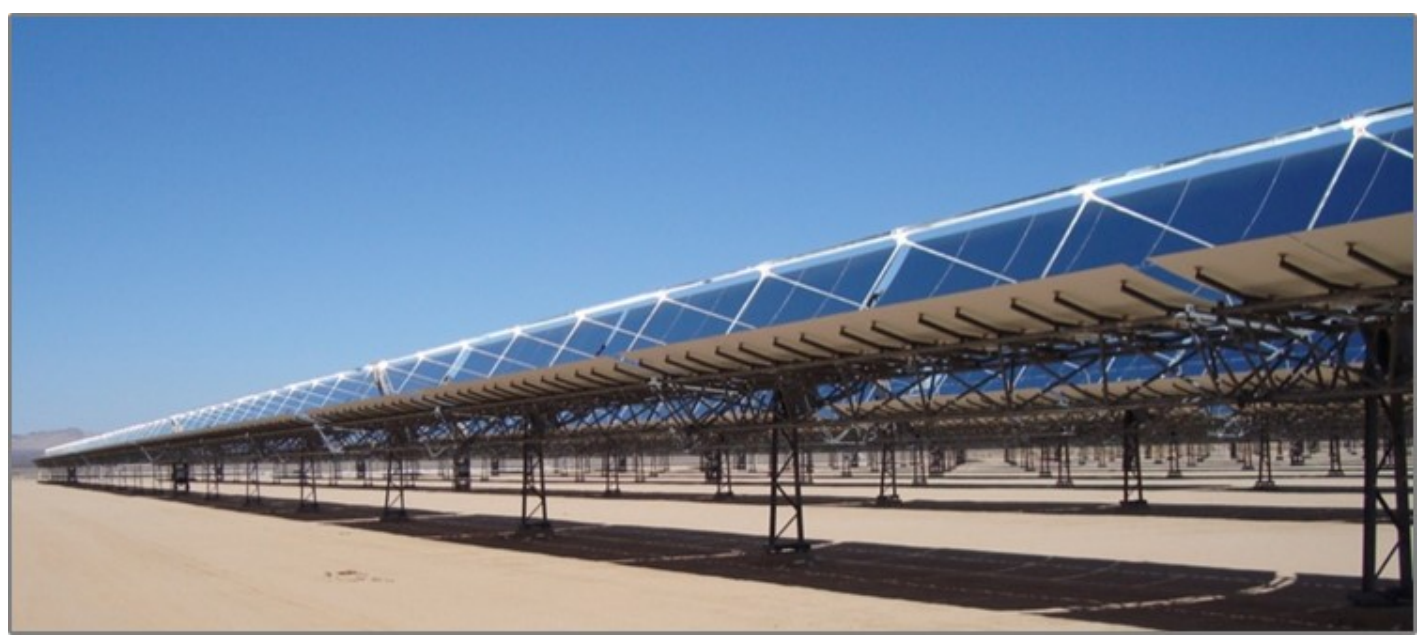

Figure 2: Parabolic reflectors with receivers at their focal line.

Commercial power plants were first built in the 1980's and have proved to be a reliable source of utility-scale electricity. Currently there are 70 commercial plants operating worldwide that have a total capacity of about $5 \mathrm{GW}$ [10]. All commercial plants use an HTF that is a mixture of two hydrocarbons - biphenyl and diphenylether. The HTF is normally stored at its lower operating temperature, $293^{\circ} \mathrm{C}$, in the expansion tanks (Figure 1). From there, it flows through the cold header to the collector field, where it flows through receivers and is heated by sunlight to its upper operating temperature of $393^{\circ} \mathrm{C}$. The HTF flows back through the hot header to the steam generators, where it drops its temperature back to $293^{\circ} \mathrm{C}$ before returning to the expansion tanks. Some power plants include a second flow loop in which the HTF heats a molten salt that functions as a thermal storage fluid. This storage fluid can generate steam at a later time, and thus allows the power plant to generate electricity during times when sunlight is not available.

\section{Problem description}

Near its upper operating temperature $\left(393^{\circ} \mathrm{C}\right)$, the HTF degrades slowly to generate hydrogen gas. The degradation reactions include polymerization of biphenyl and intramolecular ring closure of the diphenylether [11]. Both reactions are due to cleavage of carbon-hydrogen bonds within their components [12], and both have an Arrhenius temperature dependence that causes these rates to be negligible at $293^{\circ} \mathrm{C}$ and significant near $393^{\circ} \mathrm{C}$ in terms of hydrogen generation. 
The reactions produce small concentrations ( $\mathrm{ppb}$ levels) of dissolved hydrogen that circulates with the HTF throughout the collector field, steam generators, and expansion tanks. Practically, degradation is not inhibited by the presence of hydrogen in the HTF, so hydrogen generation proceeds at a significant rate when the HTF is near its upper operating temperature. Dissolved hydrogen concentrations would continue to increase except that permeation of hydrogen through the plant piping and process equipment walls causes dissolved hydrogen to reach a steady-state concentration. Piping and process equipment are composed of carbon steel, which is quite permeable to hydrogen $[13,14]$, and its permeability also has an Arrhenius temperature dependence. The steady-state dissolved hydrogen concentration is the value at which the plant-wide hydrogen generation rate equals the plant-wide hydrogen permeation rate out of the plant via piping and process equipment walls.

Figure 3 shows the receiver - the component that absorbs concentrated sunlight from the reflector and heats the HTF to $393^{\circ} \mathrm{C}$. The receiver consists of a stainless-steel tube, call the absorber, through which flows the HTF. The absorber is surrounded by a glass tube that seals to the absorber on both ends. The enclosed annulus is evacuated to eliminate conduction and convection from the absorber. The receiver functions as a thermos - allowing concentrated sunlight to pass through the glass to the absorber and minimizing heat loss from the absorber.

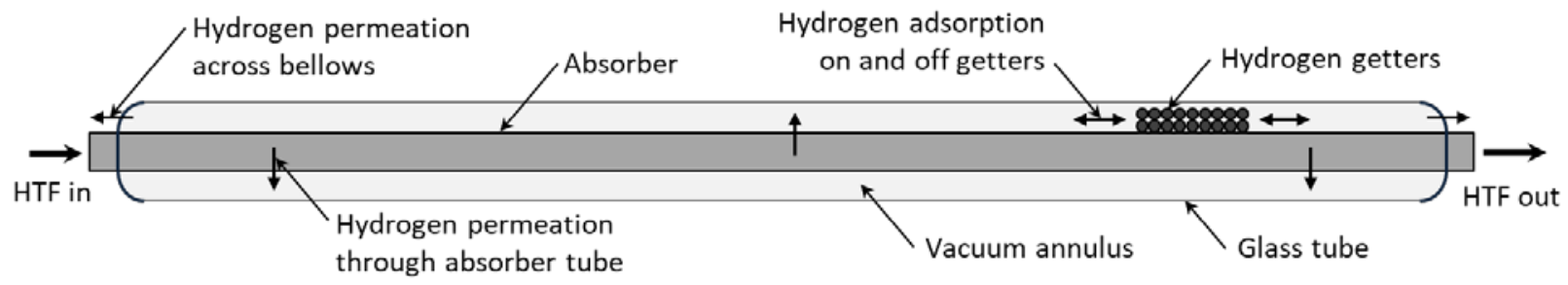

Figure 3: Parabolic reflectors with receivers at their focal line.

In the collector field, dissolved hydrogen in the HTF permeates across the absorber tube wall and into the receiver's evacuated annulus (Figure 3 ). Due to its high thermal conductivity, the presence of small hydrogen pressures (1 mbar) causes significant increase in the receiver's heat loss. The increased heat loss reduces the thermal efficiency of the collector field, and ultimately reduces electricity production by the power plant.

During the first six years of plant operation, hydrogen in the annulus is absorbed by getters. Getters are composed of a metal alloy that absorbs hydrogen to form a metal hydride. After six years, the getters saturate causing the receiver annulus to accumulate hydrogen. This buildup of hydrogen causes up to a $15 \%$ decrease in collector field thermal efficiency and power plant electricity production. 


\section{Consequences}

The issue of hydrogen generation and buildup in parabolic trough plants has become critical within the community of parabolic trough power plant owners and operators. Considering $5 \mathrm{GW}$ of total capacity for the 70 operating plants operating worldwide, a $15 \%$ efficiency loss corresponds to $750 \mathrm{MW}$ of lost power generating capacity. This loss equates to annual lost revenue of about $\$ 200$ million from these power plants.

The NSO power plant started regular operation in 2008. In 2014, NSO began measuring elevated glass temperatures for some of their in-service receivers - an indication that hydrogen was accumulating in the receivers' annuli. In 2015, NSO and NREL began work to develop a hydrogen mitigation process that reduces dissolved hydrogen concentrations in the circulating HTF and permanently solves the problem of hydrogen buildup. Essentially all other commercial parabolic trough power plants worldwide began operating after 2008 - this means that receiver conditions that were measured at the NSO plant in 2014 are indicators for what the rest of these power plants will see in coming years, and these plants will have to contend with similar thermal efficiency and revenue losses.

\section{Previous mitigation solutions}

The buildup of hydrogen in the vacuum annulus of the receivers was anticipated when the first parabolic trough power plants were designed and built by Luz. The original mitigation method was patented by Labaton et al. [15]. Their solution was to incorporate a palladium or palladium alloy membrane into the boundary between the receiver vacuum annulus and ambient air. Palladium and its alloys are exclusively permeable to hydrogen. The membrane could take the shape of a flat disc or thimble, and provided a pathway for hydrogen to permeate from the vacuum annulus to ambient air.

This method worked very well initially. However over time, the palladium membrane embrittled, lost strength, and failed. Hydrogen embrittlement occurs when a metal is exposed to hydrogen for extended periods. In addition to permeating, hydrogen dissolves into the metal and weakens metal bonds, causing the metal to lose strength. Hydrogen embrittlement can be avoided in palladium membranes if the membrane is kept above $300^{\circ} \mathrm{C}$, when it is exposed to hydrogen. The palladium membranes that were used in the original receivers may have been at elevated temperature when the receivers were on sun. However, during the evening, the receivers and membranes cooled down to ambient temperature while the palladium was still exposed to hydrogen. This condition caused the membranes to fail. 
The current method for addressing hydrogen buildup is to incorporate getters into the receiver annulus. The getter material absorbs hydrogen and maintains hydrogen pressure to less than 0.01 mbar for about the first six operating years. After this time, the getters saturate and the receiver losses performance. Replacing compromised receivers every six years is a solution. However, NSO - which has a generating capacity of $70 \mathrm{MW}$ - has 19,200 receivers in its collector field. Replacing these receivers is time consuming and expensive. Each receiver is welded in place so replacing requires cutting out the compromised receiver and welding in the new one. The cost to replace one receiver (labor \& materials) is about $\$ 1,000$, so replacing NSO's entire field costs $\$ 19$ million. In reality, not all receivers are compromised after six years but a significant number of them are and replacing them is a serious financial burden. This cost must be paid by the plant owner and/or the receiver manufacturer. Furthermore, replacing receivers is not a permanent solution to the problem. Six years after the new receivers are installed, they need to be replaced again due to the next round of hydrogen buildup. A power plant during its planned 30-year operating lifetime needs to replace receivers four times.

Most recently, a mitigation method was developed that is based on the addition of a noble gas - argon or xenon - to a receiver annulus that has accumulated hydrogen $[16,17]$. The gas acts to disrupt heat transfer due to hydrogen molecules in the annulus and significantly lowers heat loss. Adding argon or xenon to a receiver annulus without compromising the vacuum is challenging, but methods have been developed that preserve the vacuum, at least initially. This method shows promise and ultimately may be used to complement the method that was developed in this project.

\section{Project Hydrogen Mitigation Solution}

\section{NREL and Acciona Solar Power initial discussions}

During initial their discussions, NREL and APS identified specific objectives for the hydrogen mitigation method. First, the method needed to permanently reduce and maintain dissolved hydrogen concentration in the circulating HTF so that 1) the rate of hydrogen permeation into the receiver annulus is reduced enough to allow the getters to last the full 30-year lifetime of the power plant, or 2) hydrogen permeation into the receivers is reversed allowing hydrogen to permeate back out of compromised receivers, and restores their original performance. To accomplish either of these two objectives, NREL needed to develop a method that significantly reduced dissolved hydrogen concentrations - by a factor ranging from $97 \%$ to $99 \%$.

At the start of the project, APS was assessing the number and extent of compromised receivers in their collector field at NSO, so their requirement in terms of hydrogen reduction was not decided. APS and NREL did not establish exactly the 
project goal in terms of hydrogen reduction. Additionally, APS identified the need to measure hydrogen levels in the expansion tanks to understand conditions at their NSO plant.

Measuring hydrogen levels in the expansion tanks

Among our first tasks was to develop a method and instrument to measure hydrogen levels real time in the expansion tanks. This measurement would allow us to establish baseline hydrogen levels in the power plant HTF as a function of time of day and time of year. It would also allow us to measure reductions in hydrogen levels as we implement our mitigation method.

\section{Approach to hydrogen mitigation}

Prior to the start of this project, NREL identified and patented a mitigation concept that controls hydrogen levels by extracting hydrogen from the HTF in the expansion tanks [1]. The method consisted of extracting hydrogen from the headspace gas in the expansion tank at a prescribed rate. Reducing hydrogen in the headspace gas would reduce dissolved hydrogen in the liquid HTF that resides in the expansion tanks, and would ultimately reduce dissolved hydrogen in the circulating HTF. Initial modeling indicated that the method would work, but quantitative removal rates had not been estimated for the NSO power plant.

Breaking down the problem into discrete steps

To development a process based on extracting hydrogen from the expansion tanks, a project plan was put in place that identified process steps and allowed us to quantify corresponding process rates, so that we could arrive at a workable mitigation process design. To identify these steps, we considered the plant layout shown in Figure 4. Our goal was to control hydrogen levels within the collector field receivers, so the first step was to determine receiver behavior and performance versus HTF hydrogen concentration in the receiver absorber. This step consisted of modeling and experimental work, and allowed us to set target levels for dissolved hydrogen in the HTF that flows through the receiver absorbers.

The second step was understanding hydrogen generation and transport within the plant process equipment and collector field piping. This step allowed us to quantify the relationship between hydrogen levels at various locations within the power plant. Specifically, it allowed us to determine the impact of lowering hydrogen levels in the expansion tanks on hydrogen levels in the collector field HTF. 


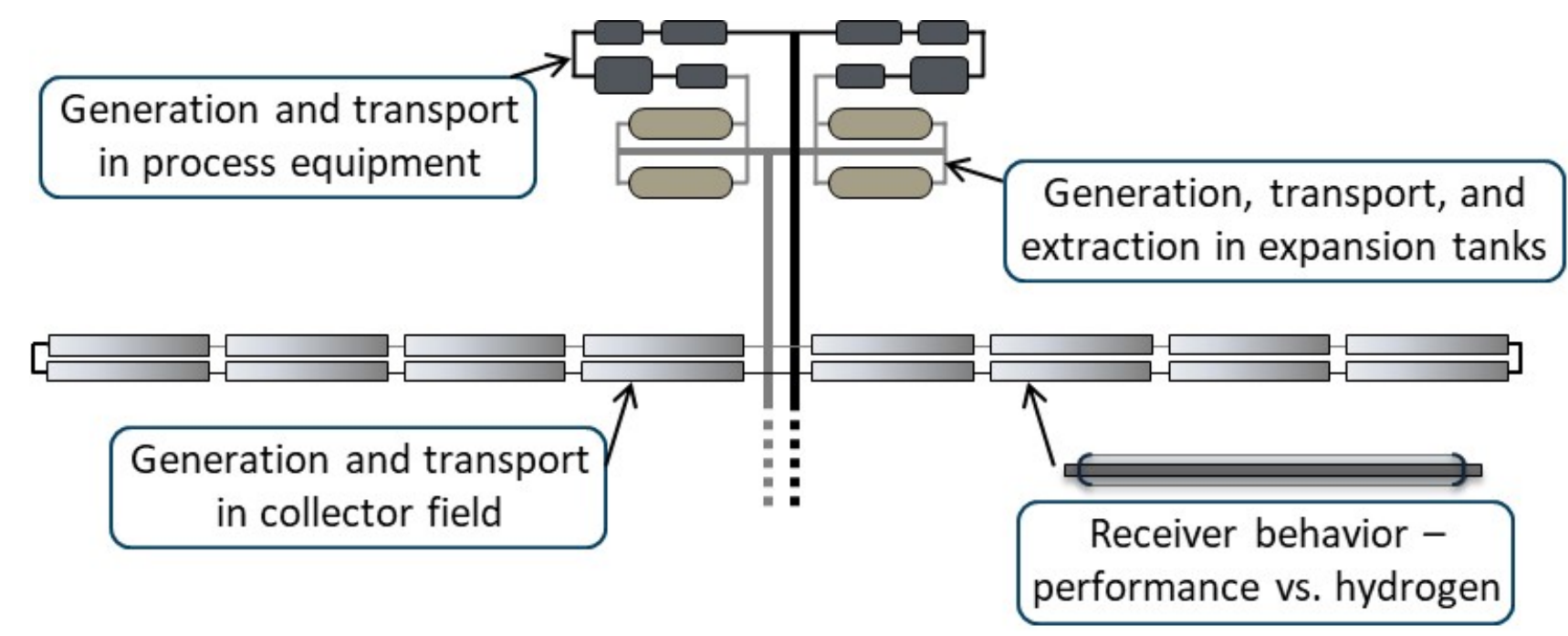

Figure 4: Steps to model and determine process rates.

Knowing the behavior of the collector field receivers versus hydrogen level and the effect of reducing expansion tank hydrogen on collector field hydrogen levels, we could generate specifications for the expansion tanks in terms of target dissolved hydrogen in the HTF, hydrogen partial pressure in the headspace gas, and the rate at which the mitigation process needs to remove hydrogen from the expansion tanks to control levels in the collector field. These steps formed the basis for the project work plan and technical objectives.

\section{Project Tasks and Results}

Sensor development - design and experiments

At the start of this work, we surveyed state-of-the-art sensors for measuring hydrogen in mixtures at varying conditions of temperature, pressure, and concentration. We identified sensors that measure hydrogen in gas mixtures by detecting changes in resistance of a platinum resistor due to hydrogen adsorption [18]. We found several electrochemical sensors for both gas-phase and liquid-phase measurements [19-22]. These sensors were not suitable for our application due to limits in either their maximum operating temperature or hydrogen detection level. A sensor made by Lamtec in Germany measures hydrogen down to $1 \mathrm{ppm}$ and tolerates gas mixture temperatures up to $600^{\circ} \mathrm{C}$. However, the sensor requires oxygen in the gas mixture that is in contact with the counter electrode to detect hydrogen at the sensing electrode. Since the HTF headspace gas mixture does not contain oxygen, this sensor was not suited for our application.

With no available commercial sensor, we proceeded to develop a hydrogen sensor that measures hydrogen partial pressure in a gas mixture that contains nitrogen and the 
HTF components - biphenyl and diphenylether. We chose a measurement method that uses a palladium/silver $(\mathrm{Pd} / \mathrm{Ag})$ alloy membrane as the active component of the sensor. Palladium and its alloys exhibit high permeability exclusively to hydrogen [23-26] due to dissociation of molecular hydrogen that is adsorbed onto the Pd surface. The resulting atomic hydrogen has high mobility within the palladium lattice and readily diffuses across the membrane thickness when a concentration gradient is present. Atomic hydrogen recombines at the opposite surface into molecular hydrogen before desorbing.

The sensor schematic is shown in Figure 5 and was designed to contact one side of the $\mathrm{Pd} / \mathrm{Ag}$ alloy membrane with a continuous flow of the gas mixture. The membrane forms a boundary between the gas mixture and a permeate volume, which is evacuated initially. Because the $\mathrm{Pd} / \mathrm{Ag}$ membrane is permeable exclusively to hydrogen, hydrogen gas flows from the gas mixture across the membrane to fill the permeate volume and establishes the same pressure as the partial pressure of hydrogen in the headspace gas mixture.

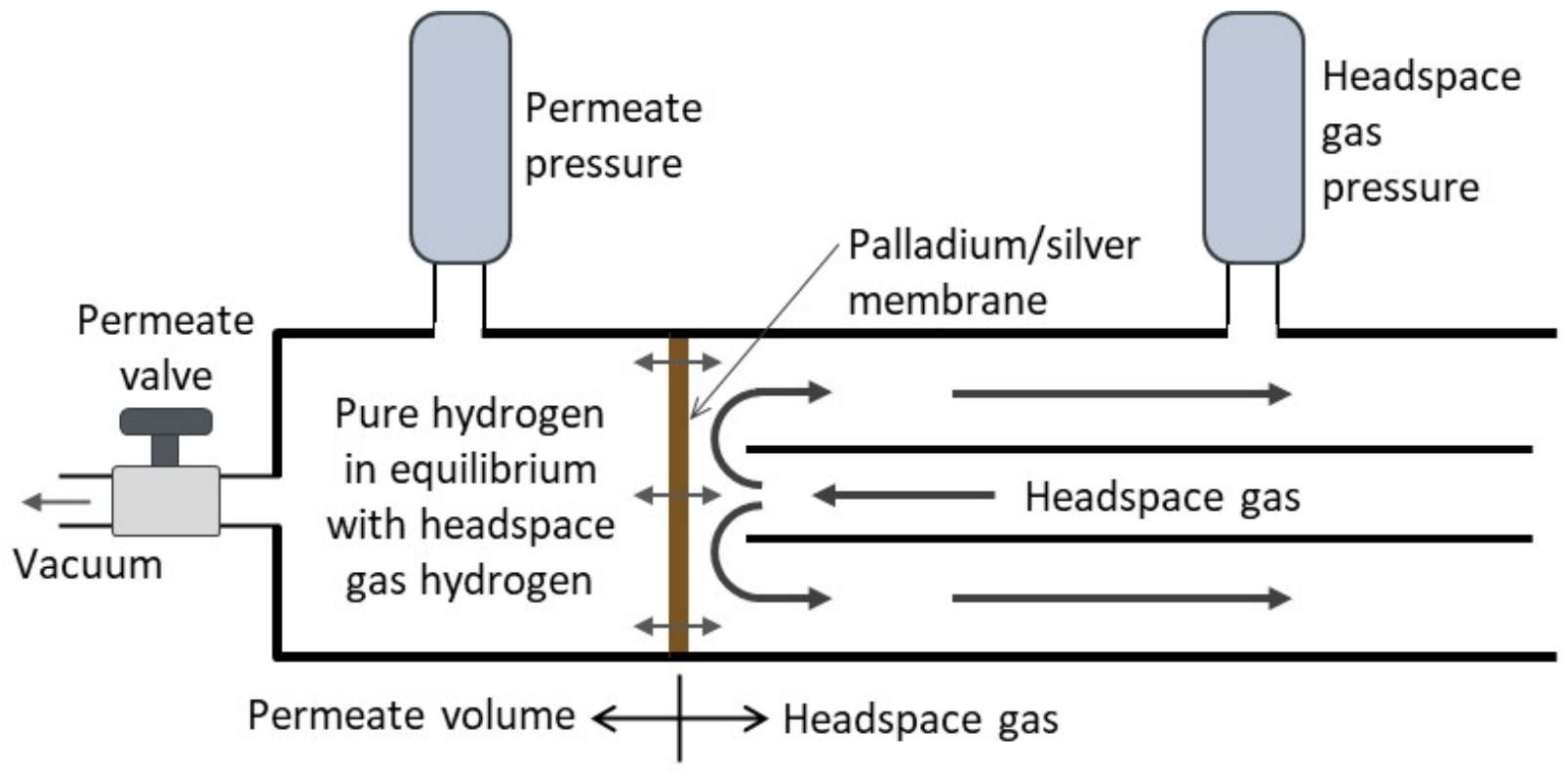

Figure 5: Hydrogen sensor design and function.

Figure 5 shows the gas mixture being delivered to the membrane through the smaller of two tubes that are positioned coaxially to each other. The gas mixture impinges on the membrane, where it reverses flow and exits the sample side of the membrane through the larger tube. As the hydrogen partial pressure in the sample gas mixture increases or decreases, the hydrogen pressure in the permeate volume adjusts accordingly and re-establishes equilibrium with the sample gas hydrogen partial pressure. Measuring the pressure of hydrogen in the permeate volume is accomplished simply by measuring total pressure. For our pressure measurement, we used 
commercial capacitance pressure gages. The total pressure of the headspace gas was measured with the same type of gage but with a sensing range near ambient pressure. The hydrogen concentration in the headspace gas (ppmv) was calculated as the ratio of permeate gas pressure to headspace gas pressure.

Figure 6 shows the laboratory test sensor that was used to establish the performance of the sensor. We evaluated commercially available palladium foils and selected the $\mathrm{Pd} / \mathrm{Ag}$ alloy. This alloy has the highest permeability for hydrogen in the temperature range of $300^{\circ} \mathrm{C}$ to $450^{\circ} \mathrm{C}$ [27]. The membrane is located inside the assembly that is centered in a tube furnace maintains the membrane temperature at $300^{\circ} \mathrm{C}$ to $400^{\circ} \mathrm{C}$ during testing. We chose $300^{\circ} \mathrm{C}$ as the lower limit because the $\mathrm{Pd} / \mathrm{Ag}$ alloy embrittles when exposed to hydrogen at lower temperatures. We chose $400^{\circ} \mathrm{C}$ as our maximum membrane temperature because HTF vapor decomposes rapidly at temperatures greater than $400^{\circ} \mathrm{C}$.

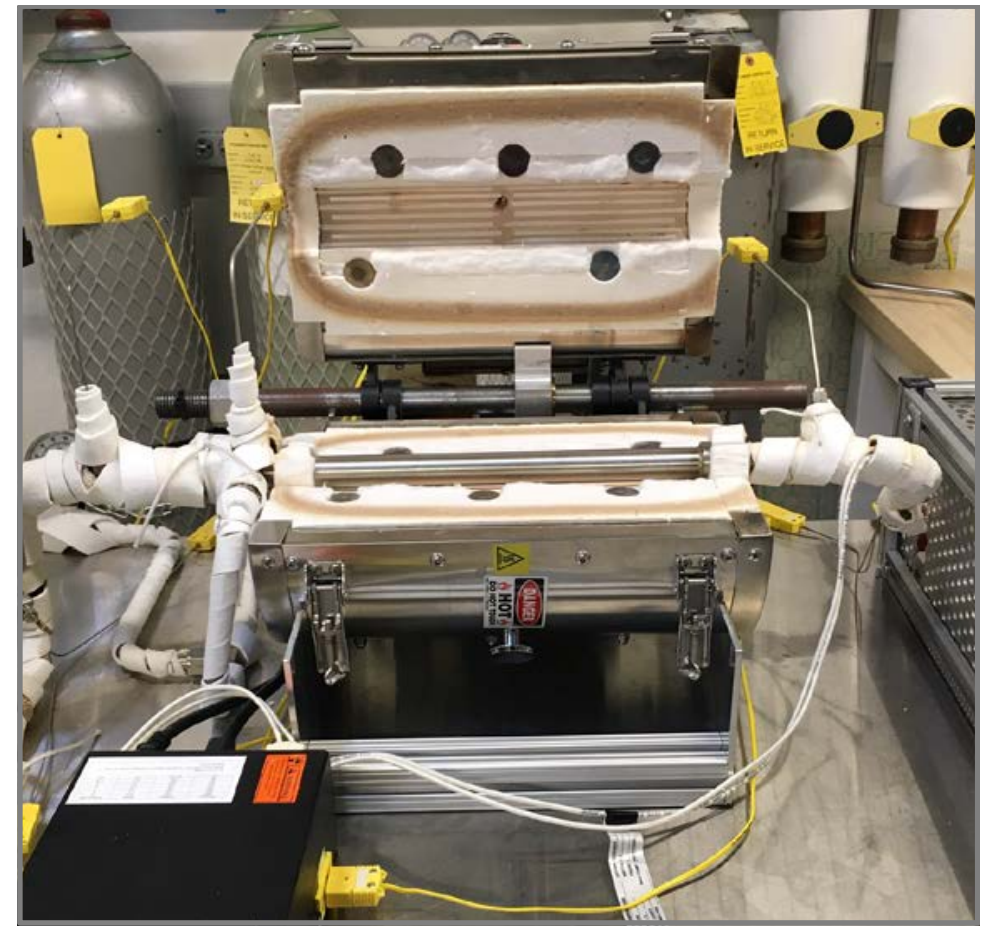

Figure 6: Hydrogen sensor for laboratory testing.

We used the sensor configuration shown in Figure 6 to measure the partial pressure of hydrogen in nitrogen within the range of $1.33 \mathrm{mbar}(1$ torr) down to $2.67 \mu \mathrm{bar}$ ( 2 mtorr). Before starting this series of measurements, we pumped the system down with the scroll and turbo pumps, first with the membrane assembly at ambient temperature and then with the assembly heated to $405^{\circ} \mathrm{C}$. The system was alternately purged with dry nitrogen and evacuated. We continued this process until the lower-range pressure gage read less than $0.1 \mu$ bar for 6 minutes after closing the permeate volume valve. 
Prior to testing the sensor, we soaked the membrane for 1 hour with $5 \%$ hydrogen in nitrogen at $405^{\circ} \mathrm{C}$. This step saturates the membrane lattice sites with atomic hydrogen and improves the initial response of the membrane.

Measurements at each pressure followed the same procedure. We flowed sample gas mixture through the supply side of the membrane using the flowmeter to verify that we had observable gas flow. We adjusted the metering valves at the entrance and exit of the supply-side volume to establish the desired sample gas pressure while maintaining gas flow. During this procedure, we evacuated the permeated volume using the scroll and turbo pumps. When the system was at steady state, we isolated the permeate volume from the pumps by closing the permeate valve. This step marked $t=0$ for the measurement. We recorded permeate volume pressure at half-minute intervals for 5-6 minutes. When finished recording pressures, we opened the permeate volume to the vacuum pumps and evacuated it for the next measurement.

We measured permeate volume pressure at six hydrogen partial pressures from $1.33 \mathrm{mbar}$ to $2.67 \mu \mathrm{bar}$. For each pressure, we measured the pressure response five times. For all measurements except $2.67 \mu$ bar, the supply gas hydrogen concentration was $2,000 \mathrm{ppmv} \pm 40 \mathrm{ppmv}$. For $2.67 \mu \mathrm{bar}$, the supply gas hydrogen concentration was 10 ppmv \pm 0.5 ppmv. Figure 7 shows the permeate pressure response for 0.015 mbar hydrogen partial pressure in the sample mixture.

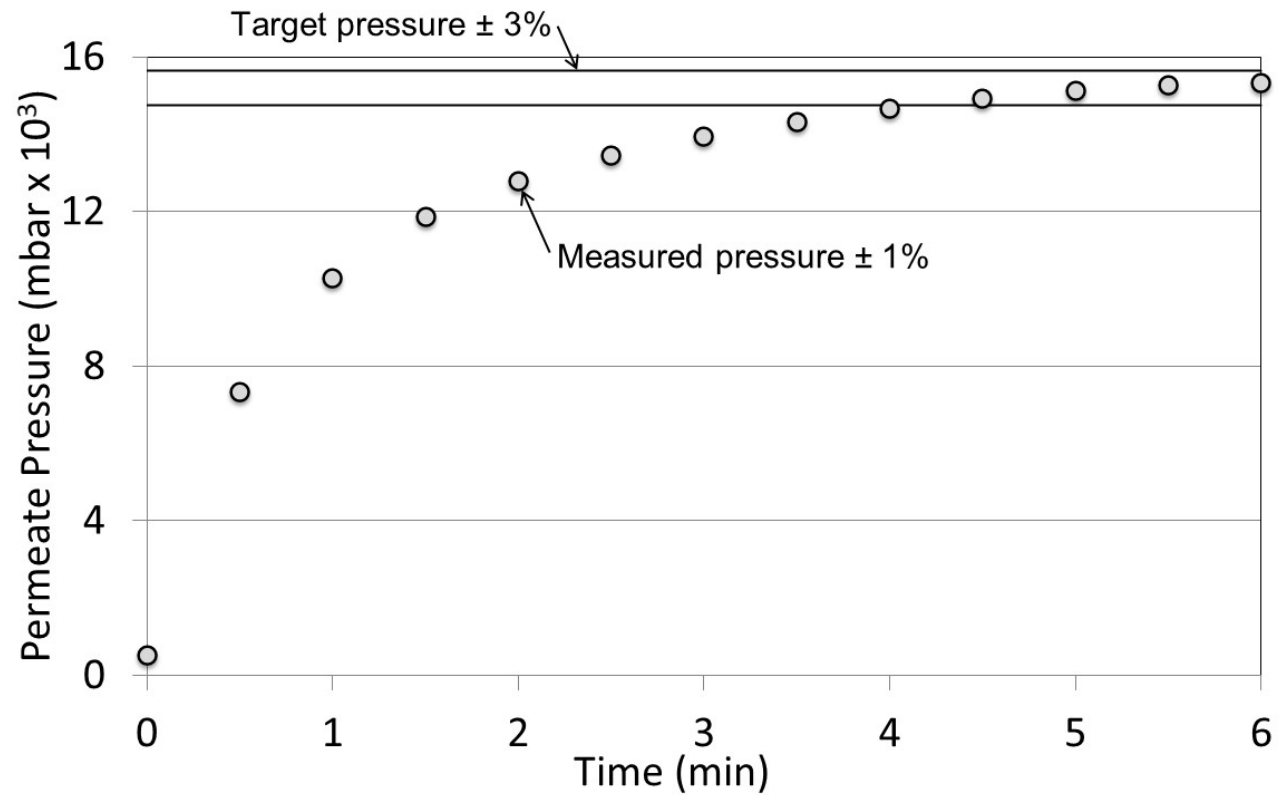

Figure 7: Sensor response versus time for $\mathrm{H}_{2} / \mathrm{N}_{2}$ gas mixture. The target $\mathrm{H}_{2}$ partial pressure was 0.015 mbar with $\pm 3 \%$ uncertainty range bounded by horizontal lines. Measurement uncertainty of $\pm 1 \%$ is represented by height of the data points. Permeate volume pressure was $0.533 \mu \mathrm{bar} @ \mathrm{t}=0 \mathrm{~min}$. Membrane temperature was $405^{\circ} \mathrm{C}$. 
Upper and lower bounds of the target hydrogen partial pressure due to pressure measurement uncertainty $( \pm 1 \%)$ [28] and gas composition uncertainty $( \pm 2 \%)$ [29] are shown as lines. Sensor measurements of the permeate pressure are shown as discrete points and their uncertainty $( \pm 1 \%)$ is represented as the height of the data points. The permeate pressure responses for measurements of 1.33 mbar, 0.267 mbar, 0.133 mbar, $26.7 \mu$ bar, $13.3 \mu$ bar, and $2.67 \mu$ bar were similar to those shown in Figure 7 . The time required to come to the final pressure varied from 5 to 6 minutes.

Figure 8 plots the measured hydrogen pressure in the permeate volume versus the target partial pressure in the sample gas mixture. The diagonal line denotes exact agreement between the two values. The three higher-pressure measurements agreed with their target values within their uncertainty limits. We note that the measured means for the three lower-pressure measurements (26.7-2.67 $\mu \mathrm{bar})$ were greater than their corresponding target values.

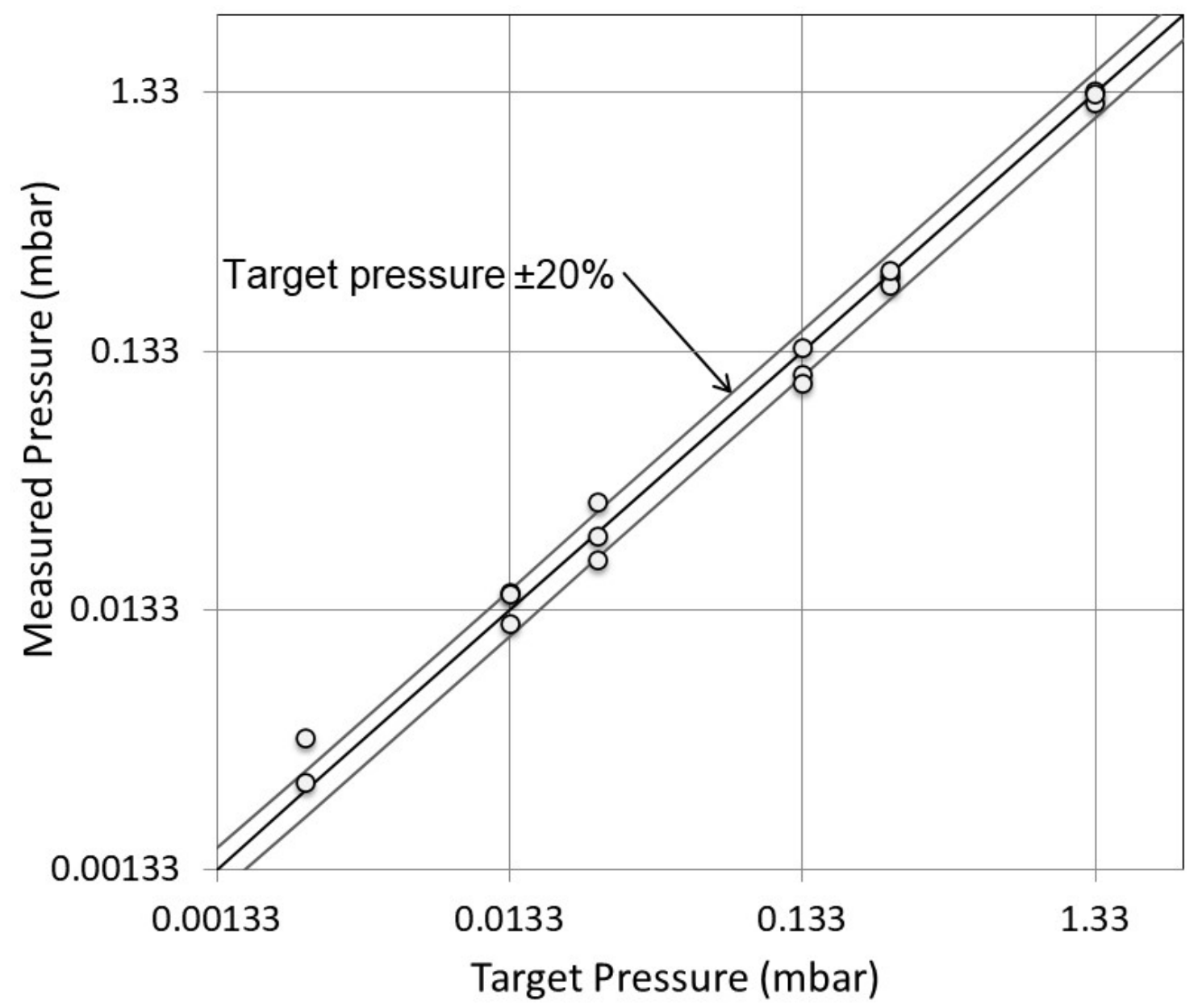

Figure 8. Summary of all sensor measurements with $\mathrm{H}_{2} / \mathrm{N}_{2}$ gas mixture. Measurements were within $\pm 20 \%$ uncertainty except for one measurement at $2.7 \mu \mathrm{bar}$. 
Following our initial testing with hydrogen/nitrogen $\left(\mathrm{H}_{2} / \mathrm{N}_{2}\right)$ gas mixtures, we adapted the instrument inlet to add HTF vapor to the gas mixture. Figure 9 shows a schematic of modifications that were made to the gas mixture inlet. HTF addition was accomplished by passing the $\mathrm{H}_{2} / \mathrm{N}_{2}$ gas mixture through liquid HTF in a bubbler before flowing to the inlet of the sensor. The bubbler consisted of a glass tube that sealed on its bottom end and held several milliliters of liquid HTF during testing. A smallerdiameter tube extended into the liquid HTF and supplied the $\mathrm{H}_{2} / \mathrm{N}_{2}$ gas mixture. $\mathrm{H}_{2} / \mathrm{N}_{2}$ gas passed through the liquid HTF in the bubbler and picked up HTF vapor before entering the sensor. During testing, the glass tube was heated to $260^{\circ} \mathrm{C}$ to ensure complete transfer of the HTF to the supply-gas flow stream. The normal boiling point of the Dowtherm $A^{\mathrm{TM}}$ and Therminol VP- $1^{\mathrm{TM}}$ is $257^{\circ} \mathrm{C}$ [30].

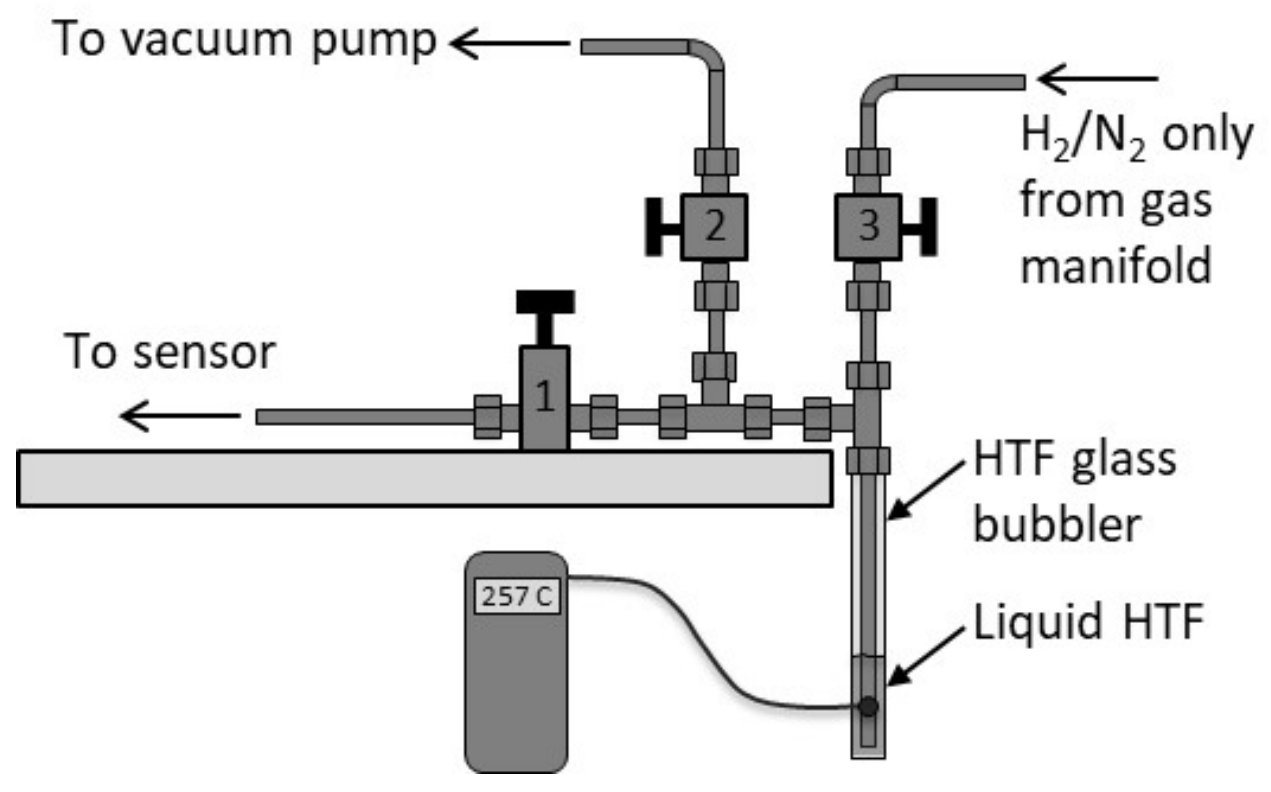

Figure 9. Modifications made to gas mixture inlet to add HTF vapor.

We used the sensor and inlet configuration shown in Figures 6 and 9 to measure hydrogen partial pressure in the supply gas mixture. With each measurement, we followed the same procedure as we stepped through a set of pressures. We flowed sample gas mixture through the supply side of the membrane using a flowmeter to verify that we had observable gas flow. We adjusted the metering valves at the entrance and exit of the supply-side volume to establish the desired sample gas pressure while maintaining gas flow. During this procedure, we evacuated the permeated volume using scroll and turbo pumps in series. When the system was at steady state, we isolated the permeate volume from the pumps. This step marked $t=0$ for the measurement. We recorded permeate volume pressure at half-minute intervals for 5-6 minutes. When the pressure response was complete, we opened the permeate volume to the vacuum pumps and evacuated the volume for the next measurement. 
We measured hydrogen in supply gas mixtures with HTF vapor at partial pressures of $1.33 \mathrm{mbar}, 0.267 \mathrm{mbar}, 0.133 \mathrm{mbar}, 26.7 \mu \mathrm{bar}$, and $13.3 \mu \mathrm{bar}$. Figure 10 summarizes all measurements that were made with the sensor using supply gases of $\mathrm{H}_{2} / \mathrm{N}_{2}$ only and $\mathrm{H}_{2} / \mathrm{N}_{2}$ with added $\mathrm{HTF}$ vapor. All measurements fall within the $\pm 20 \%$ uncertainty range of the target value except for one measurement at 0.0027 mbar. Measurements were made using two different $25-\mu \mathrm{m}$-thick $\mathrm{Pd} / \mathrm{Ag}$ membranes. Some measurements were made in order of descending pressure and the others were made in order of ascending pressure. We observed that pressures measured slightly high when measured in descending order and slightly low when measured in ascending order. Considering all variations in measurement time, measurement order, membranes, and gas composition, the results shown in Figure 10 have very good consistency and linearity over the full range of pressures.

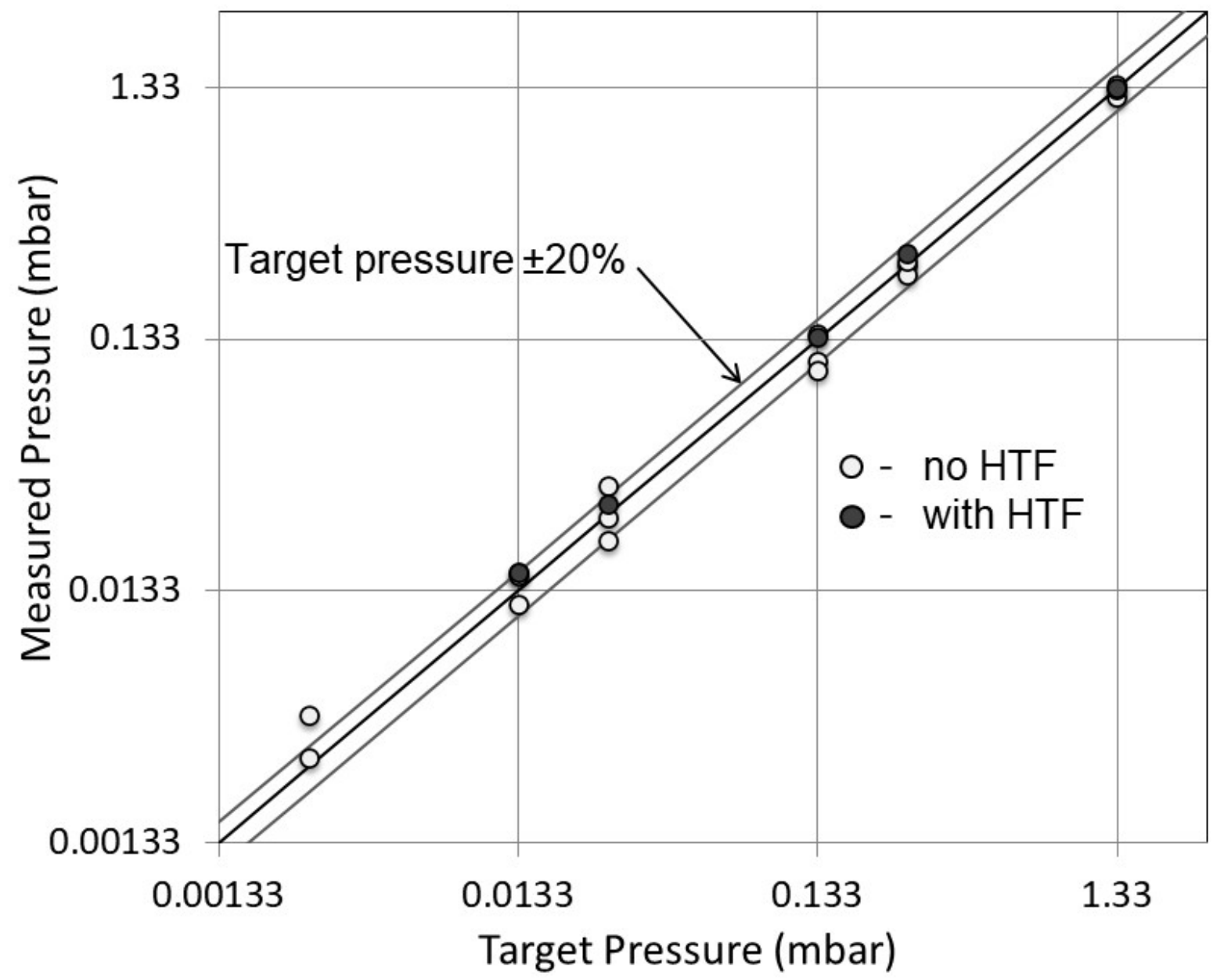

Figure 10. Summary of all sensor measurements with and without $\mathrm{HTF}$ included $\mathrm{H}_{2} / \mathrm{N}_{2}$ gas mixture. Measurements were within $\pm 20 \%$ uncertainty except for one measurement at $2.7 \mu \mathrm{bar}$. 
The $\mathrm{Pd} / \mathrm{Ag}$ membrane that was used to measure hydrogen partial pressure in the expansion tanks needed to tolerate $300^{\circ} \mathrm{C}$ while exposed to HTF vapor. To evaluate the membrane compatibility with these conditions, we removed and examined the $\mathrm{Pd} / \mathrm{Ag}$ membrane after completing measurements using the gas mixture with HTF components. This membrane was exposed to HTF vapor at $400^{\circ} \mathrm{C}$ for several hours and did not show any signs of deterioration or HTF decomposition deposits. Figure 11 shows that the membrane is in the same condition as a new membrane. The membrane that we use in the sensor that measures hydrogen levels in the expansion tanks operates at $310^{\circ} \mathrm{C}$ to $350^{\circ} \mathrm{C}$, so based on limited testing at $400^{\circ} \mathrm{C}$, we did not expect membrane fouling due to HTF components.

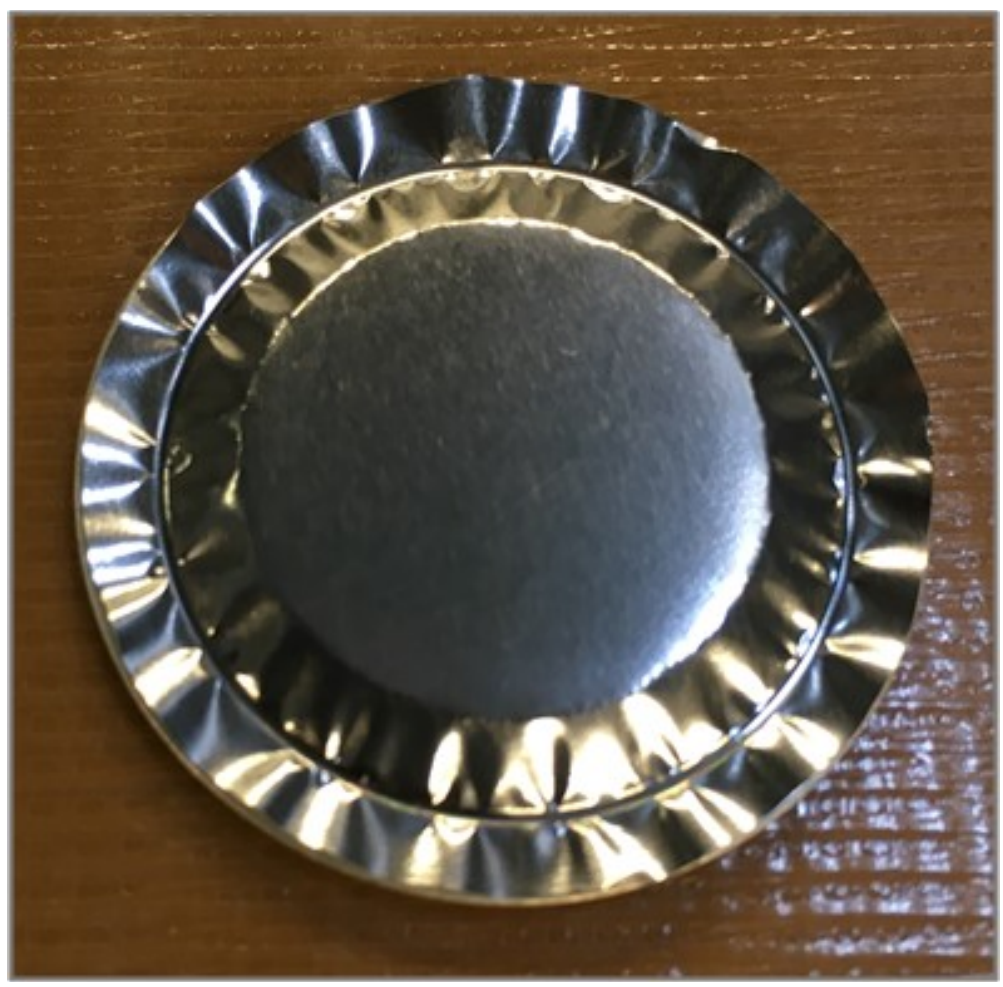

Figure 11. $\mathrm{Pd} / \mathrm{Ag}$ membrane removed from sensor after exposure to $\mathrm{HTF}$ vapor at $400^{\circ} \mathrm{C}$.

Sensor development - modeling transient response

For a typical hydrogen pressure measurement in a gas mixture with or without HTF vapor, the response reaches its equilibrium value in about 5 minutes. To understand the transport mechanisms that determine the response time, we developed equations that accounted for the mechanisms that contribute to the dynamic response of the sensor. Figure 12 shows the sensor design with gas mixture and permeate volumes separated by the membrane. For the sensor response, we modeled hydrogen transfer from the bulk gas mixture to the permeate volume as: 1) diffusion through the boundary layer adjacent to the membrane and 2) permeation through the membrane. 


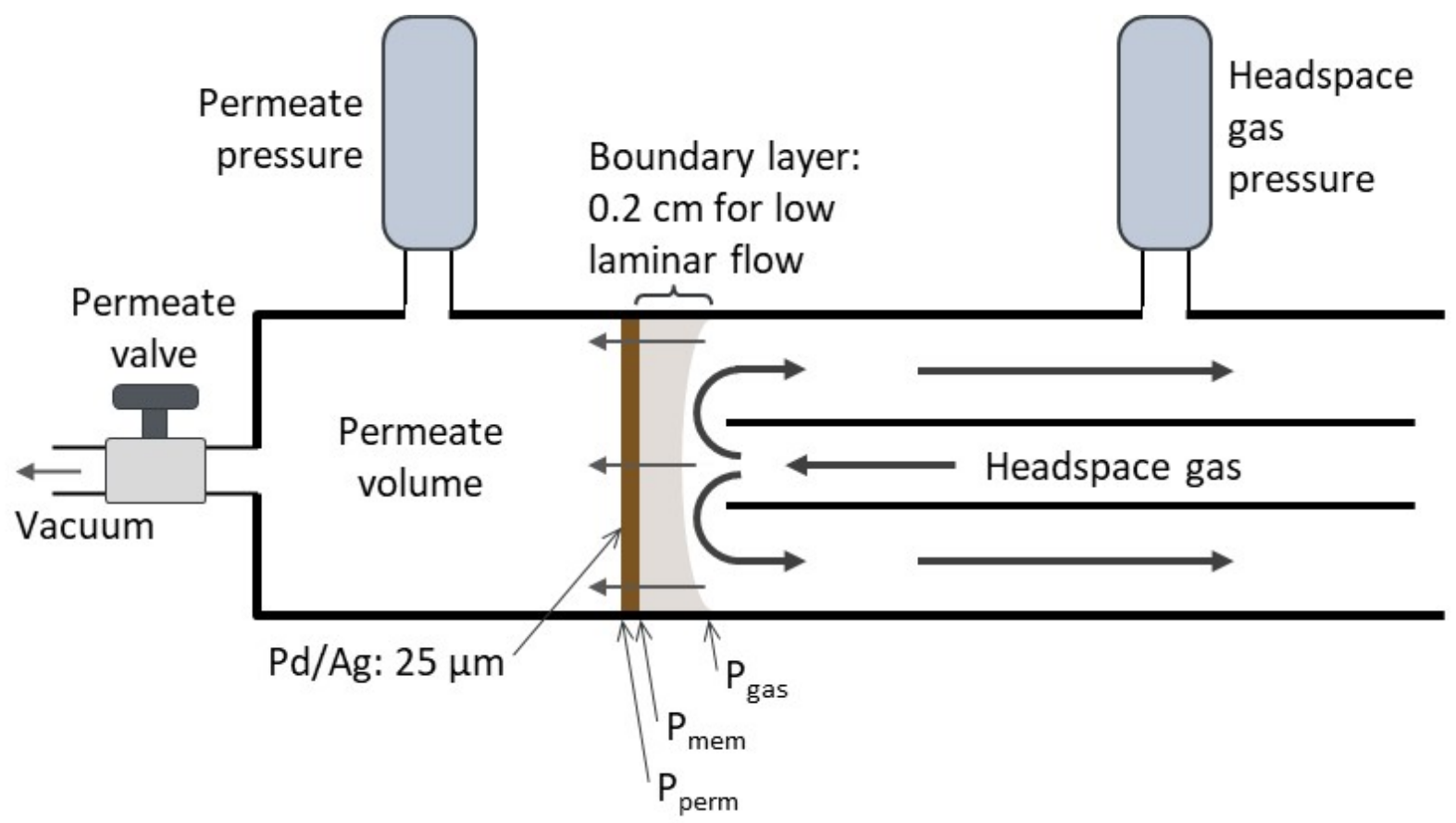

Figure 12. Sensor diagram showing diffusion boundary layer and pressures $-\boldsymbol{P}_{\text {gas, }}, \boldsymbol{P}_{\text {mem }}$, and $\boldsymbol{P}_{\text {perm. }}$.

To estimate the diffusion-layer thickness, we first assumed the limit of no flow (stagnant) for the gas-mixture side of the membrane and used an estimated diffusionlayer thickness for this gas-mixture composition, temperature, and pressure. For the noflow condition, the thickness of the gas diffusion layer at the liquid/gas interface is 0.1 to $1 \mathrm{~cm}$, based on experimental measurements [31]. During all measurements, we maintained minimal gas-mixture flow so that the hydrogen partial pressure in the gas mixture at the outer edge of the boundary layer $\left(P_{\text {gas }}\right)$ remained constant during the time of the measurement. Due to the minimal gas flow, we expected the range for the average diffusion-layer thickness to be the lower end of the no-flow (stagnant) range: 0.1 to $0.4 \mathrm{~cm}$.

Our model included the following transport and material balance equations. The hydrogen molar diffusion rate through the boundary layer, $\frac{d n}{d t}$, is defined by:

$$
\frac{d n}{d t}=\frac{D_{f} A_{m e m}}{R T_{g a s} \delta_{B L}}\left(P_{g a s}-P_{m e m}\right)
$$

where $D_{f}$ is the diffusion coefficient for hydrogen in the headspace gas, $A_{m e m}$ is the membrane area, and $\delta_{B L}$ is the boundary-layer thickness, $R$ is the gas constant, and $T_{\text {gas }}$ is the gas absolute temperature. The hydrogen permeation rate through the membrane equals the diffusion rate and is defined by:

$$
\frac{d n}{d t}=\frac{A_{\text {mem }} \phi_{\text {mem }}}{\delta_{\text {mem }}}\left(\sqrt{P_{\text {mem }}}-\sqrt{P_{\text {perm }}}\right)
$$


where $\phi_{m e m}$ is the hydrogen permeation coefficient in the membrane and $\delta_{\text {mem }}$ is the membrane thickness. Finally, the increase in permeate pressure during the response is given by:

$$
\frac{d P_{\text {perm }}}{d t}=\frac{R T_{\text {perm }}}{V_{\text {perm }}} \frac{d n}{d t}
$$

where $T_{\text {perm }}$ and $V_{\text {perm }}$ are the permeate gas temperature and volume. In these equations, $P_{\text {gas }}, P_{\text {mem }}$, and $P_{\text {perm }}$ are hydrogen partial pressures in the gas mixture, at the membrane surface, and in the permeate volume, respectively, as designated in Figure 12. $P_{\text {gas }}$ is constant during a sensor measurement while $P_{\text {mem }}$ and $P_{\text {perm }}$ vary with response time.

We solved these equations numerically to determine $P_{\text {mem }}$ and $P_{\text {perm }}$ versus time during a sensor measurement. We show model results for $P_{\text {perm }}$ as compared to the measured permeate pressure responses for two measurements of hydrogen partial pressures -0.136 and 0.27 mbar. For each partial pressure, we solved for the sensor response: 1) assuming no boundary layer (BL) and 2) with boundary-layer thicknesses from 0.1 to $0.4 \mathrm{~cm}$. The $0.2-\mathrm{cm}$ boundary-layer thickness gave the best fit for the measured data. Figures 13 and 14 show the measured pressure data and the modeling results for the two partial pressures.

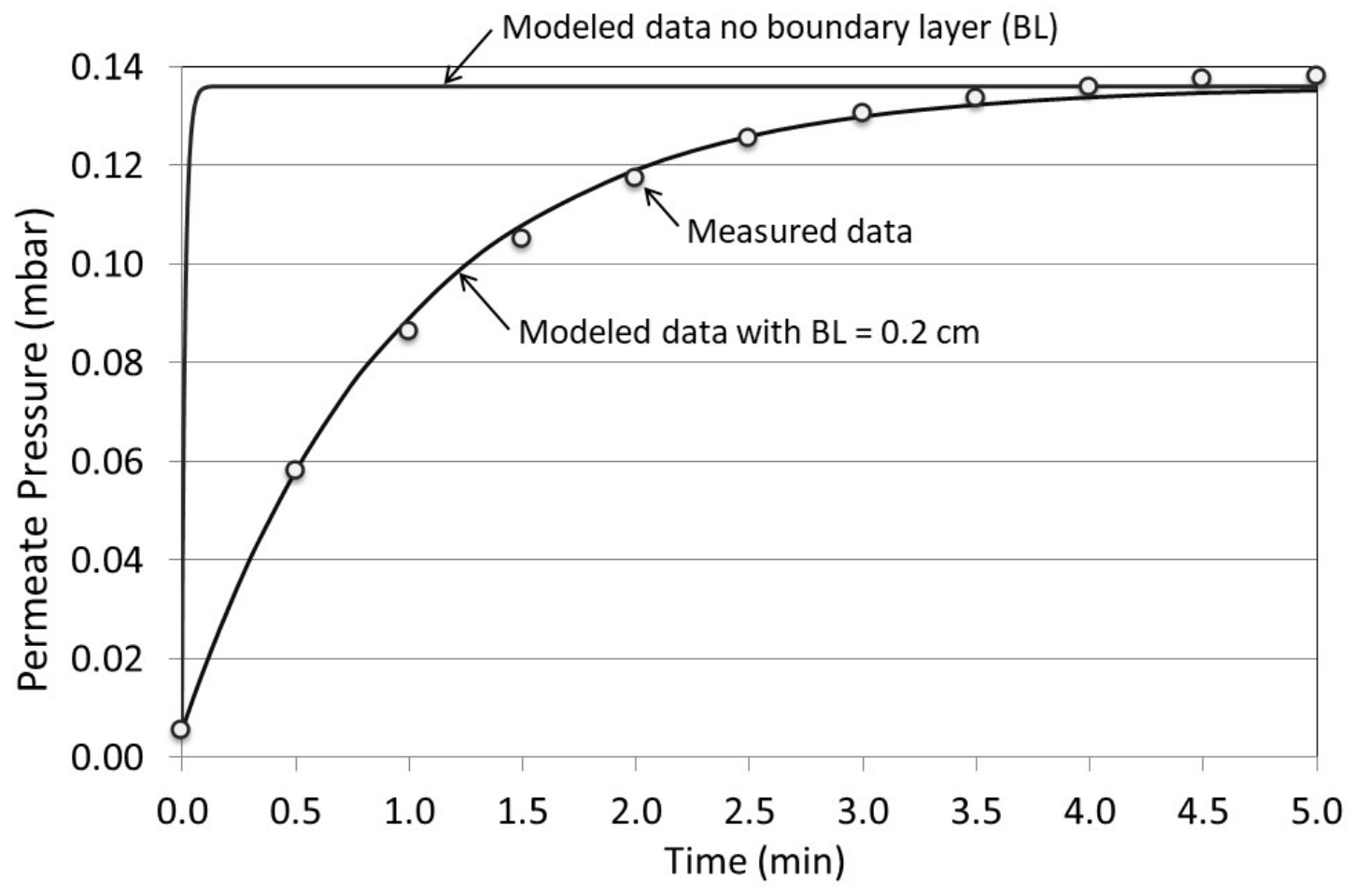

Figure 13. Measured and modeled permeate pressure responses for sensor measurement of hydrogen partial pressure of $0.13 \mathrm{mbar}$. 
Figures 13 and 14 clearly show that the results from the model when accounting for both boundary-layer diffusion and membrane permeation agreed very closely with the measured data for both partial pressures. The assumed boundary-layer thickness of 0.2 $\mathrm{cm}$ agrees well with our estimated range of 0.1 to $0.4 \mathrm{~cm}$ for minimum gas flow. When diffusion is not included in the model, the model predicts pressure responses that reach steady state in about 15 seconds. Our model results show that boundary-layer diffusion controls overall hydrogen transport from the gas mixture to the permeate volume when the sensor is measuring hydrogen partial pressure.

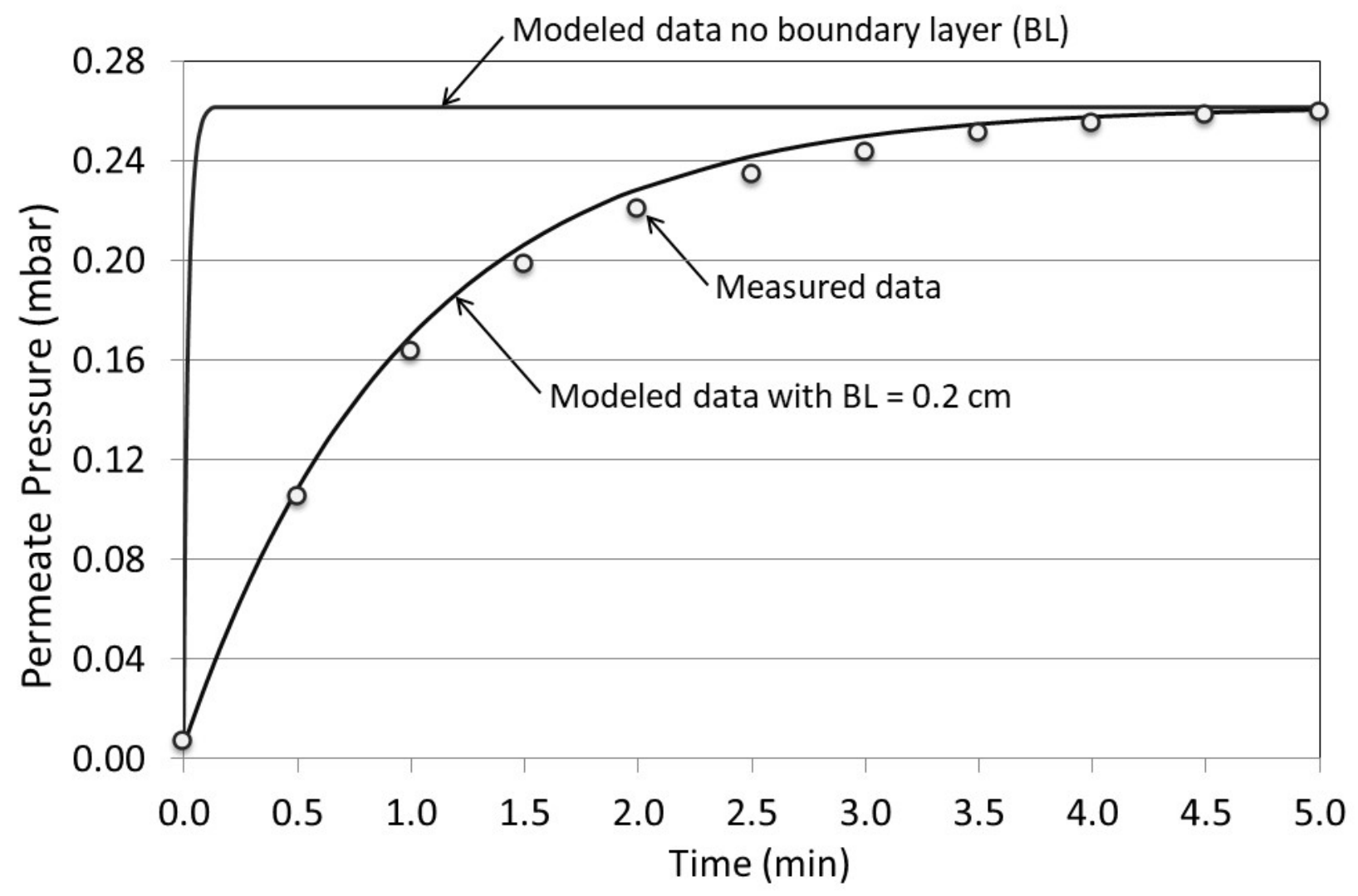

Figure 14. Measured and modeled permeate pressure responses for sensor measurement of hydrogen partial pressure of 0.27 mbar.

Receiver heat loss testing

The key effect of hydrogen buildup in the HTF is the accumulation of hydrogen in the receiver annuli due to permeation through the absorber tube wall. To better understand this process, NREL conducted extended heating of a receiver that had been in service at NSO for its first seven operating years and had elevated glass temperature. The purpose of the testing was to determine if hydrogen permeation into the receiver annulus is reversed and partially restores compromised receiver performance. 
Figure 15 shows the transport modes of hydrogen within a receiver. During normal plant operation, hydrogen in the HTF permeates across the absorber wall into the annulus and adsorbs into the getters. Some hydrogen also permeates across the bellows to ambient air. When the getters saturate, hydrogen pressure in the annulus increases until permeation out through the bellows equals permeation across the absorber wall into the annulus. At this point, the receiver is at steady state with respect to hydrogen transport and the getters no longer have any effect on hydrogen pressure in the annulus.

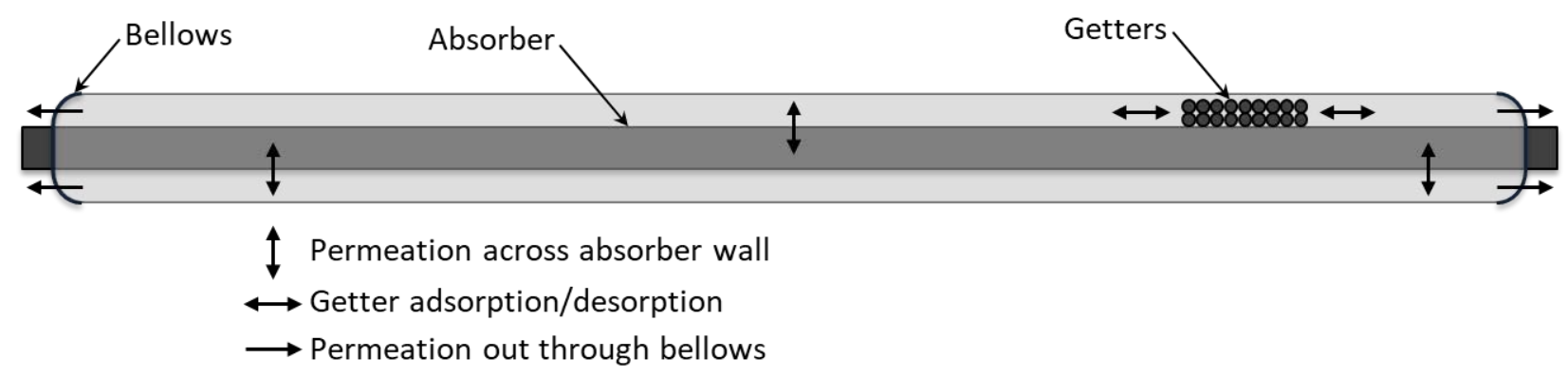

Figure 15. Hydrogen transport within an operating receiver.

If dissolved hydrogen is actively removed from the HTF, hydrogen pressure in the annulus pressure will be greater than hydrogen pressure in the HTF, and permeation will reverse going out of the annulus. Additionally, hydrogen will desorb from the getters to the annulus to maintain pressure according to the getter isotherm. Over time, hydrogen pressure in the annulus decreases and receiver performance improves.

To demonstrate this effect, the NREL performed extended daily heating of a receiver that initially contained high levels of hydrogen in its annulus. Testing was performed using an in-service receiver that was removed from the Nevada Solar One (NSO) collector field and shipped to NREL. During testing, the receiver did not contain HTF but was heated with electric resistance heaters that were positioned inside the receiver absorber.

Figure 16 shows NREL's receiver test stand, which has been used to measure heat loss and hydrogen permeation rates of prototype receivers [32, 33]. Figure 16 shows a receiver mounted on the test stand along with power electronics for temperature measurement and heater control. Four electrical heaters are inserted into the absorber tube (two from each end) and supply up to $4,000 \mathrm{~W}$ of resistive heating power to the receiver. Four power meters measure power to the four heaters at any given time. Two additional guard heaters are located just outside the absorber on its ends. These heaters do not contribute to absorber heating but maintain constant axial temperatures at the ends of the absorber. 


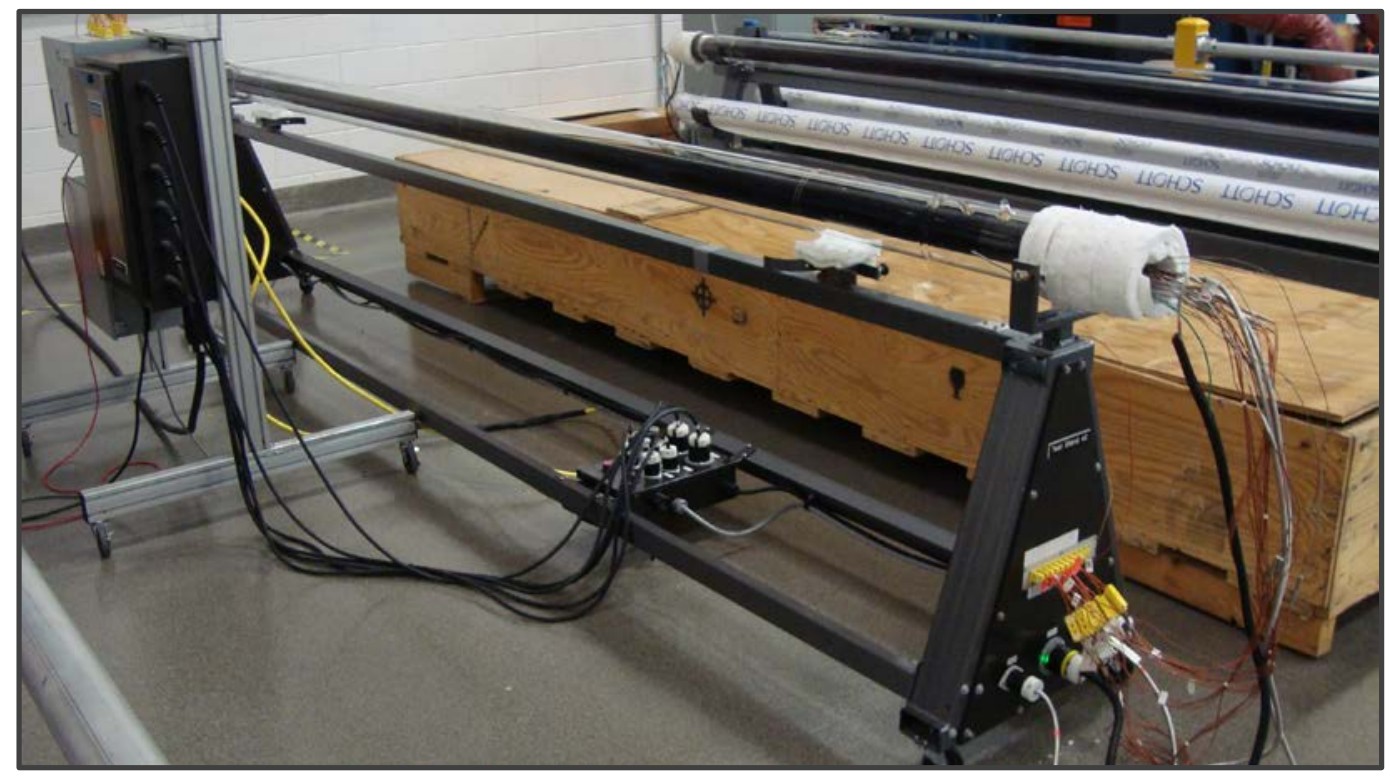

Figure 16. NREL heat-loss test stand for daily heating of in-service receiver.

This feature eliminates axial heat loss from the ends of the absorber. Multiple thermocouples measure temperatures of the inside surface of the absorber along its axial length. Additional thermocouples measure heater-core temperatures at several locations to control absorber and heater temperatures. Three thermocouples are located on the outside glass surface at the receiver ends and at its center to measure glass temperatures.

Receiver heat loss is measured by bringing the receiver to steady state at the temperature of interest. When all absorber and glass temperatures are stable, the electric power supplied to the four internal resistive heaters is measured. At steady state, the power supplied to the receiver equals its heat loss, so the sum of the four power measurements is the receiver heat loss at that temperature.

NREL installed the in-service receiver onto its receiver test stand and measured its heat loss over 100 days of heating. Figure 17 shows the heat loss of a new receiver, the initial heat-loss of the in-service receiver at $300^{\circ} \mathrm{C}, 350^{\circ} \mathrm{C}$, and $380^{\circ} \mathrm{C}$, along with the same receiver's heat loss after 100 days of heating. The difference between the new receiver heat loss at a given temperature and the initial heat loss of the in-service receiver at the same temperature is the additional heat loss incurred by the receiver due to the buildup of hydrogen in its annulus. Total heat loss from a receiver that has hydrogen buildup is $3-4$ times greater than a new receiver with no hydrogen.

Figure 17 shows that the in-service receiver recovered $14-20 \%$ of its original performance after 100 days of heating. These results show that hydrogen permeation in receivers is reversible and eliminating hydrogen from the HTF that flows through the receivers will improve their performance over time. 


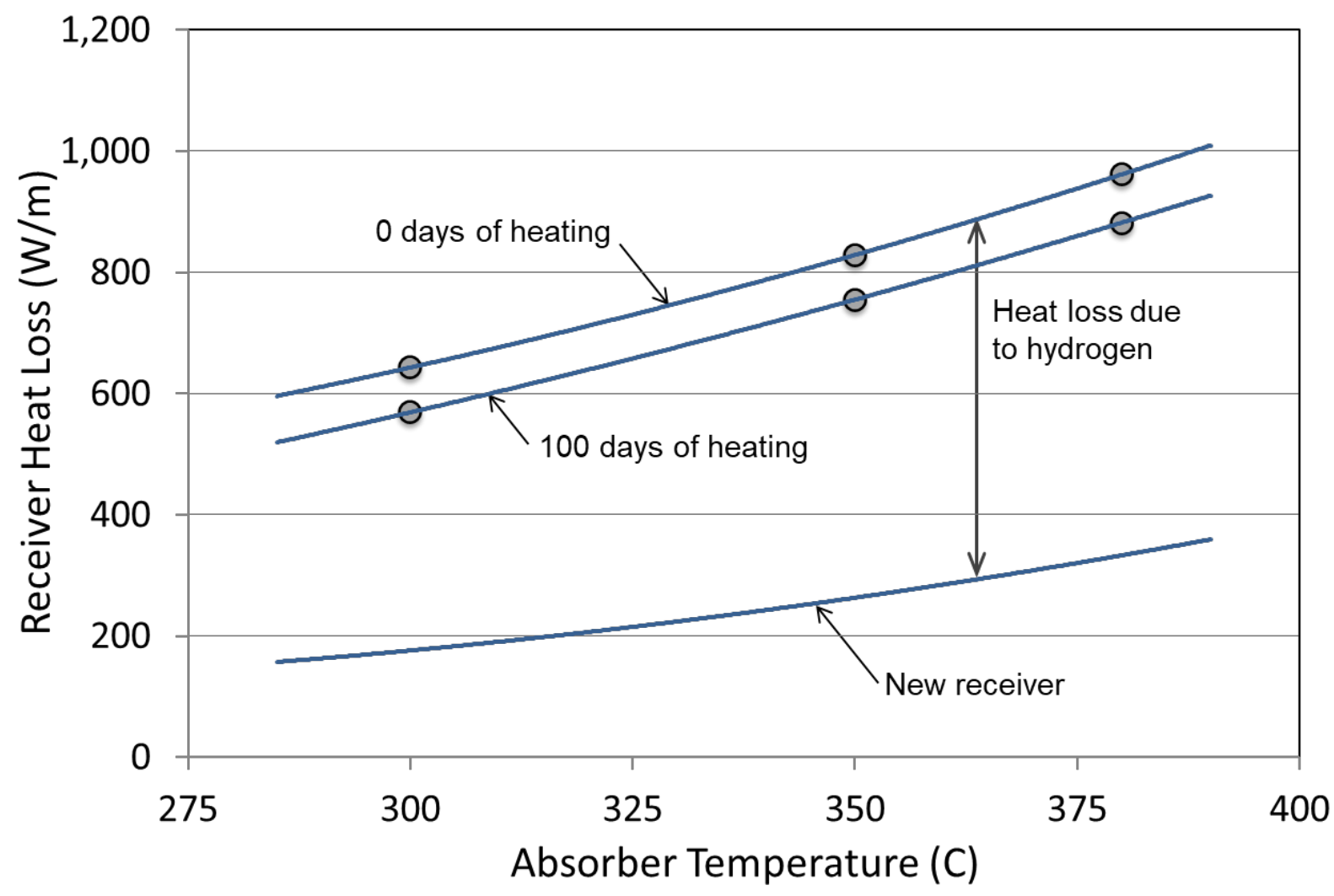

Figure 17. New and in-service receiver heat loss measurements.

Power plant modeling

To effectively design and evaluate possible process mitigation options, we needed to quantify the generation and transport of hydrogen throughout the power plant. These mechanisms determine the levels of hydrogen in the collector-field receivers, hot and cold headers, and power-block components that contain HTF. We developed a full-plant steady-state computational model that accounts for hydrogen generation and transport in all components of the parabolic trough power plant, and that predicts steady-state dissolved hydrogen concentrations within the circulating HTF and hydrogen pressures in the collector-field receiver annuli. We used this model to estimate hydrogen extraction or purge rates from the expansion tanks that reduce and maintain dissolved hydrogen concentrations to target levels within the circulating HTF. The predicted hydrogen purge rate and headspace partial pressure were the critical design specifications for the mitigation process.

The objectives for this work were to 1) model the steady-state levels of dissolved hydrogen within all components of a commercial parabolic trough power plant, 2) predict hydrogen pressures in receiver annuli according to location in the collector field and 
design operating temperature, and 3) predict steady-state hydrogen levels in the receiver when hydrogen is actively purged from the expansion tanks at specified rates.

We based our model on general characteristics of the Nevada Solar One (NSO) power plant including layouts of the collector field, cold and hot header, and power block components. The model estimated dissolved hydrogen concentrations and partial pressures within plant components and subsystems assuming that they were operating at their design temperatures.

For each plant component, the model calculates 1) hydrogen influx due to HTF flow into the component, 2) hydrogen efflux due to HTF flow out of the component, 3) hydrogen efflux due to permeation across the component walls, and 4) hydrogen generation due to degradation of the HTF [40]. Mathematical expressions were assigned for transport and generation rates for every component in the power plant including receivers in the collector field. Figure 18 shows generation and transport modes for hydrogen in the expansion tank.

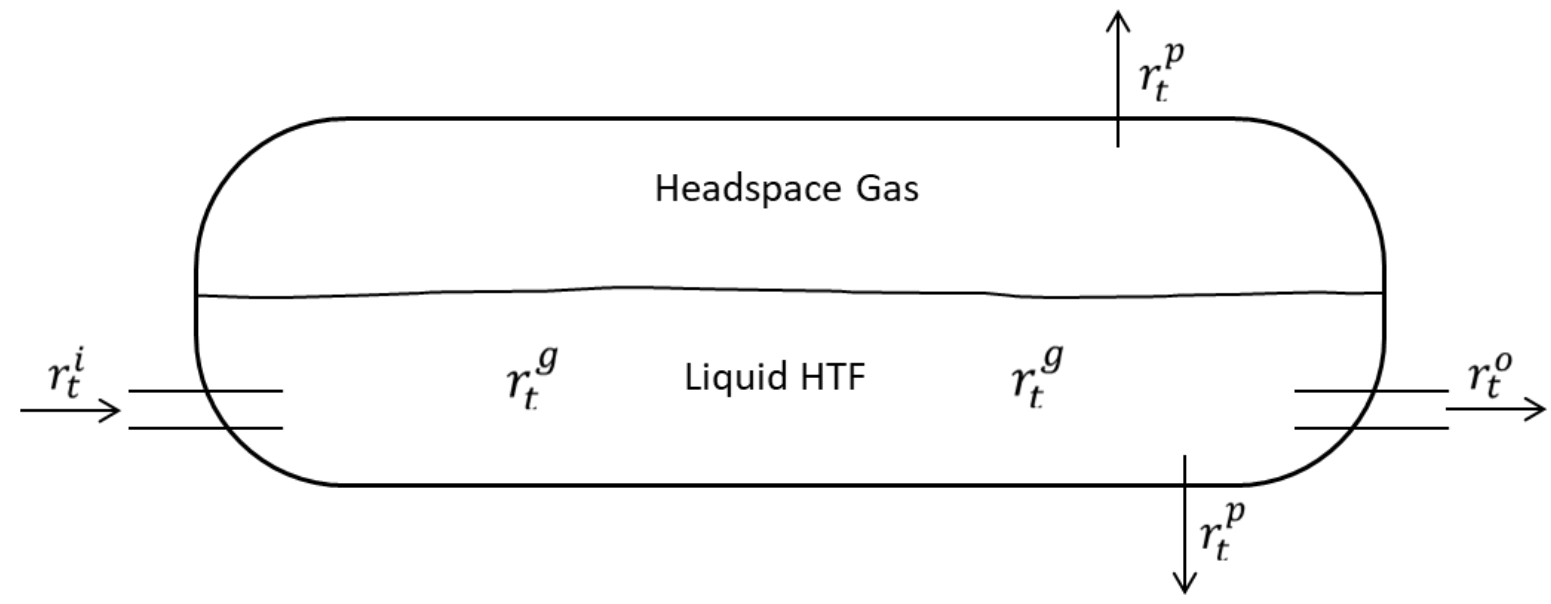

Figure 18. Hydrogen transport to and from of the expansion tanks.

For the case of the expansion tank, the rate of hydrogen influx due to HTF flow, $r_{t}^{i}$, is:

$$
r_{t}^{i}=\frac{m_{t}}{\rho_{t}^{i}} C_{t}^{i}
$$

where $m_{t}$ is HTF mass flow rate into and out of the tank, $\rho_{t}^{i}$ is the density of the HTF entering the tank, and $C_{t}^{i}$ is the hydrogen molar concentration in the HTF entering the tank. The hydrogen efflux due to HTF flow, $r_{t}^{o}$, is:

$$
r_{t}^{o}=\frac{m_{t}}{\rho_{t}} C_{t}
$$


where $C_{t}$ is the hydrogen molar concentration in the tank HTF, and $\rho_{t}$ is the tank HTF density. The rate of hydrogen efflux due to permeation through the tank wall, $r_{t}^{p}$, is:

$$
r_{t}^{p}=\frac{A_{t} \phi_{t}}{d r_{t}} \sqrt{P_{t}}
$$

Here, $A_{t}$ and $d r_{t}$ are the wall area and thickness of the expansion tank. $P_{t}$ is the partial pressure of gas-phase hydrogen in the tank. $\phi_{t}$ is the permeation coefficient for hydrogen for the expansion tank wall material, which is carbon steel $[13,34] . \phi_{t}$ is a function of temperature and is defined as:

$$
\phi_{t}=\phi_{0} e^{\frac{-E_{\phi}}{R T_{t}}}
$$

where $T_{t}$ is tank temperature, $E_{\phi}$ is the activation energy, $R$ is the gas constant, and $\phi_{0}$ is the pre-exponential constant. The partial pressure of hydrogen in the tank, $P_{t}$, relates to the hydrogen HTF molar concentration, $C_{t}$, by Henry's Law:

$$
P_{t}=H_{t} C_{t}
$$

where $H_{t}$ is Henry's partitioning coefficient and is defined by:

$$
H_{t}=H_{0} e^{\frac{-E_{H}}{R T_{t}}}
$$

Again, $E_{H}$ is the activation energy and $H_{0}$ is the pre-exponential constant for Henry's coefficient. The kinetic rate equation for decomposition of the HTF within the expansion tank, $r_{t}^{g}$, is given by:

$$
r_{t}^{g}=K_{t} C_{t}^{H T F} V_{t}^{H T F}
$$

where $V_{t}^{H T F}$ is the HTF liquid volume in the tank, $C_{t}^{H T F}$ is the HTF molar concentration, and $K_{t}$ is the reaction rate coefficient given by:

$$
K_{t}=K_{0} e^{\frac{-E_{K}}{R T_{t}}}
$$

where $E_{K}$ and $K_{0}$ are the activation energy and pre-exponential constant, respectively.

The overall steady-state material balance for hydrogen then determines the equilibrium concentration and partial pressure of hydrogen in the expansion tank, and is given by:

$$
r_{t}^{g}+r_{t}^{i}=r_{t}^{o}+r_{t}^{p}
$$


Analogous expressions were developed for all components and piping within the NSO power plant and incorporated into the model. We used experimentally determined values for the HTF Henry's coefficient and decomposition rate coefficient as functions of temperature [35]. We used an averaged value of permeation coefficients for austenitic stainless steels as a function of temperature for the absorber and bellows [36, 37].

Acciona provided NREL with specifications to model components within the NSO power plant. Specifications included HTF flow rates, volumes, and temperatures in the expansion tank, superheaters, steam generators, re-heaters, pre-heaters, header sections, and cross-over piping. For each component, NSO specified wall material (carbon steel), wall thicknesses, and HTF wetted surface areas. NSO provided piping layouts, schedules, diameters, and lengths for piping that connects the power-block components, hot and cold headers, and loop cross-over piping. Piping lengths and diameters were provided for the hot and cold header sections within the collector field that neck down as the headers extend away from the power block and into the collector field.

Figure 19 shows the general layout for the NSO power plant. The collector field is divided into four sections - two south and two north. Each section consists of 25 loops. Each loop contains 8 solar collector assemblies (SCAs), and each SCA contains 24 receivers; so the collector field contains a total of 19,200 receivers. The main cold and hot headers that exit and enter the power block each split into north and south headers. The cold and hot south headers supply and collect HTF to/from the two south sections. The cold and hot north headers supply and collect HTF to/from the two north sections. HTF flow from the south cold header supplies respective loops in the two south sections in parallel. In other words, the south cold header supplies HTF to the first loop in the first section at the same point as the first loop in the second section, and so forth. Returning flow from respective loops in the two sections enter the hot header at the same points. The same flow pattern occurs in the two north sections and the north cold and hot headers. 


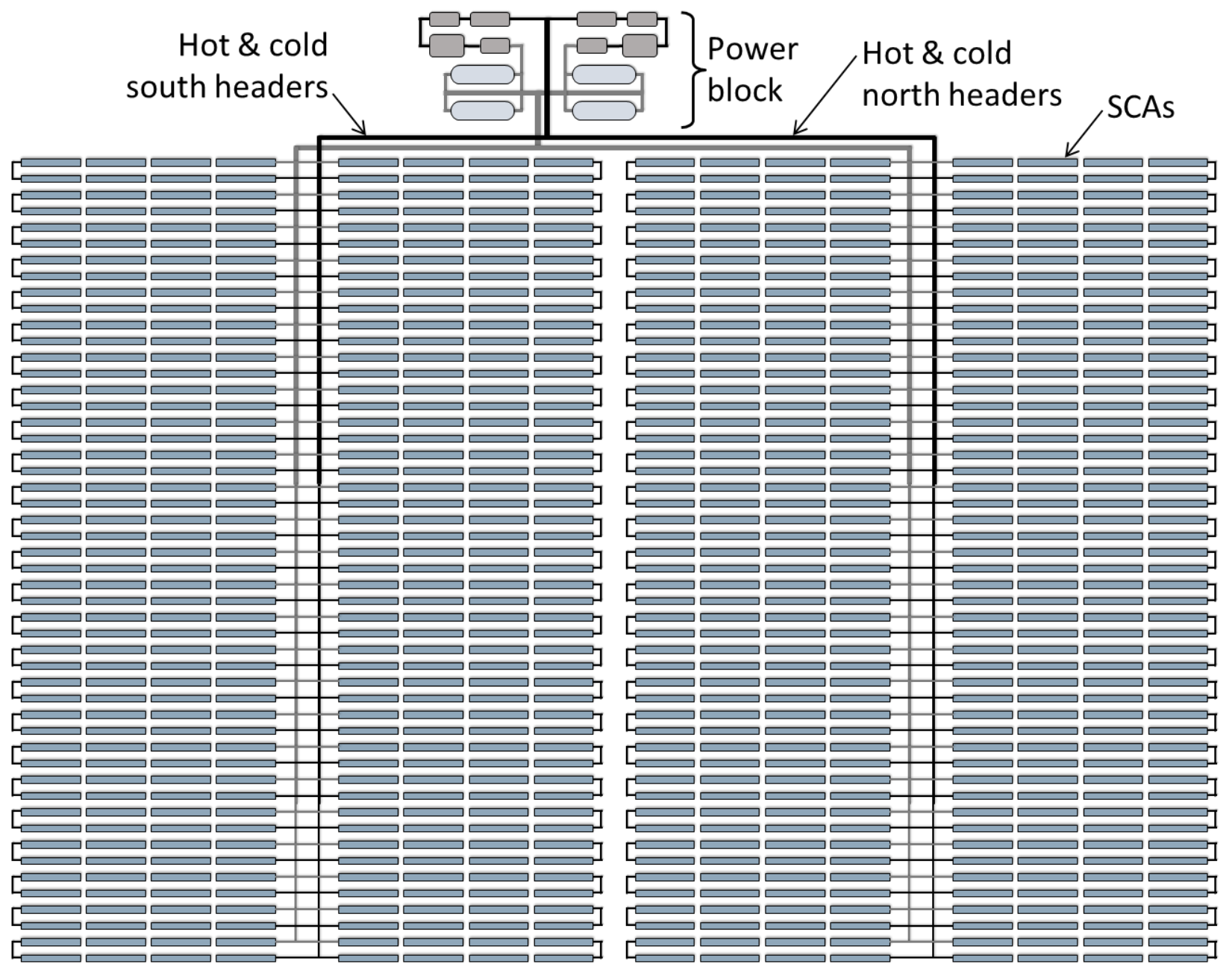

Figure 19. NSO power plant layout.

The cold and hot headers that are located within the collector field do not have constant diameters going from loop 1 to loop 25. The headers neck down twice to form three sections within the collector field. The reduced diameters accommodate reduced HTF flow as the headers move away from the power block. HTF flow rates within all of the loops were assumed to be equal. HTF flows from the power block in the main cold header and splits equally between the north and south cold headers. The flow rate in each of the loops in sections 1 and 2 is $1 / 50^{\text {th }}$ of the south cold header flow rate. The same flow arrangement is true for the north cold header and the loops in sections 3 and 4. The north and south hot headers collect returning HTF flow from the loops in sections 1-4 and combine before entering the power block. The total HTF flow rates in the main hot and cold headers are each 100 times the loop flow rate.

Header piping flow within the collector field regularly splits as the cold header provides HTF to subsequent collector loops and recombines as HTF flows back into the hot header. When an HTF flow splits, the dissolved hydrogen concentration in the two 
resulting split flows equals the dissolved hydrogen concentration of the original flow. When two HTF flows combine, the resulting dissolved hydrogen concentration equals the weighted average of the concentrations of the two combining flows. The weighting factors are the normalized mass flow rates for the two combining flows.

HTF returning from the collector field in the north and south hot headers combine into the main hot header before entering the power block. The main hot header flow splits and flows into two identical steam trains. In each train, high-temperature HTF flows to one superheater followed by two steam generators that have parallel HTF flows. The HTF flows to two re-heaters in series and finally to a single pre-heater. Equations that account for hydrogen generation and transport within all of these components were developed in a similar way as those for the expansion tank described previously. HTF flows in the steam generators and re-heaters are on the tube side, so the area for hydrogen permeation is the tube area only. HTF flows in the superheater and pre-heater are on the shell side, so the areas for hydrogen permeation in those components include both the tube area and the vessel wall area.

Equations that account for hydrogen generation and transport were also developed for all piping sections between the steam-train components. Cold HTF flows that exit the steam trains flow to the expansion tanks (two tanks per train). The four expansion tanks hold the HTF inventory that is not in circulation and supplies low-temperature HTF to the main cold header for flow to the collector field.

Receiver modeling was based on the Schott PTR70 design. Absorber, glass tube, and bellows dimensions were obtained from Schott Solar [38]. Hydrogen generation and transport within the absorber for each receiver was modeled in the same way as the expansion tank. The hydrogen material balance for the absorber tube was:

$$
r_{a}^{g}+r_{a}^{i}=r_{a}^{o}+r_{a}^{p}
$$

where each term is defined in the same way as those for the expansion tank (Eq. 12). In this expression, $r_{a}^{p}$ is the rate of hydrogen permeation from the absorber into the receiver annulus. For each receiver, we defined the hydrogen material balance for the annulus as:

$$
r_{a}^{p}=r_{b}^{p}
$$

where $r_{a}^{p}$ is the rate of hydrogen permeation across the absorber wall into the annulus and $r_{b}^{p}$ is the rate of hydrogen permeation out of the annulus across the bellows:

$$
r_{a}^{p}=\frac{A_{a} \phi_{a}}{d r_{a}} \sqrt{P_{a}}
$$




$$
r_{b}^{p}=\frac{A_{b} \phi_{b}}{d r_{b}} \sqrt{P_{a n n}}
$$

In Eq. 15, $A_{a}, d r_{a}$, and $\phi_{a}$ are the wall area, thickness, and permeation coefficient for the absorber tube. $P_{a}$ is the partial pressure of hydrogen in the absorber. In Eq. 16, $A_{b}, d r_{b}$, and $\phi_{b}$ are the area, thickness, and permeation coefficient for the two bellows. $P_{a n n}$ is the partial pressure of hydrogen in the annulus. For each receiver annulus, the steady-state hydrogen pressure in the annulus, $P_{\text {ann }}$ balances the two permeation rates into and out of the annulus. $P_{a n n}$ for all receivers in the collector field determine the condition of the receivers with respect to thermal performance and heat loss due to hydrogen in their annuli. It is important to point out that the getters have no effect on $P_{a n n}$ when the receivers are at steady state. Getter loading simply equilibrates with $P_{a n n}$ according to the getter isotherm at the getter temperature.

Mathematically, the model consists of hydrogen material balances on every component within the power plant as described for the expansion tank and receivers. In addition for adjacent or linked components, the hydrogen efflux leaving the first component, $r_{x}^{o}$, must equal the hydrogen influx entering the second component, $r_{x+1}^{i}$ :

$$
r_{x+1}^{i}=r_{x}^{o}
$$

The HTF mass flow rates, $m_{x+1}, m_{x}$, have the same constraint for adjacent components:

$$
m_{x+1}=m_{x}
$$

These constraints hold for all receivers within each loop, the cold and hot headers, and all piping and components within the power block. These constraints, along with the component hydrogen material balances, form a set of algebraic expressions that has a single solution for a given set of HTF flow rates and component temperatures.

The model was solved mathematically using Engineering Equation Solver [39], a high-level programming language that is used to solve large sets of algebraic equations for engineering applications. The expressions developed for the NSO plant model were coded into an EES script. The model solved for hydrogen levels in all plant components, including the receivers, as a function of their collector-field location. Our model solves for hydrogen generation and transport rates, concentrations in the HTF, and partial pressures for a steady-state condition in which these variables are constant for all components in the power plant. This steady-state condition represents the operating state of the power plant when all receiver getters have saturated, and the plant is operating at its design point. The modeling results have practical value in that the hydrogen pressures predicted for the receiver annuli are the maximum pressures that 
can be reached when the plant is operating at its design point, and so represent the worst-case scenario.

\section{Modeling results for NSO power plant with no hydrogen extraction}

We solved the full-plant steady-state model for the NSO power plant at design operating temperatures and HTF flow rates. Figure 20 shows hydrogen partial pressures within the components of the power plant when there is no active removal of hydrogen from the expansion tank. This condition assumes that the hydrogen partial pressures are at steady state in every component including the receivers. Additionally, this condition assumes that for each receiver, the getter loading is in equilibrium with the annulus partial pressure. In Figure 20, SCA 1 refers to the partial pressure in receivers in the first SCA of the loop. SCA 8 refers to the partial pressure in receivers in the last SCA of the loop. For the SCAs, hydrogen pressures are in equilibrium with the HTF dissolved hydrogen. The cold header refers to the cold header section that exits the power block just before splitting into the north and south cold headers. The north and south hot headers refer in the main header sections that combine their flows just before entering the power block.

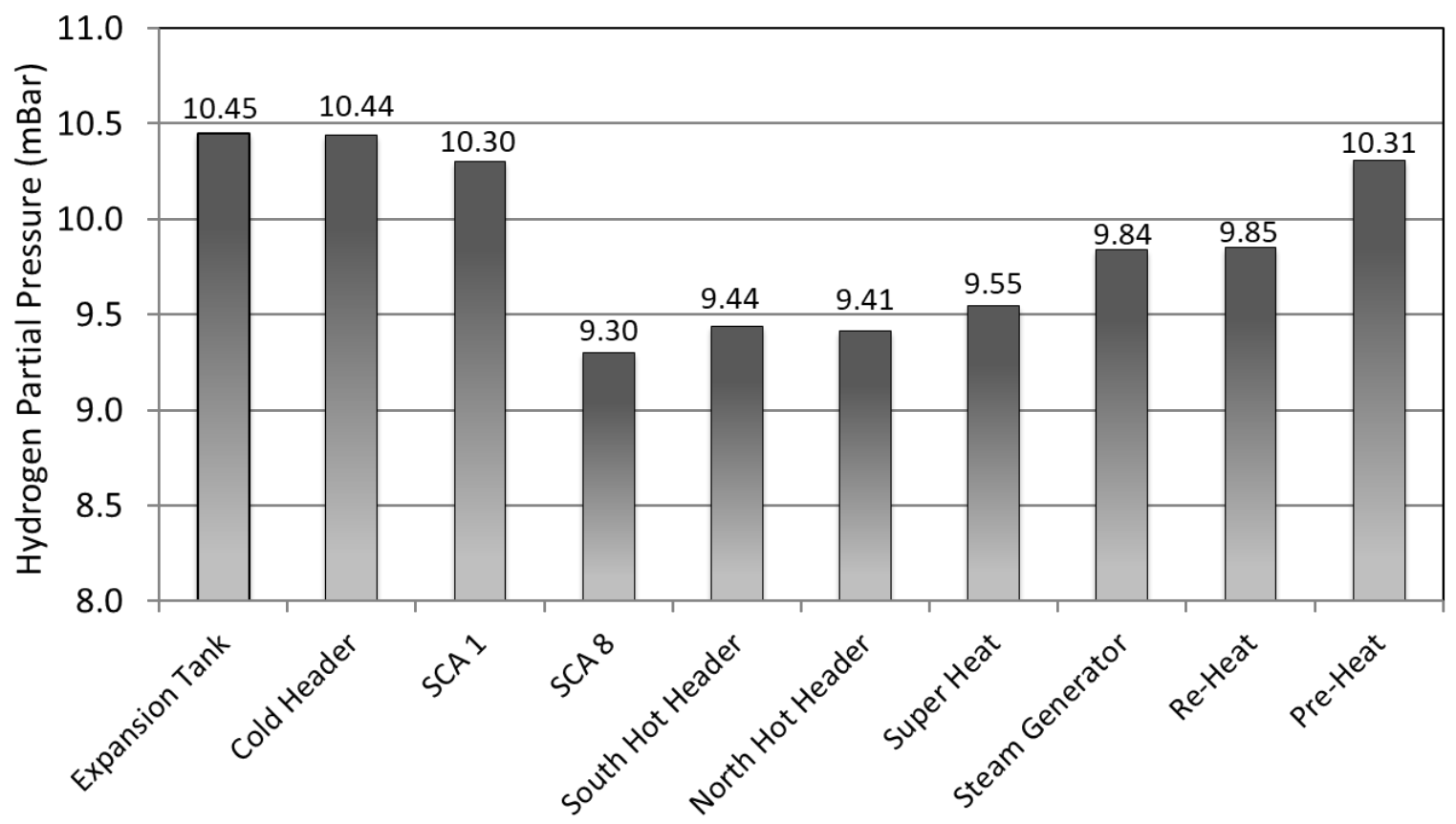

Figure 20. Hydrogen partial pressures in power-plant components at steady state.

Figure 20 shows that hydrogen partial pressures decrease as the HTF flows through the SCAs. This decrease is due somewhat to hydrogen permeate across the absorber tube into the receiver annulus. The main reason is that hydrogen solubility in the HTF increases with increasing temperature, so hydrogen partial pressures decrease 
even though dissolved hydrogen increase as the HTF flows from SCA1 to SCA8. Hydrogen partial pressure increases slightly when the HTF enters the hot headers from the collector field and gradually increases through the power-block subsystems before reaching its maximum partial pressure of 10.45 mbar in the expansion tank.

We expected hydrogen levels to increase in the hot header sections because the HTF is at its maximum temperature. At high HTF operating temperature, the thermal decomposition reaction rate increases significantly relative to the low operating temperature. Permeability through the carbon steel pipe walls also increases at high temperature but the relatively large volume to surface area ratio in the header piping reduces this effect. The net effect is for hydrogen levels to increase in the hot header piping. Hydrogen levels are constant in the cold header piping because both the thermal decomposition and permeation rates are low due to the low HTF temperature. Overall hydrogen partial pressures are more or less uniform throughout the power-plant subsystems when the expansion tank is not purged.

Recently at the 2018 Solar PACES Conference in Casablanca, Christian Yung of DLR presented his measurements of dissolved hydrogen concentrations in the circulating heat transfer fluid (HTF) at the NSO power plant [40]. Yung collected liquid HTF samples from a collector loop outlet at various times of the day and year to characterize dissolved hydrogen concentrations at the NSO plant. When the plant was operating at its design conditions during the summer months, the dissolved hydrogen concentration at the loop outlet ranged from $0.088 \mathrm{ppm}$ to $0.099 \mathrm{ppm}$.

These results agree very closely with dissolved hydrogen concentrations that we predicted using our power plant hydrogen model. Figure 21 shows predicted dissolved hydrogen concentrations in the receivers as functions of SCA position. The predicted value of SCA 8 is the hot outlet location, where Yung sampled the liquid HTF. His measured values were $0.088 \mathrm{ppm}$ to $0.099 \mathrm{ppm}$. Our modeling result $(0.091 \mathrm{ppm})$ is right in the range of his measured values. 


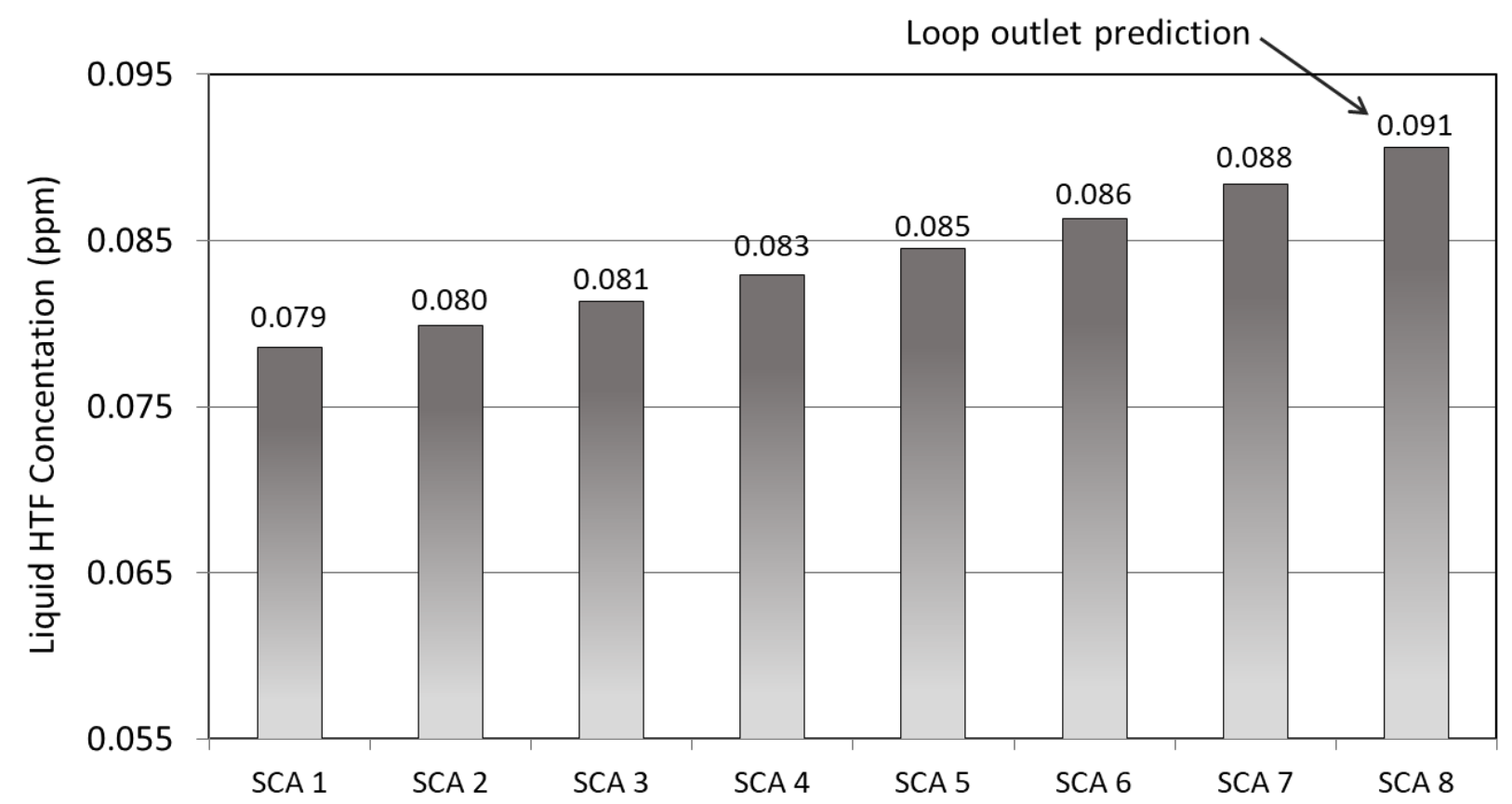

Figure 21: Full-plant model predictions for dissolved hydrogen concentrations.

Modeling results for NSO power plant with hydrogen mitigation extraction

Figure 22 shows the extra transport mode when hydrogen is actively purged from the expansion tank.

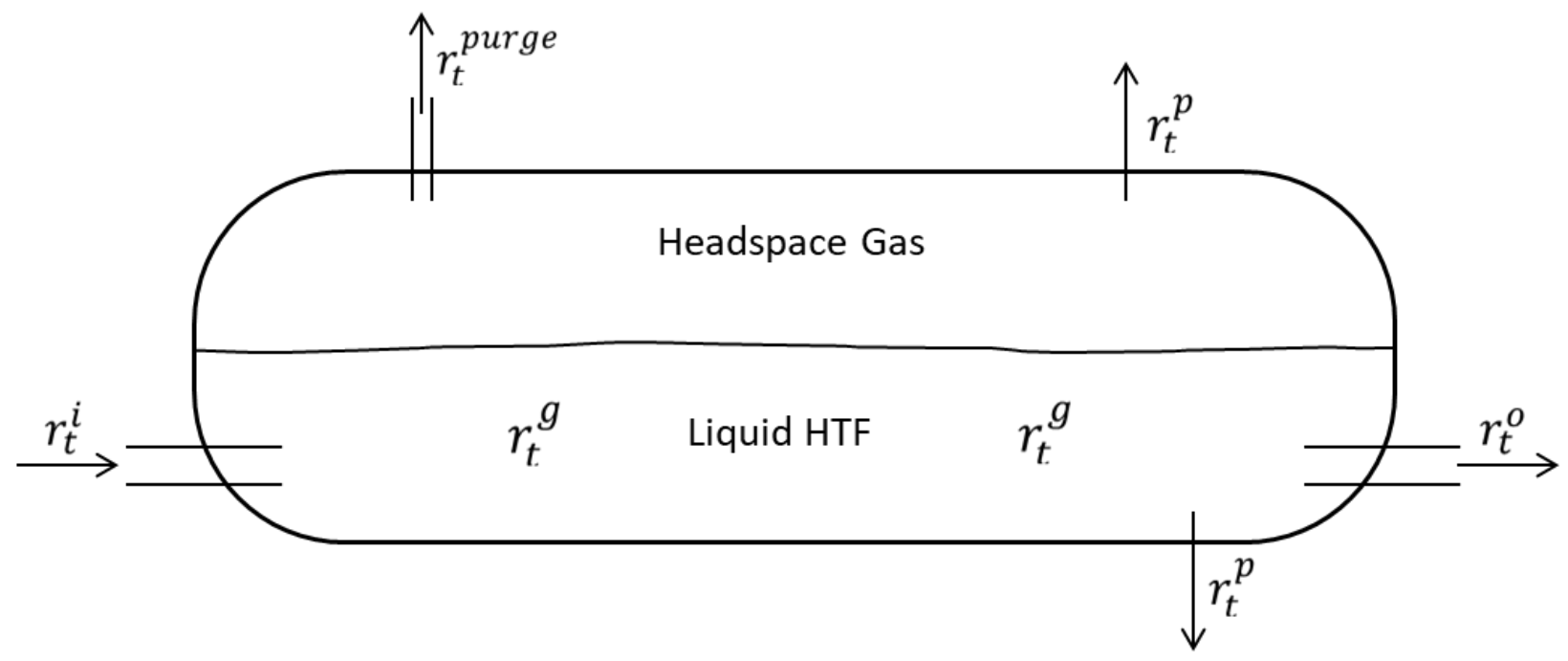

Figure 22. Hydrogen transport to and from of the expansion tanks when hydrogen is actively purged. 
We modeled active hydrogen removal from the expansion tank by adding an additional term to Eq. 12:

$$
r_{t}^{g}+r_{t}^{i}=r_{t}^{o}+r_{t}^{p}+r_{t}^{\text {purge }}
$$

Here, $r_{t}^{\text {purge }}$ is the rate at which hydrogen in removed from the expansion tank headspace gas by purging. This term does not specify or define the process for accomplishing this purge. The model simply assumes that there is an additional path for hydrogen removal from the expansion tank and solves for the other hydrogen transport and generation rates in the expansion tank, and all other plant components accordingly.

Figure 23 shows hydrogen partial pressures for the same power-plant components when $r_{t}^{\text {purge }}=2 \times 10^{-4}$ moles $/ \mathrm{s}$ or $1.4 \mathrm{~g} / \mathrm{hr}$. The model results showed that hydrogen levels were maintained at the design pressure for new receivers ( $<0.003 \mathrm{mbar}$ ) in SCAs $1-7$, but increased to $0.023 \mathrm{mbar}$ in SCA 8 . Hydrogen pressure increased dramatically in the south and north hot headers and continued to build pressure as HTF moved through the steam trains. Hydrogen pressure returned to low levels in the expansion tanks due to active purging of the tanks. The model results show that removing hydrogen from the expansion tanks is effective in keeping receivers in SCAs 1-7 at their design point pressure $(0.003 \mathrm{mbar})$ even if these receivers did not contain getters. The model shows that receivers in SCA 8 would require getters to maintain their hydrogen levels at the design point pressure.

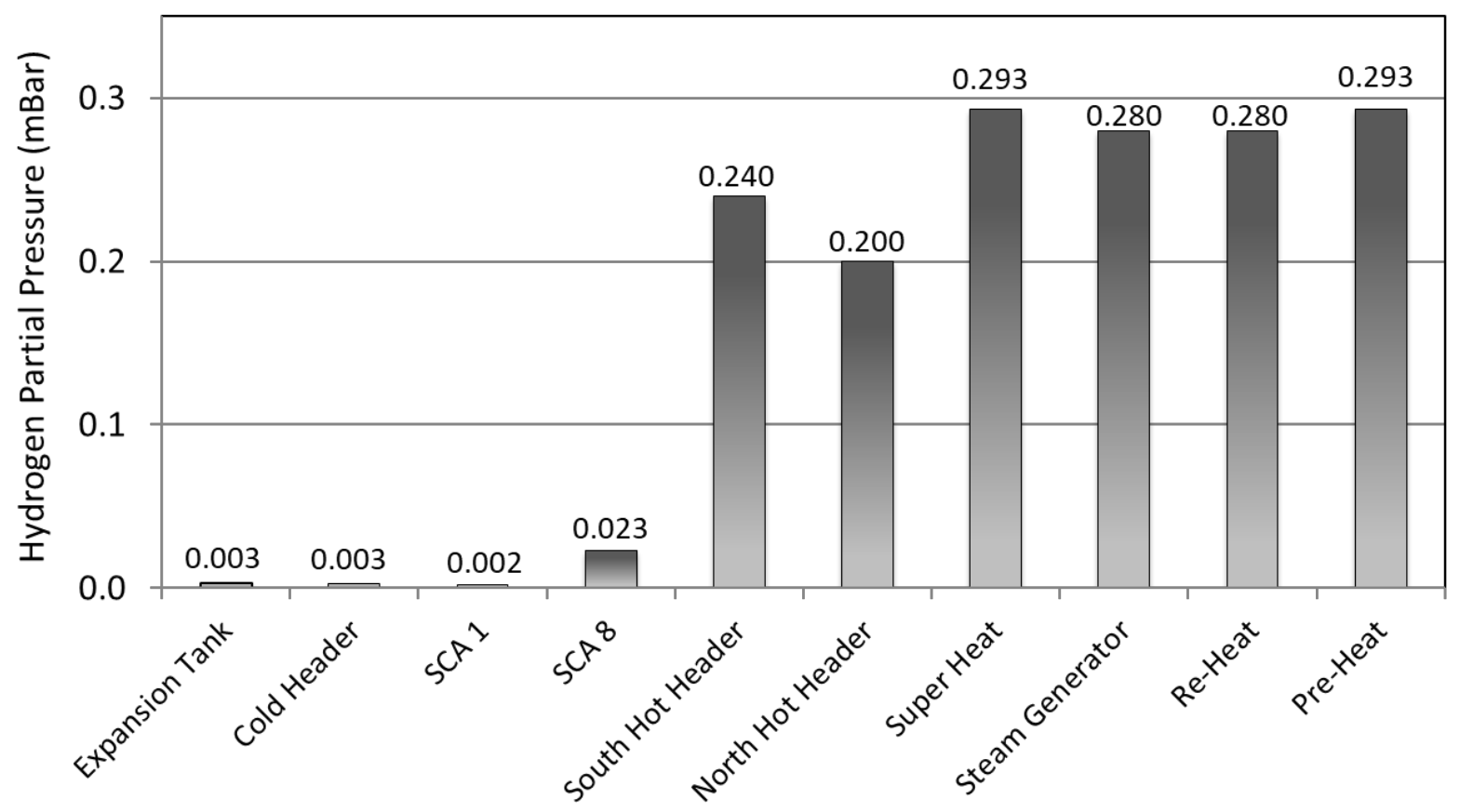

Figure 23. Hydrogen partial pressures in power-plant components when hydrogen is actively removed from the expansion tanks to reduce partial pressure to $0.003 \mathrm{mbar}$. 
We also modeled the hydrogen purge rate that is required to reduce and maintain hydrogen partial pressure in the expansion tanks to 0.3 mbar, which is the target pressure for the expansion tank that was reported by Kuckelkorn [35] that allows new receivers to maintain their performance for the full 30-year lifetime of the power plant. Figure 24 shows the results for a hydrogen purge rate of $1.8 \times 10^{-4} \mathrm{moles} / \mathrm{s}$ or $1.3 \mathrm{~g} / \mathrm{hr}$. This purge rate from each expansion tank maintains hydrogen partial pressure in the headspace gas at 0.3 mbar. Receiver HTF and annulus pressures are maintained at values of about $0.4 \mathrm{mbar}$ as shown in Figure 24.

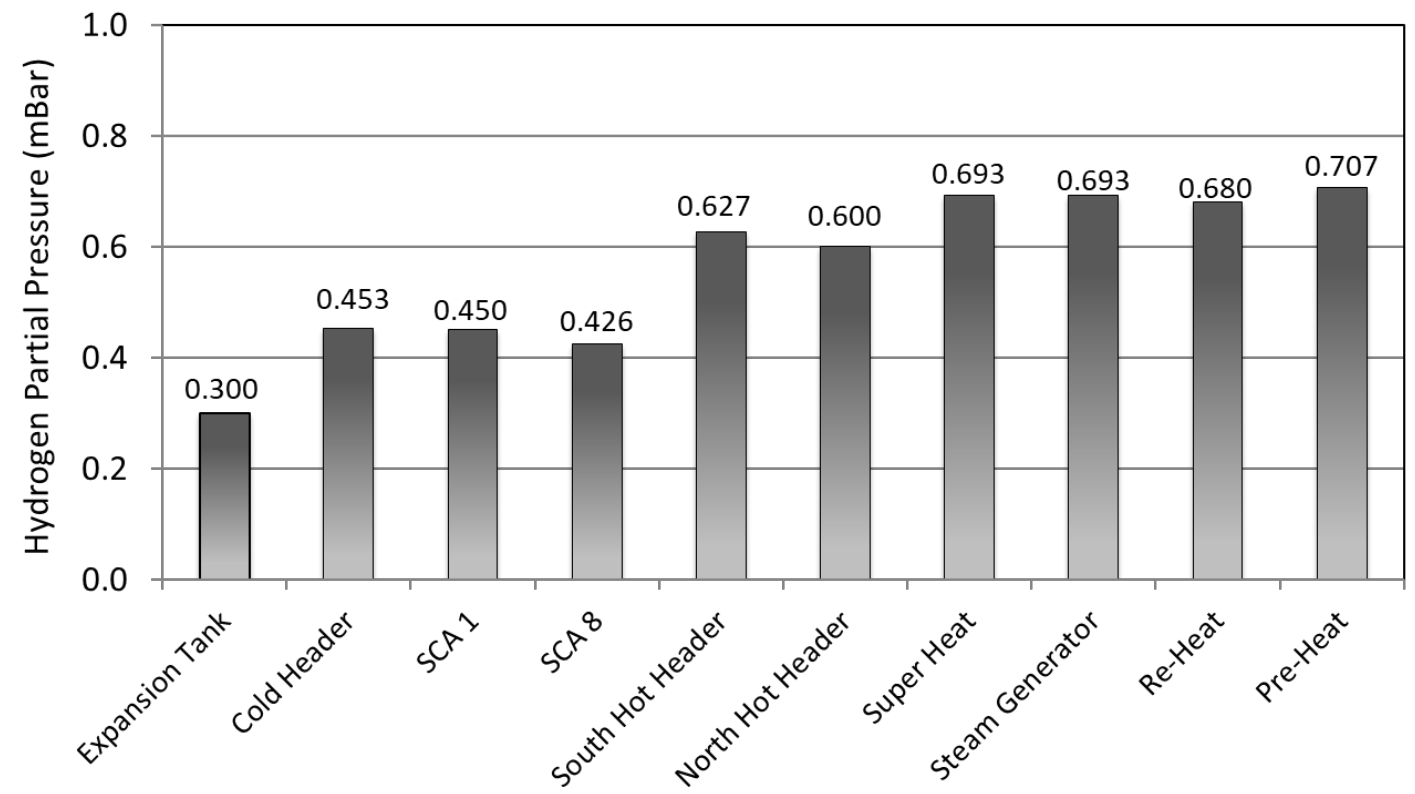

Figure 24. Hydrogen partial pressures in power-plant components when hydrogen is actively removed from the expansion tanks to reduce partial pressure to $0.3 \mathrm{mbar}$.

The significance of this work is illustrated in Figures 20,23, 24. The hydrogen pressures shown in Figure 20 indicate the levels of hydrogen that eventually build up in power-plant components and field receivers when operating at its design point if no mitigation strategy is employed. Receiver pressure of 1.3 mbar causes excessive heat loss so the 9-10 mbar pressure indicated by our modeling results will cause significant degradation of receiver thermal efficiency and overall plant performance.

Although many years of operation are needed to reach these levels, the concern for the eventual loss of plant performance motivates us to seek permanent solutions to this problem. Figures 23 and 24 clearly show that selectively removing hydrogen from the expansion tanks at a specified rate reduces the level of hydrogen in the collector field. In the process of performing this work, we learned that hydrogen may not need to be reduced to very low levels in the collector field (Fig. 23) but may only need to be reduced to an intermediate level (Fig. 24) to allow the power plant to maintain its design performance for its full operating lifetime. 
Receiver lifetime modeling

We used dissolved hydrogen concentration predictions from the power plant model to predict receiver lifetime in the collector field as a function of SCA position. The receiver lifetime model considered -

1. Dissolved hydrogen concentration as predicted by the power plant model,

2. equivalent hydrogen partial pressure of the HTF using Henry's Law constant,

3. permeability of the stainless-steel absorber tube,

4. permeability of the stainless-steel bellows,

5. adsorption capacity of the getters as a function of hydrogen pressure in the annulus and getter temperature.

All of these properties - Henry's constant, stainless steel permeability, and getter capacity are highly temperature dependent, and so vary according to SCA position in the flow loop. We first estimated receiver lifetime for the collector field in which there is no hydrogen extraction. Figure 25 shows receiver hydrogen pressure versus operating years for SCAs 1-8. Receiver lifetime for an SCA was assumed to be the year that hydrogen pressure reached $0.6 \mathrm{mbar}$ in the annulus. Figure 25 shows that the hottest SCA 8 had the shortest predicted lifetime of 5.5 years, while the coolest SCA 1 had the longest lifetime of 30.5 years. These results are consistent with anecdotal information from NSO and other power plants. Generally, receivers in the hottest SCA start to show elevated glass temperatures in about six years, and receivers in the coolest SCA tend to last the lifetime of the power plant.

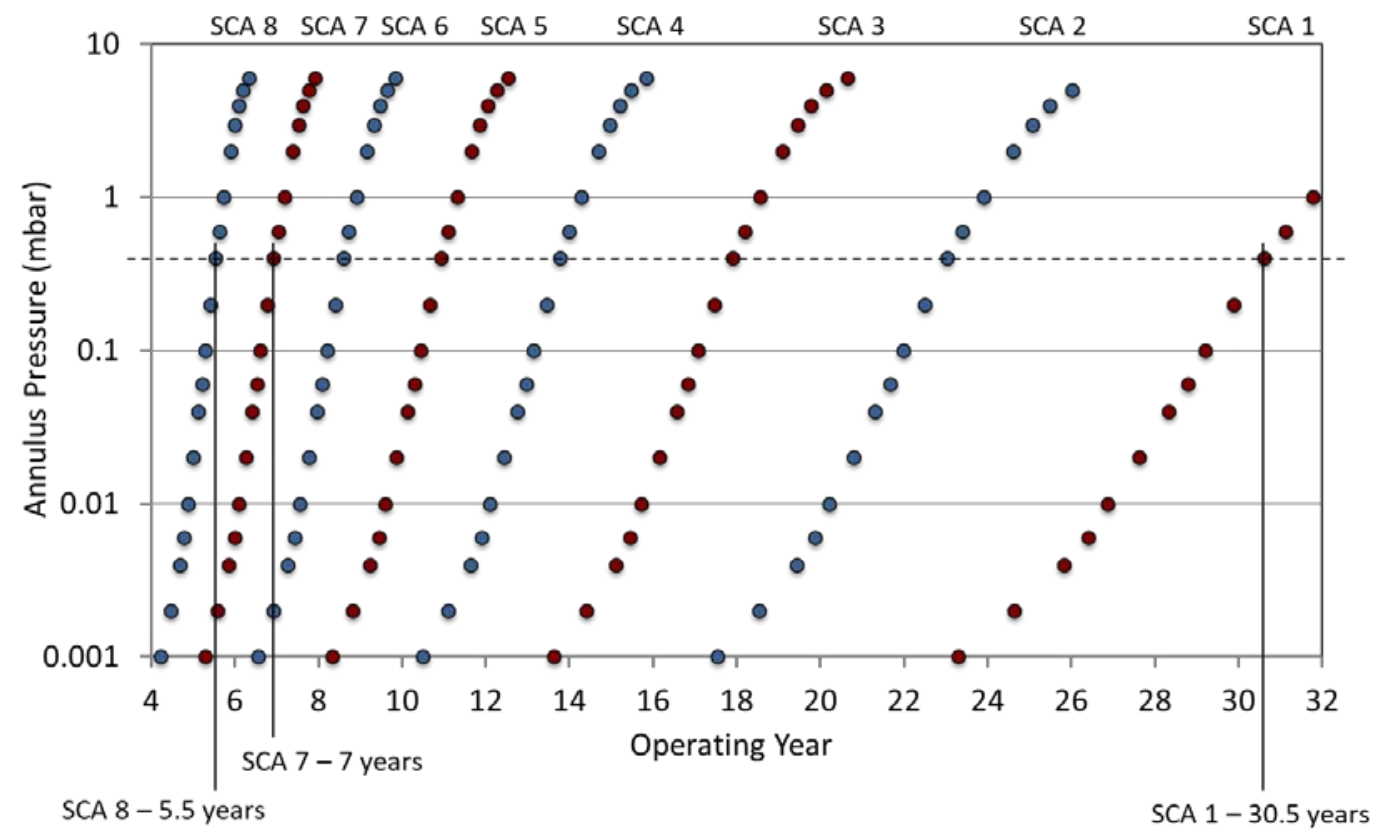

Figure 25. Receiver lifetime versus SCA loop position with no hydrogen extraction. 
Second, we estimated receiver lifetime for the collector field in which hydrogen mitigation reduced hydrogen partial pressure in the expansion tanks' headspace gas down to 0.3 mbar. This value is generally accepted as the target level that allows the collector field to last the 30 -year lifetime of the power plant. Figure 26 shows the results for the hot end of the flow loop, including SCAs 5-8. SCA 8 lasted 31 years with the other SCAs lasting well beyond the lifetime of the power plant. These results predict that the collector field will maintain its performance for the full 30-year lifetime of the power plant if hydrogen is reduced and maintained at 0.3 mbar in the expansion tanks' headspace gas.

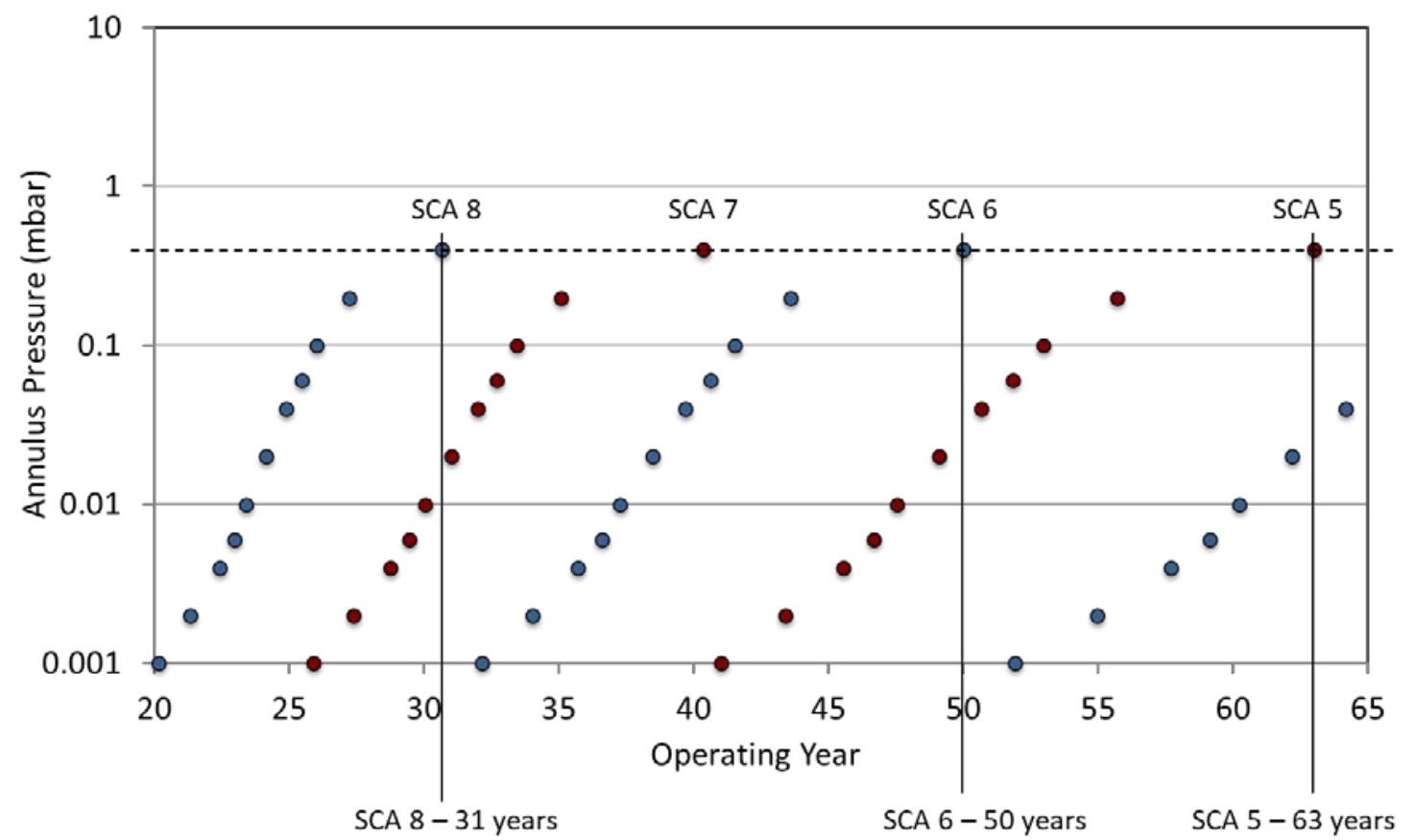

Figure 26. Receiver lifetime versus SCA loop position with treatment that reduces hydrogen to $0.3 \mathrm{mbar}$ in the expansion tanks' headspace gas.

NREL's receiver lifetime and power plant models allowed us to establish performance metrics for the mitigation process that would be specified and installed at the NSO power plant.

\section{Expansion tank modeling}

As stated in the Background, our initial approach was to base our mitigation process on extracting hydrogen from the expansion tanks. During several discussions with NSO personnel, they expressed their need to not locate any process equipment within the expansion tanks. Considering this constraint, we focused our design effort on developing a process that was located outside the expansion tanks and extracts hydrogen from the headspace gas. Figure 27 shows the general process layout. 


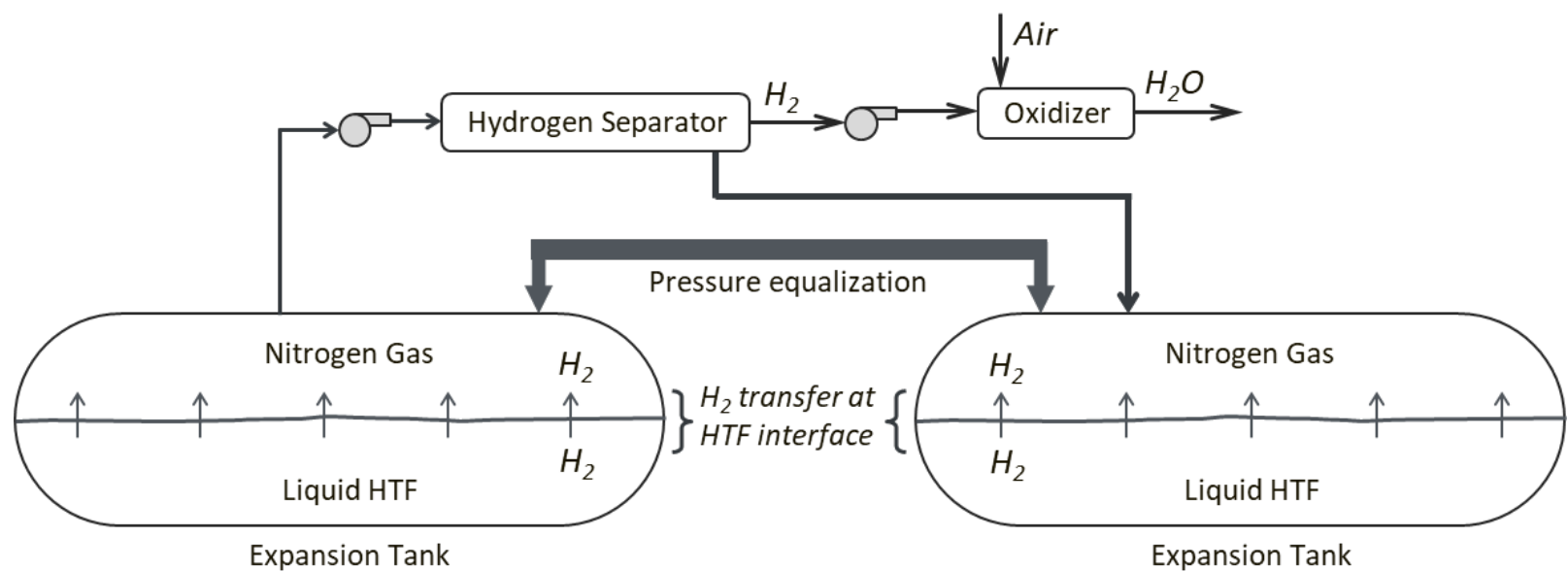

Figure 27. General hydrogen mitigation process layout.

We planned to flow headspace gas from one or more expansion tanks, extract a portion of the hydrogen, and return the headspace gas to the other tanks. The expansion tanks have a ullage piping system that equalizes headspace gas pressure in all tanks.

A key process step in Figure 27 is transfer of hydrogen from the liquid HTF to the headspace gas. This is critical because the goal is to control hydrogen levels in the liquid HTF. With this in mind, we performed an analysis to estimate the rate of hydrogen transfer across the interface and corresponding mass transfer coefficient with and without active HTF mixing.

Various mechanisms are available that promote removal of a volatile component from a solvent, e.g. removal of $\mathrm{H}_{2} \mathrm{~S}$ from sour water in refineries or VOCs from groundwater or wastewater. These mechanisms are typically categorized in towers (e.g. spray tower, packed tower) and aerators (e.g. diffused aerator, mechanical surface aerator), with each technique documented in detail by Crittenden et al. (2012) [31]. The applicability of each method depends on the desired removal percentage and Henry's constant of the volatile component, as illustrated in Figure 28. 


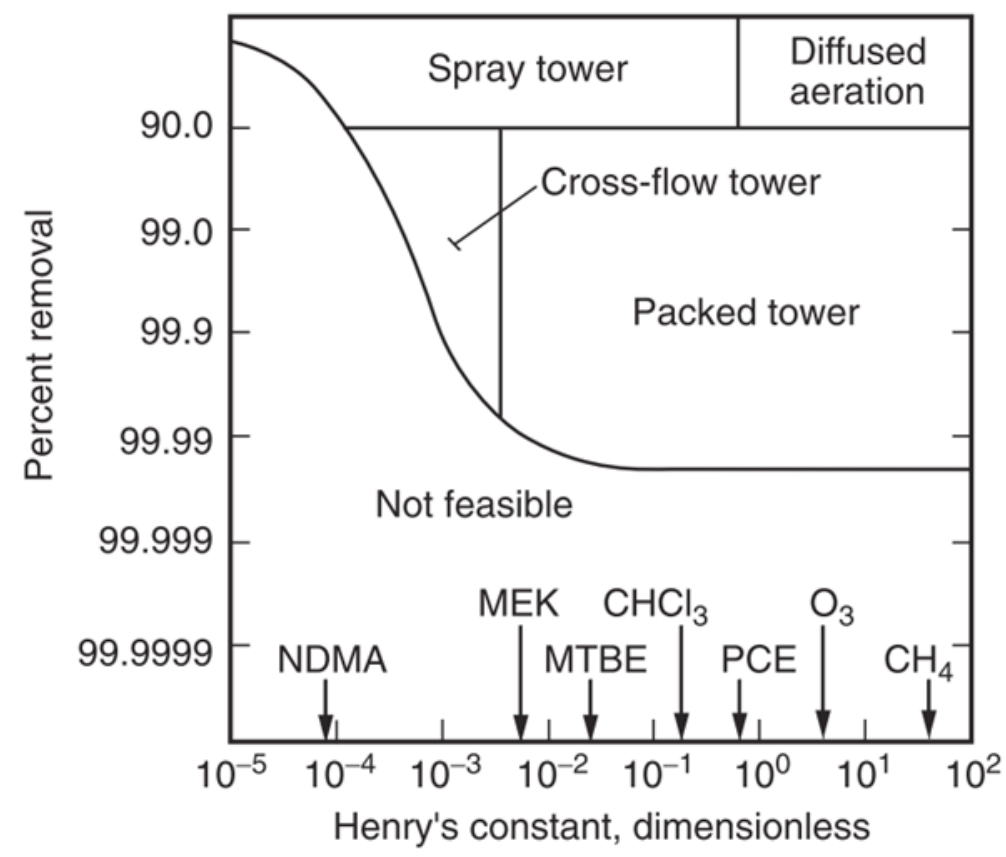

Figure 28. Feasible aeration processes as a function of Henry's constant and required removal percentage of volatile component (Crittenden et al., 2012).

Previous simulations $[41,5]$ showed that a removal percentage of about 20 to $50 \%$ is required to mitigate the hydrogen issue over the lifetime of the Nevada Solar One (NSO) parabolic trough power plant. Further, the dimensionless Henry's constant, calculated later, has a value of about 7 . According to Figure 28 , this low removal rate and high Henry's constant suggest utilizing a diffused aeration system for the NSO plant. A diagram of the diffused aeration system envisioned is shown in Figure 29. The head space gas itself will be compressed and injected at the bottom of the expansion tank.

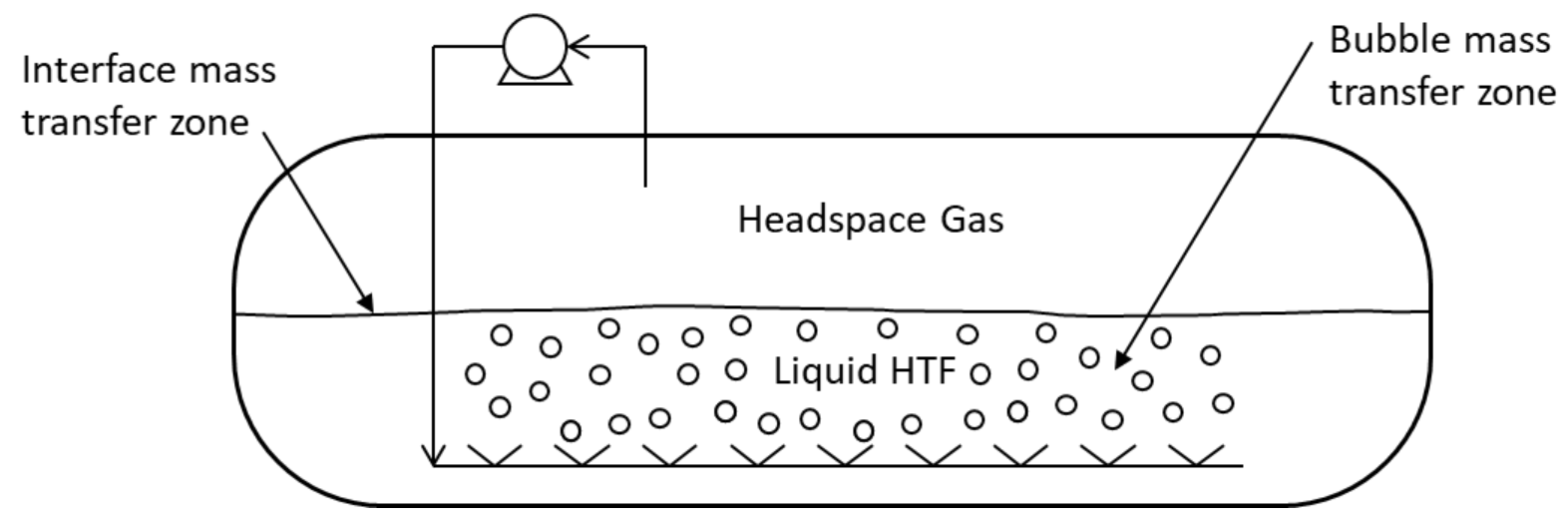

Figure 29. Schematic diagram of diffused aeration system envisioned for NSO. The head space gas (HSG) is compressed and injected through a diffuser at the bottom of the tank. Volatile components from the liquid transfer into the bubbles within the liquid, as well as into the head space gas at the surface. 
Estimating diffusion coefficients of hydrogen in heat transfer fluid

The diffusion coefficients for hydrogen in the heat transfer fluid (HTF), both in the gas and liquid phase, are calculated in this section. Knowledge of these diffusion coefficients is required for the mass transfer models developed in the next section to estimate the amount of hydrogen removed from the expansion tank using a diffused aeration system.

\section{Diffusion coefficient of hydrogen in head space gas}

The heat transfer fluid in the gas phase in the expansion tank, further referred to as "head space gas" (HSG), has a composition in molar fraction of Biphenyl (0.4) Diphenylether (0.4) $-\mathrm{N}_{2}(0.19997)-\mathrm{H}_{2}(0.00003)$. It is assumed a non-polar ideal gas with temperature and pressure of $566.15 \mathrm{~K}$ and 10 bar, respectively (NSO plant conditions). The diffusion coefficient of hydrogen in this gas mixture is estimated using the Chapman-Enskog Theory for binary gases (Cussler, 2009) [42] in combination with an equation for a gaseous diffusion coefficient in a multicomponent system.

The Chapman-Enskog Theory predicts the diffusion coefficient $D\left[\mathrm{~cm}^{2} / \mathrm{s}\right]$ for a binary mixture using the kinetic theory of gases with the following correlation (accurate to about eight percent):

$$
D=\frac{1.834 \cdot 10^{-3} T^{3 / 2} \sqrt{\frac{1}{M_{1}}+\frac{1}{M_{2}}}}{p \sigma_{12}^{2} \Omega}
$$

with $T$ the absolute temperature $[\mathrm{K}], M_{1}$ and $M_{2}$ the molecular weight of the 2 components $[\mathrm{g} / \mathrm{mol}]$, and $p$ the pressure [bar]. The parameters $\sigma_{12}$ and $\Omega$ are molecular properties depending on the interaction and collision characteristics between the two components (Cussler, 2009) [42]. The results for the diffusion coefficient for hydrogen in a mixture with each individual gas component are listed in Table 1.

Table 1: Diffusion coefficient of hydrogen in gas mixture with individual components.

\begin{tabular}{|l|c|c|c|}
\hline \multicolumn{1}{|c|}{ Binary Mixture } & $\sigma_{12}[$ Ångstrom] & $\Omega[-]$ & $D\left[\mathrm{~cm}^{2} / \mathrm{s}\right]$ \\
\hline $\mathrm{H}_{2}-$ Biphenyl & 4.57 & 0.946 & 0.09 \\
\hline $\mathrm{H}_{2}-$ Diphenylether & 4.57 & 0.942 & 0.09 \\
\hline $\mathrm{H}_{2}-\mathrm{N}_{2}$ & 3.31 & 0.759 & 0.22 \\
\hline
\end{tabular}

The diffusion coefficient of hydrogen in the HSG mixture $D_{H_{2}, H S G}$ is now calculated using an equation for a multicomponent stagnant gas mixture (Hines and Maddox, 1985) [36]:

$$
D_{H_{2}, H S G}=\frac{1-y_{H_{2}}}{\frac{y_{N_{2}}}{D_{H_{2}, N_{2}}}+\frac{y_{B P}}{D_{H_{2}, B P}}+\frac{y_{D P}}{D_{H_{2}, D P}}}=0.1 \mathrm{~cm}^{2} / \mathrm{s}
$$


with $\mathrm{BP}$ and DP referring to biphenyl and diphenylether and $y$ the molar fractions of the various components in the HSG, provided at the beginning of this section. A value of 0.1 $\mathrm{cm}^{2} / \mathrm{s}$ is of same order of magnitude as the diffusion coefficient for various other gas mixtures (see for example (Cussler, 2009) [42]).

\section{Diffusion coefficient of hydrogen in heat transfer liquid}

The Wilke - Chang theory (Wilke and Chang, 1955) [44] is applied to estimate the diffusion coefficient of in the heat transfer fluid. The liquid is assumed to be a non-polar mixture of $50 \%$ biphenyl $-50 \%$ diphenylether at $566.15 \mathrm{~K}$ and 10 bar (NSO conditions). The Wilke - Chang theory estimates the diffusion coefficient $D\left[\mathrm{~cm}^{2} / \mathrm{s}\right]$ of a solute in a dilute solution as (Wilke and Chang, 1955) [44]:

$$
D=7.4 \cdot 10^{-8} \frac{\sqrt{\zeta M} T}{\eta V^{0.6}}
$$

with $\zeta$ the association factor of the solvent, $M$ the molecular weight of the solvent $[\mathrm{g} / \mathrm{mol}], T$ the absolute temperature $[\mathrm{K}], \eta$ the dynamic viscosity of the solution [cp], and $V$ the molar volume of the solute $\left[\mathrm{cm}^{3} / \mathrm{mol}\right]$.

The association factor depends on the type of solvent: $\zeta$ is 1 for non-polar solvents, 1.5 for ethanol, 1.9 for methanol, and 2.6 for water (Cussler, 2009 [42]; Hines and Maddox, 1985 [45]). The biphenyl-diphenylether mixture is assumed a non-polar solvent, and therefore a value of 1 is considered for $\zeta$. The polarity of the diphenylether might result in an increase in $\zeta$ and hence an increase in $D$. As a result, assuming a value of 1 would be conservative. Further, the molecular weight $M$ and the viscosity $\eta$ of the solvent is $162.2 \mathrm{~g} / \mathrm{mol}$ and $0.229 \mathrm{cp}$, respectively. The molar volume $V$ of hydrogen is $14.3 \mathrm{~cm} / \mathrm{mol}$. The result for the diffusion coefficient of hydrogen in the HTF is $D_{H_{2}, H T L}=4.7 \cdot 10^{-4} \frac{\mathrm{cm}^{2}}{\mathrm{~s}}$. This result is of the same order as other diffusion coefficients for various solutes in aqueous and non-aqueous solvents (Cussler, 2009) [42]. For example, the diffusion coefficient for hydrogen in water at room temperature is $4.5 \cdot 10^{-5}$ $\mathrm{cm}^{2} / \mathrm{s}$. Our result is higher due to the higher temperature, and lower viscosity and higher molecular weight of the solvent.

Mass transfer model of hydrogen diffusion from heat transfer liquid into head space gas using diffused aeration

Using a diffused aeration system, mass transfer of hydrogen from the HTF into the HSG occurs both at the bubble liquid-gas interface and the surface liquid-gas interface. Following a similar approach as Chern and Yu (1995) [45], this section develops a mass transfer model for each interface separately, and eventually combines both models to estimate the overall hydrogen removal rate from the HTF. 
Modeling of mass transfer at surface liquid-gas Interface

The removal of hydrogen from the HTF in the expansion tank across the liquid-gas interface at the surface can be estimated using a simple gas-liquid interface mass transfer model. The molar rate at the surface, $N_{s}[\mathrm{~mol} / \mathrm{s}]$, is represented as (Cussler, 2009) [39]:

$$
N_{S}=K_{G} A\left(p_{H 2, H T L}-p_{H_{2}, H S G}\right)
$$

with $K_{G}$ the overall gas-side mass transfer coefficient $\left[\mathrm{mol} /\left(\mathrm{cm}^{2} \cdot \mathrm{s} \cdot\right.\right.$ bar)], $A$ the area of the liquid-gas interface $\left[\mathrm{cm}^{2}\right], p_{H 2, H T L}$ the hypothetical partial pressure of hydrogen that would be in equilibrium with the bulk liquid concentration [bar], and $p_{H_{2}, H S G}$ the partial pressure of hydrogen in the head space gas [bar]. The partial pressure $p_{H 2, H T L}$ in equilibrium with the bulk liquid concentration can be calculated using Henry's law $\left(p_{H 2, H T L}=H_{p c} \cdot c_{H_{2}, H T L}\right)$ with $c_{H_{2}, H T L}$ the bulk concentration of hydrogen in the heat transfer liquid [mol/l] and $H_{p c}$ the Henry's Law constant for the $\mathrm{H}_{2}$-HTF system $[\mathrm{bar} \cdot \mathrm{l} / \mathrm{mol}]$, estimated as:

$$
H_{p c}=H_{0} \cdot \exp \left(-\frac{E}{R T}\right)=1.47 \cdot 10^{2} \cdot \exp \left(\frac{3758}{8.314 \cdot T}\right)
$$

For a temperature $T$ of $566.15 \mathrm{~K}, H_{p c}$ for the $\mathrm{H}_{2}$-HTF system has a value of 326.6 bar $\cdot 1 /$ mol. Assuming an ideal gas, the dimensionless Henry's constant is: $H_{c c}=\frac{H_{p c}}{R T}=$ 6.9.

The overall mass transfer coefficient $K_{G}$ incorporates the resistance to mass transfer on the gas-phase side of the interface as well as the liquid-side of the interface and is expressed as (Cussler, 2009) [42]:

$$
K_{G}=\frac{1}{\frac{1}{k_{g}}+\frac{H_{p c}}{k_{l}}}
$$

with $k_{g}$ the gas-phase mass transfer coefficient $\left[\mathrm{mol} /\left(\mathrm{cm}^{2} \cdot \mathrm{s} \cdot\right.\right.$ bar)] and $k_{l}$ the liquidphase mass transfer coefficient [cm/s].

Various models exist to calculate $k_{g}$ and $k_{l}$. The most common is the film theory model (Cussler, 2009) [42], which expresses the mass transfer as diffusion coefficient $D$ $\left[\mathrm{cm}^{2} / \mathrm{s}\right]$ over the film layer thickness. The stagnant film thickness is assumed 10 to 100 $\mu \mathrm{m}(0.001$ to $0.01 \mathrm{~cm})$ for liquids and 0.1 to $1 \mathrm{~cm}$ for gases (Crittenden et al., 2012) [37]. In non-stagnant fluids, the film thickness is unknown and should be determined experimentally. In most cases, $\frac{1}{k_{g}}$ is at least an order of magnitude smaller than $\frac{H_{p c}}{k_{l}}$ in Eq. 25, meaning the mass transfer of hydrogen from HTF into HSG is dominated by the liquid-side resistance. Another widely used model is the surface renewal model (Hines and Maddox, 2015) [43], which is not discussed in further detail here. 
Modeling of mass transfer at the bubbles' liquid-gas interface

A model for removal of hydrogen through diffusion from the liquid in the gas bubbles is derived based on a bubble model developed by Chern and Yu (1995) [45]. The governing hydrogen mass balance equation assuming pseudo-steady state conditions is (Chern and $\mathrm{Yu}, 1995)$ [45]:

$$
G \frac{d y_{H_{2}, \text { bubble }}}{d z}=K_{G} a_{\text {bubble }}(1-\epsilon) A\left(p_{H_{2}, H T L}-p_{H_{2}, \text { bubble }}\right)
$$

with $G$ the molar flow rate of the gas released at the bottom of the expansion tank [mol/s], $y_{H_{2}, \text { bubble }}$ the molar fraction of hydrogen in a bubble, and $z$ the vertical direction [m]. Further, $K_{G}$ is the overall gas-side mass transfer coefficient [mol/( $\mathrm{cm}^{2} \cdot \mathrm{s} \cdot$ bar $)$ ], $a_{\text {bubble }}$ the bubble interfacial mass transfer area per unit volume of liquid [1/m], $\epsilon$ the gas fraction in the liquid (gas holdup), and $A$ the cross-sectional area $\left[\mathrm{m}^{2}\right] . p_{H_{2}, \text { bubble }}$ is the partial pressure of hydrogen in the bubble [bar] and is a function of the vertical position $z$. The hydrogen concentration in the liquid is assumed uniform throughout the tank. Further, all bubbles are assumed identical and flowing vertically upward in plug flow. The tank is simplified to have a cuboid shape and hence constant cross-sectional area $A$ in the $z$ direction. When defining now the parameters $K_{1}$ and $K_{2}$ as follows:

$$
\begin{aligned}
& K_{1}=\frac{K_{G} a_{\text {bubble }}(1-\epsilon) A}{G} P \\
& K_{2}=\frac{K_{G} a_{\text {bubble }}(1-\epsilon) A}{G} p_{H_{2}, H T L}
\end{aligned}
$$

the solution of this ordinary first-order linear differential equation is:

$$
y_{H_{2}, \text { bubble }}(z)=\frac{K_{2}}{K_{1}}+\left(y_{H_{2}, H S G}-\frac{K_{2}}{K_{1}}\right) \cdot \exp \left(-K_{1} z\right)
$$

The molar hydrogen removal rate through the bubbles is then calculated as:

$$
N_{b}=G \cdot\left(y_{H_{2}, \text { bubble }}\left(z_{\text {liquid }}\right)-y_{H_{2}, H S G}\right)
$$

Knowledge of the bubble diameter $d_{\text {bubble }}[\mathrm{m}]$ is required to estimate the bubble interfacial mass transfer area $a_{\text {bubble }}$ as well as the gas holdup $\epsilon$. It is assumed each bubble is identical and the diameter stays constant along the rise of the bubble since the pressure $P$ is assumed constant. The velocity $v_{\text {bubble }}[\mathrm{m} / \mathrm{s}]$ of a bubble is estimated using the terminal velocity equation for Stokes flow.

An alternative correlation replacing Eq. 25 to calculate $K_{G}$ for Eqs. 26, 27, 28 is provided by Cussler (2009) [42]:

$$
K_{G}=\frac{1}{R T} \cdot 0.31 \cdot \frac{D_{H_{2}, H T L}}{d_{b u b b l e}} \cdot\left(\frac{d_{\text {bubble }}^{3} \cdot g \cdot\left(\rho_{H T L}-\rho_{\text {bubble }}\right)}{\rho_{H T L} \cdot v_{H T L}^{2}}\right)^{0.333} \cdot\left(\frac{v}{D_{H_{2}, H T L}}\right)^{0.333}
$$


Using Eq. 31 instead of Eq. 25 for calculating the mass transfer coefficient $K_{G}$ results in a 10 to $20 \%$ lower mass transfer rate at the bubble gas-liquid interface.

\section{Combining bubble and surface mass transfer}

The surface and bubble hydrogen mass transfer is now combined to estimate the overall hydrogen purge rate in the tank. A hydrogen mass balance on the tank is applied to calculate the hypothetical equilibrium pressure in the liquid as a function of the diffused aeration operating conditions:

$$
V_{\text {in }} \cdot c_{H_{2}, \text { in }}+n_{H_{2}, \text { gen }}=V_{\text {out }} \cdot c_{H_{2}, \text { out }}+n_{H_{2}, \text { surf }}+n_{H_{2}, \text { bubbles }}+n_{H_{2}, \text { tank wall }}
$$

In this mass balance, $V_{\text {in }}$ and $V_{\text {out }}$ are the incoming and outgoing flow rate [1/s] which are assumed equal (steady-state), and $c_{H_{2}, \text { in }}$ and $c_{H_{2} \text {,out }}$ are the hydrogen concentration in the incoming and outgoing fluid [mol/s]. Further, $n_{H_{2}, \text { gen }}$ is the hydrogen generation rate due to dissociation of the HTF and $n_{\mathrm{H}_{2} \text {,tank wall }}$ is the diffusion rate of hydrogen through the walls of the expansion tank. Finally, $n_{H_{2}, \text { surf }}$ and $n_{H_{2}, \text { bubbles }}$ are the surface and bubble hydrogen mass transfer, respectively [mol/s]. The tank is assumed well mixed and hence the concentration of hydrogen in the outgoing fluid is assumed identical to the concentration of hydrogen in the HTF within the expansion tank. The mass transfer model has been implemented in MATLAB (MathWorks, 2012) [46] to estimate the purge rate as a function of the hydrogen partial pressure in the HSG and the volume rate of the injected gas at the bottom of the tank.

\section{Nevada Solar One expansion tank geometry and operating parameters}

The mass transfer model is applied to the Nevada Solar One (NSO) expansion tank operating conditions and geometry. The expansion tank is considered at uniform temperature of $566.15 \mathrm{~K}$. The pressure of the headspace gas is 10 bar. The volume flow rate of the in- and outgoing fluid is $235.4 \mathrm{l} / \mathrm{s}$. Previous simulations (Glatzmaier et al., 2016) $[41,5]$ have shown that in steady-state operation, the hydrogen issue can be mitigated over the lifetime of the plant for a hydrogen purge rate in the range $1.7 \cdot 10^{-4}$ to $2.0 \cdot 10^{-4} \mathrm{~mol} / \mathrm{s}$. Two cases are simulated corresponding to the lower limit (low purge rate) and higher limit (high purge rate) of this range. The expansion tank operating conditions are listed in Table 2. 
Table 2: NSO expansion tank operating conditions for low and high purge rate.

\begin{tabular}{|l|c|c|}
\hline \multicolumn{1}{|c|}{ Parameter } & Low purge rate & High purge rate \\
\hline Purge rate $(\mathrm{mol} / \mathrm{s})$ & $1.67 \cdot 10^{-4}$ & $1.98 \cdot 10^{-4}$ \\
\hline Removal rate $(\%)$ & 17.2 & 47.5 \\
\hline Inlet HTF H${ }_{2}$ concentration $(\mathrm{mol} / \mathrm{l})$ & $4.12 \cdot 10^{-6}$ & $1.77 \cdot 10^{-6}$ \\
\hline Inlet HTF H molar rate $(\mathrm{mol} / \mathrm{s})$ & $9.69 \cdot 10^{-4}$ & $4.16 \cdot 10^{-4}$ \\
\hline Outlet HTF H $\mathrm{H}_{2}$ concentration $(\mathrm{mol} / \mathrm{l})$ & $3.41 \cdot 10^{-6}$ & $9.28 \cdot 10^{-7}$ \\
\hline Outlet HTF $\mathrm{H}_{2}$ molar rate $(\mathrm{mol} / \mathrm{s})$ & $8.03 \cdot 10^{-4}$ & $2.18 \cdot 10^{-4}$ \\
\hline $\mathrm{H}_{2}$ permeation rate $(\mathrm{mol} / \mathrm{s})$ & $1.12 \cdot 10^{-7}$ & $5.82 \cdot 10^{-8}$ \\
\hline $\mathrm{H}_{2}$ generation rate $(\mathrm{mol} / \mathrm{s})$ & $2.85 \cdot 10^{-8}$ & $2.85 \cdot 10^{-8}$ \\
\hline
\end{tabular}

Simulation results for Nevada Solar One parabolic trough power plant

The total hydrogen purge rate $\left(n_{H_{2}, \text { surf }}+n_{H_{2}, \text { bubbles }}\right)$ is plotted in Figure 30 for low purge rate conditions (left diagrams) and high purge rate conditions (right diagrams) and various hydrogen partial pressure in the HSG (pressure increases from top to bottom diagrams) as a function of gas volume injection rate at the bottom of the tank. The low and high purge rate conditions and target purge rate are provided in Table 2.

Uncertainty exists with respect to the mass transfer parameters. A range is assumed for bubble diameter $(1-3 \mathrm{~mm})$ and film layer thickness in the surface mass transfer model $(0.01$ to $0.001 \mathrm{~cm})$, and two models are considered for calculating the mass transfer coefficient at the bubble liquid-gas interface (surface renewal model and Cussler correlation).

The results show that for the low purge rate conditions, the target purge rate $\left(1.667 \cdot 10^{-4} \mathrm{~mol} / \mathrm{s}\right)$ can easily be obtained maybe even without a diffused aeration system (passive removal). For the high purge rate conditions, to meet the target rate $\left(1.976 \cdot 10^{-4} \mathrm{~mol} / \mathrm{s}\right)$, passive removal is probably not sufficient, and a diffused aeration system is required with injected gas volume rates of up to $100 \mathrm{l} / \mathrm{s}$. 
Low Purge Rate
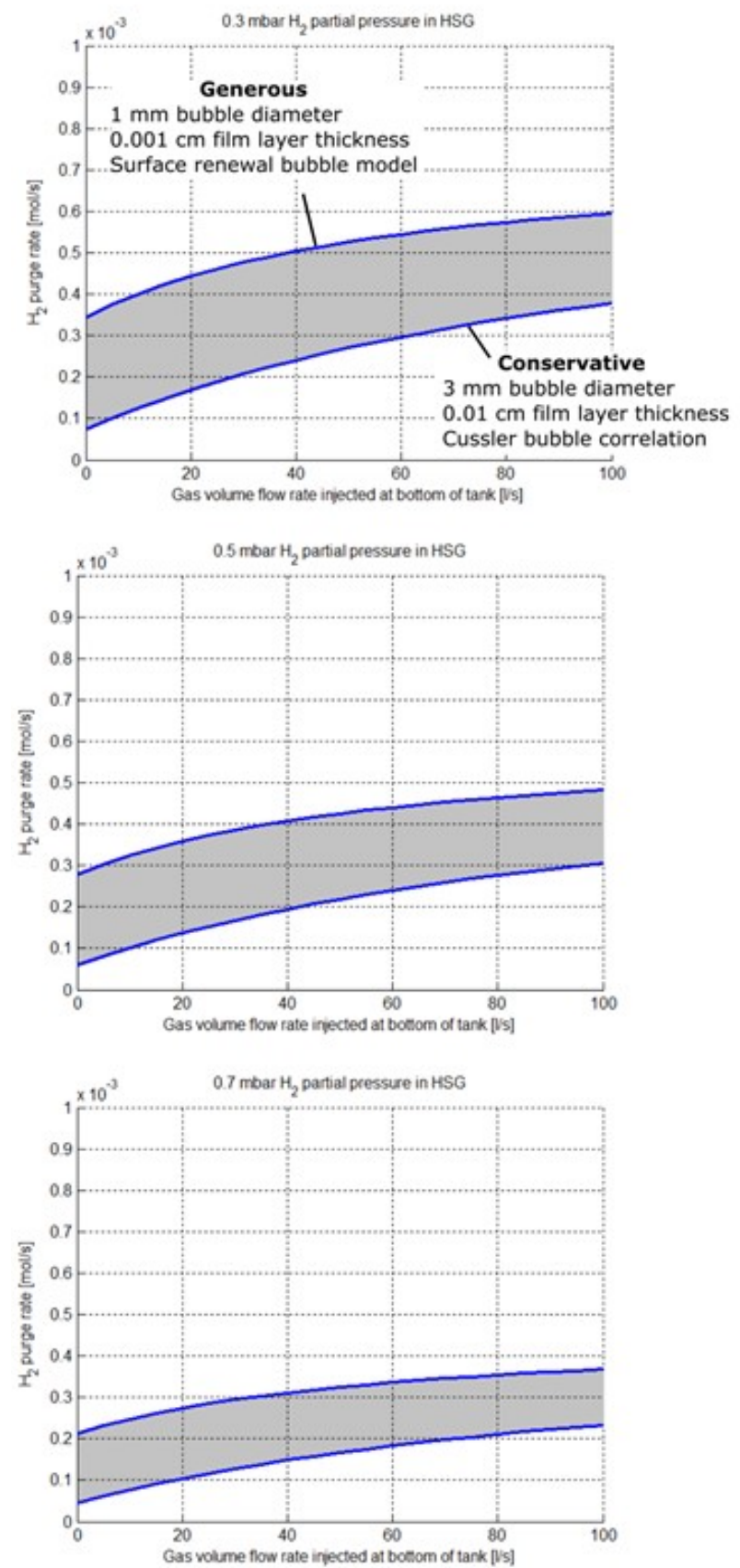

High Purge Rate
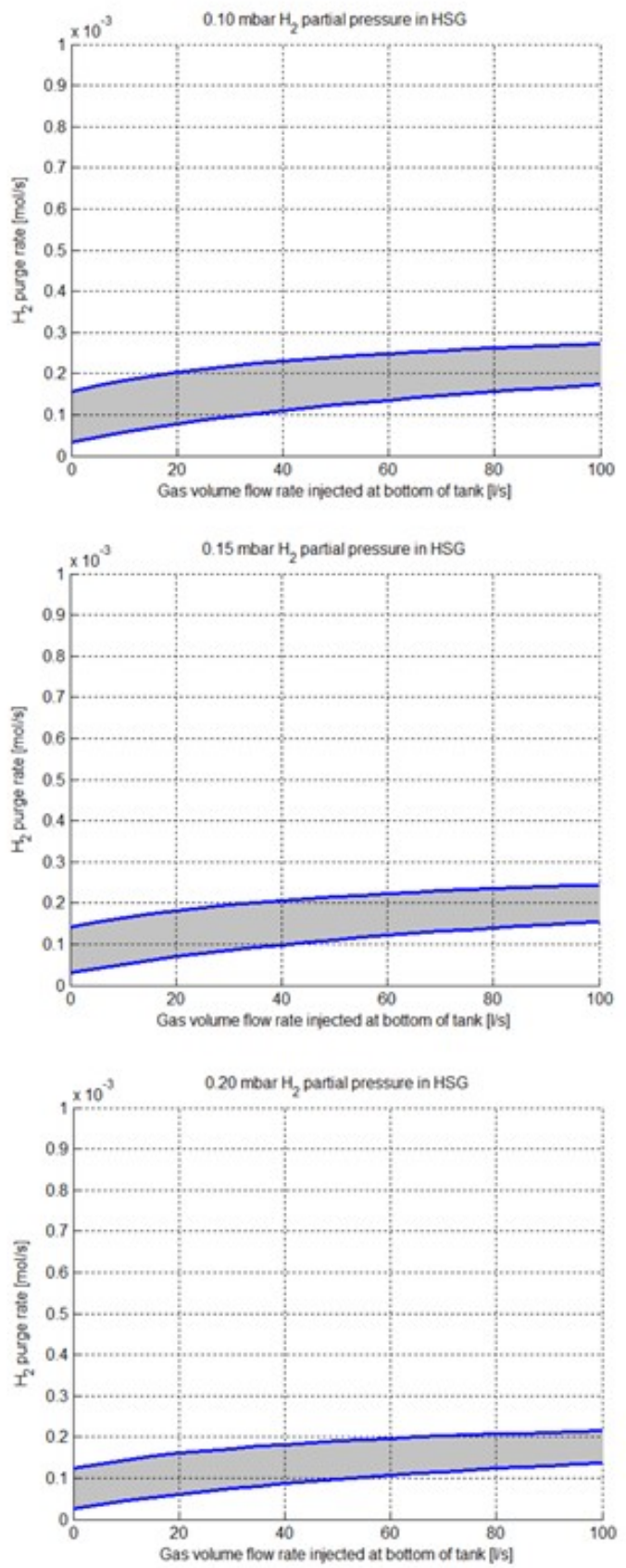

Figure 30. Simulation results for low purge rate conditions (left diagrams) and high purge rate conditions (right diagram) as a function of hydrogen partial pressure in HSG and gas volume rate injected at bottom of tank. 


\section{Expansion tank experimental work}

Our modeling of hydrogen transfer across the liquid/gas interface in the expansion tank showed that passive diffusion with no active mixing would likely generate an adequate hydrogen transfer rate from liquid to gas without deviating to far from equilibrium as determined by Henry's Law Constant. To be certain, we design and performed a set of experiments to measure the Henry's Law Constant and mass transfer coefficient for the hydrogen/HTF system. We used the power plant model to determine a sufficient value for the hydrogen molar transfer coefficient for the liquid/gas interface within the expansion tanks. Our model predicted that a hydrogen molar coefficient of $10^{-5}$ moles $/ \mathrm{s}-\mathrm{mbar}-\mathrm{m}^{2}$ would generated an adequate hydrogen transfer rate across the interface.

The experiment that we designed and developed is an adapted version of a steadystate experiment that derives Henry's Law Constant by measuring the head space gas composition after the liquid and gas phase are in equilibrium (Dewulf et al., 1995 [47]). This setup closely mimics the actual expansion tank conditions and after modifying the procedure, the experiment allows by measuring the pressure to derive in a single run the mass transfer coefficient from the transient behavior as well as the Henry's Law Constant from the equilibrium state. A schematic diagram and the actual layout are shown in Figures 31 and 32, respectively.

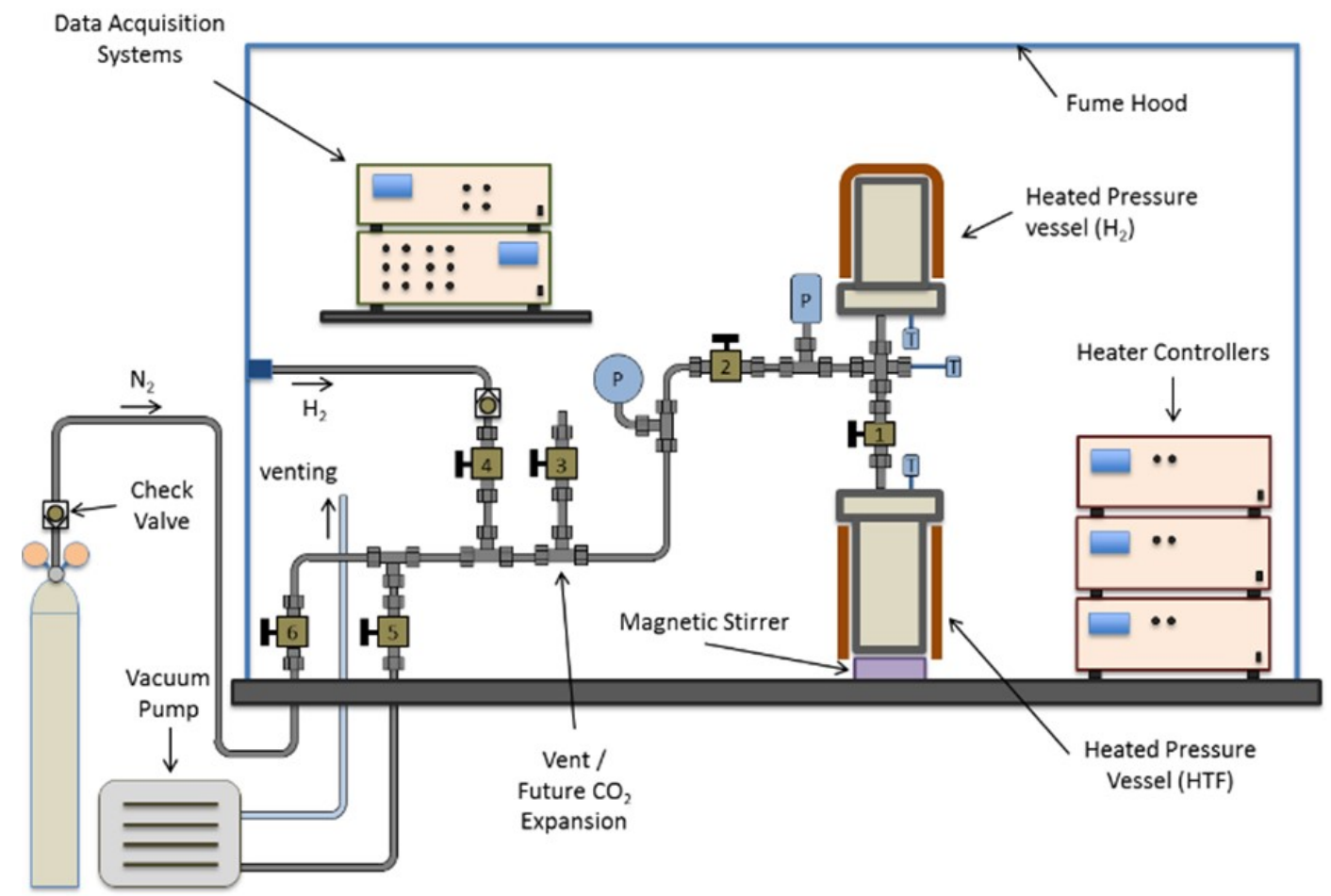

Figure. 31. Schematic diagram of Hydrogen/HTF interface properties experiment 


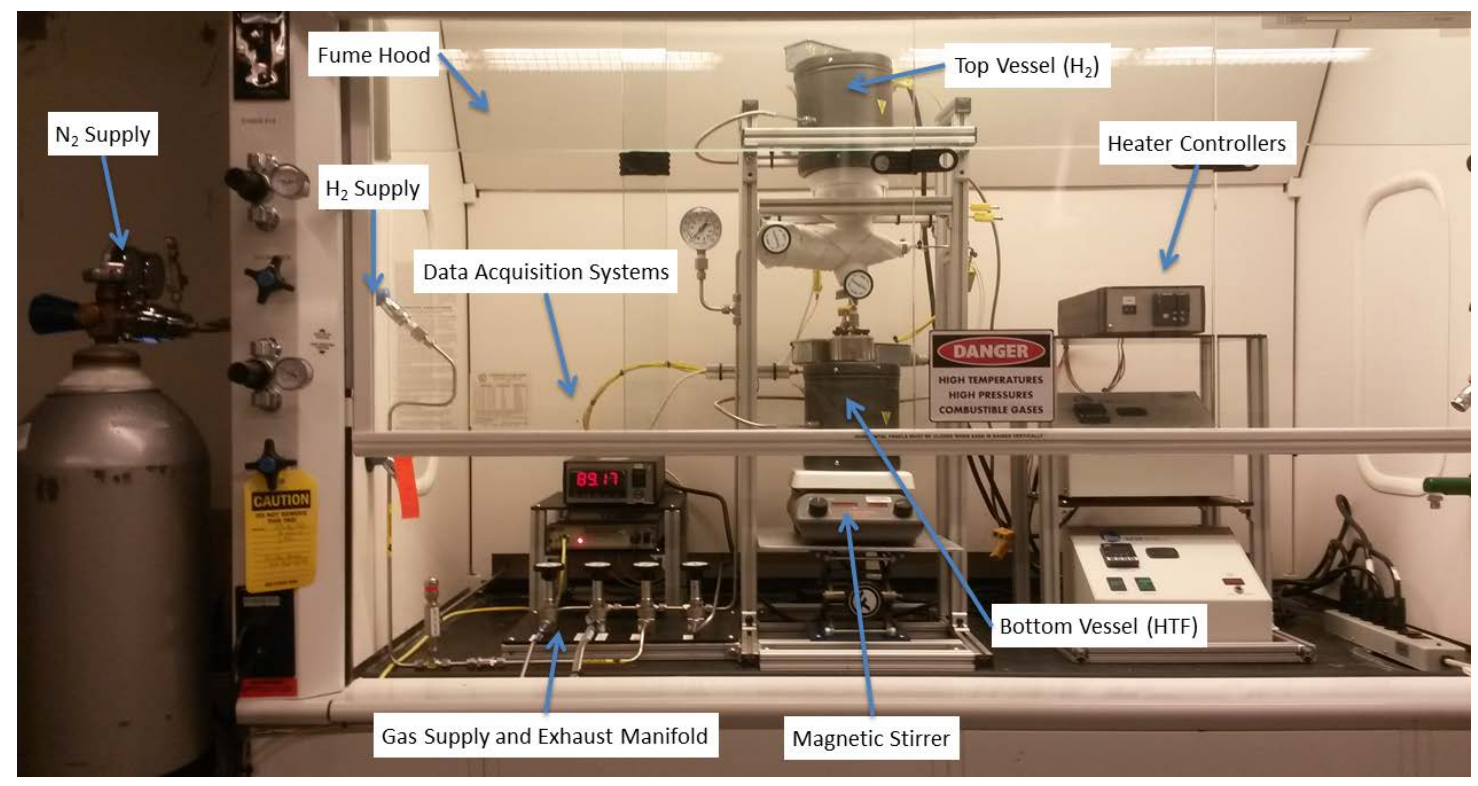

Figure 32. Actual layout of hydrogen/HTF interface properties experiment

Hydrogen/HTF interface properties measurements - experimental procedure

An experimental run consists of 5 steps - with the corresponding pressure profile shown in Figure 33:

1. At the beginning of the experiment, the central valve is closed and both vessels are isolated from each another. The top vessel is filled with pure hydrogen (or a hydrogen/nitrogen mixture) at high pressure (up to 10 bar), and the bottom vessel is filled with pure HTF. Both vessels are kept at elevated temperature (up to $300^{\circ} \mathrm{C}$ ).

2. The valve connecting both vessels is opened. The gas in the top vessel fills up Immediately the gas space above the HTF in the bottom vessel causing an instantaneous pressure drop and marking the start of the mass transfer.

3. For a period of $10 \mathrm{~min}$. (high temperatures) to over an hour (low temperatures), hydrogen absorbs into the HTF causing the pressure to decrease along an exponential decline curve. Measuring this transient decline allows to determine the mass transfer coefficient.

4. Eventually the hydrogen in the gas phase equilibrates with the hydrogen absorbed in the HTF and the mass transfer stops. The pressure remains constant from which the Henry's Law Constant can be calculated.

5. At the end of the experiment, the valve is closed, and the top vessel is vented. By reopening the valve, the mass transfer occurs in reverse and hydrogen gets removed from the HTF. This process is iterated a few times to completely remove all hydrogen from HTF and top vessel. The setup is now ready for the next test. 


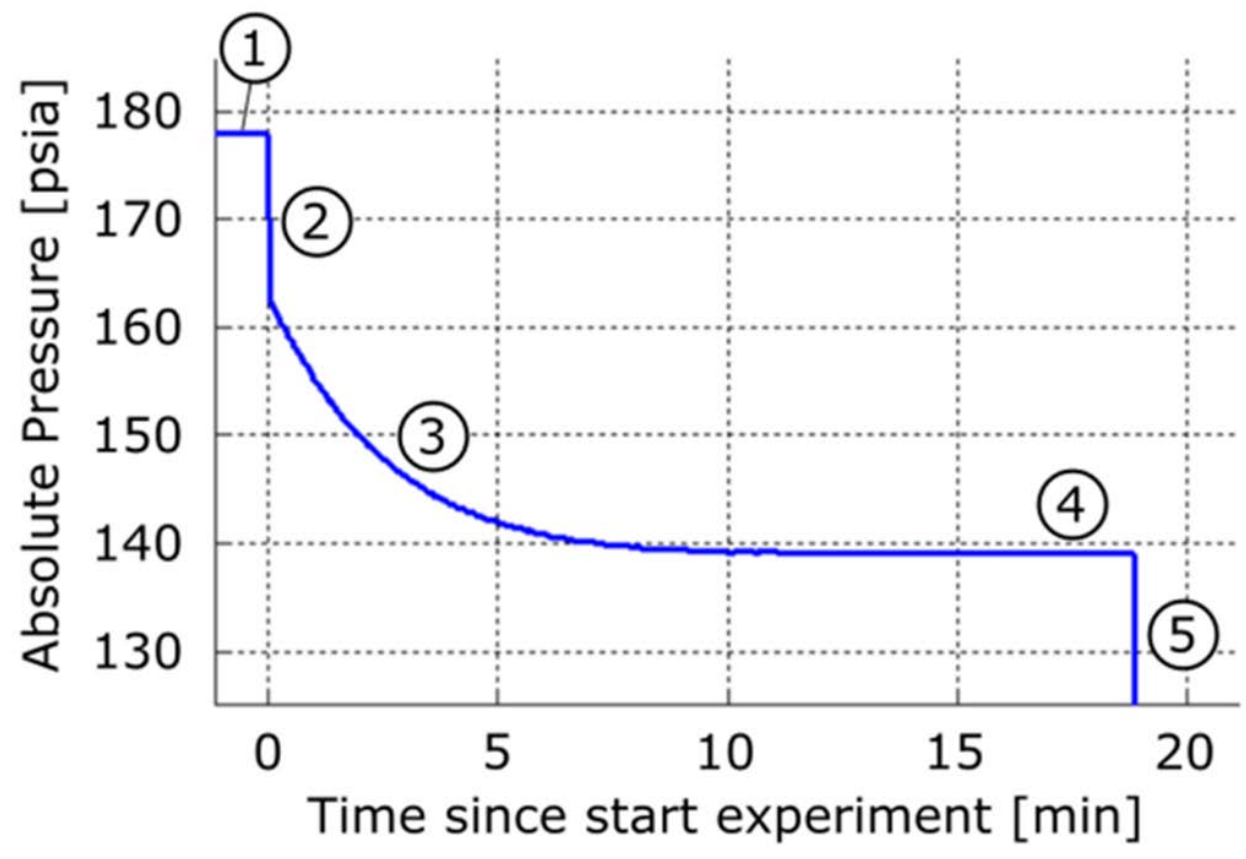

Figure 33. Transient pressure profile measured during successful experiment

At the end of an experiment when equilibrium is reached, the Henry's Law Constant $H$ [bar-L/mol] can be calculated from Henry's Law which provides the relation between the hydrogen partial pressure in the HSG, $p_{H_{2, e q}}[\mathrm{bar}]$, and the concentration of hydrogen absorbed in the HTF, $c_{H_{2, e q}}[\mathrm{~mol} / \mathrm{L}]$ :

$$
p_{H_{2, e q}}=H \cdot c_{H_{2, e q}}
$$

The hydrogen concentration in the HTF is not directly measured but calculated from the total pressure drop in combination with the ideal gas law. The system is closed (assuming no leaks) and therefore all moles of hydrogen leaving the top vessel (and causing the pressure to decline) end up absorbed in the HTF.

The mass transfer coefficient $K_{G}\left[\mathrm{~mol} /\left(\mathrm{s} \cdot \mathrm{mbar} \cdot \mathrm{m}^{2}\right)\right]$ is calculated using the standard mass transfer equation caused by a pressure differential as driving force [42]:

$$
N=K_{G} A\left(p_{H_{2}, H S G}-p_{H_{2}, H T F}\right)
$$

with $N$ the molar rate [mol/s], $A$ the area of the liquid-gas interface $\left[\mathrm{m}^{2}\right], p_{H_{2}, H S G}$ the partial pressure of hydrogen in the head space gas [mbar], and $p_{H_{2}, H T F}$ the hypothetical partial pressure of hydrogen that would be in equilibrium with the bulk liquid concentration [mbar] (using Henry's Law). The molar rate can be calculated from the slope of the pressure decline with time, in combination with the ideal gas law. 
The most commonly encountered problem when conducting an experiment were leaks. Figure 34 illustrates a failed experiment where pressure decreased before opening the valve and failed to reach steady-state during the experiment. Leaks were usually traced back to fittings becoming leaky after opening/closing them several times. Opening and closing the fittings were required because the bottom vessel regularly needed to be removed to re-measure the HTF mass and refill if necessary. Leaks were detected quickly by regularly conducting high-pressure leak tests, as shown in Figure 35. This test shows that without any leaks, the vessel and piping can hold hydrogen at constant pressure for at least 3 hours, much longer than the time constant of the mass transfer experiment (10 to 60 minutes depending on temperature).

Accurate calculation of the Henry's Law Constant and mass transfer coefficient requires accurate pressure measurement. An Omega digital pressure transducer measuring absolute pressure with uncertainty of 0.3 psi was selected. Several pressure tests were repeatedly conducted to ensure proper operation of the pressure transducer including measurement of vacuum, atmospheric pressure, and HTF vapor pressure (Figure 35).

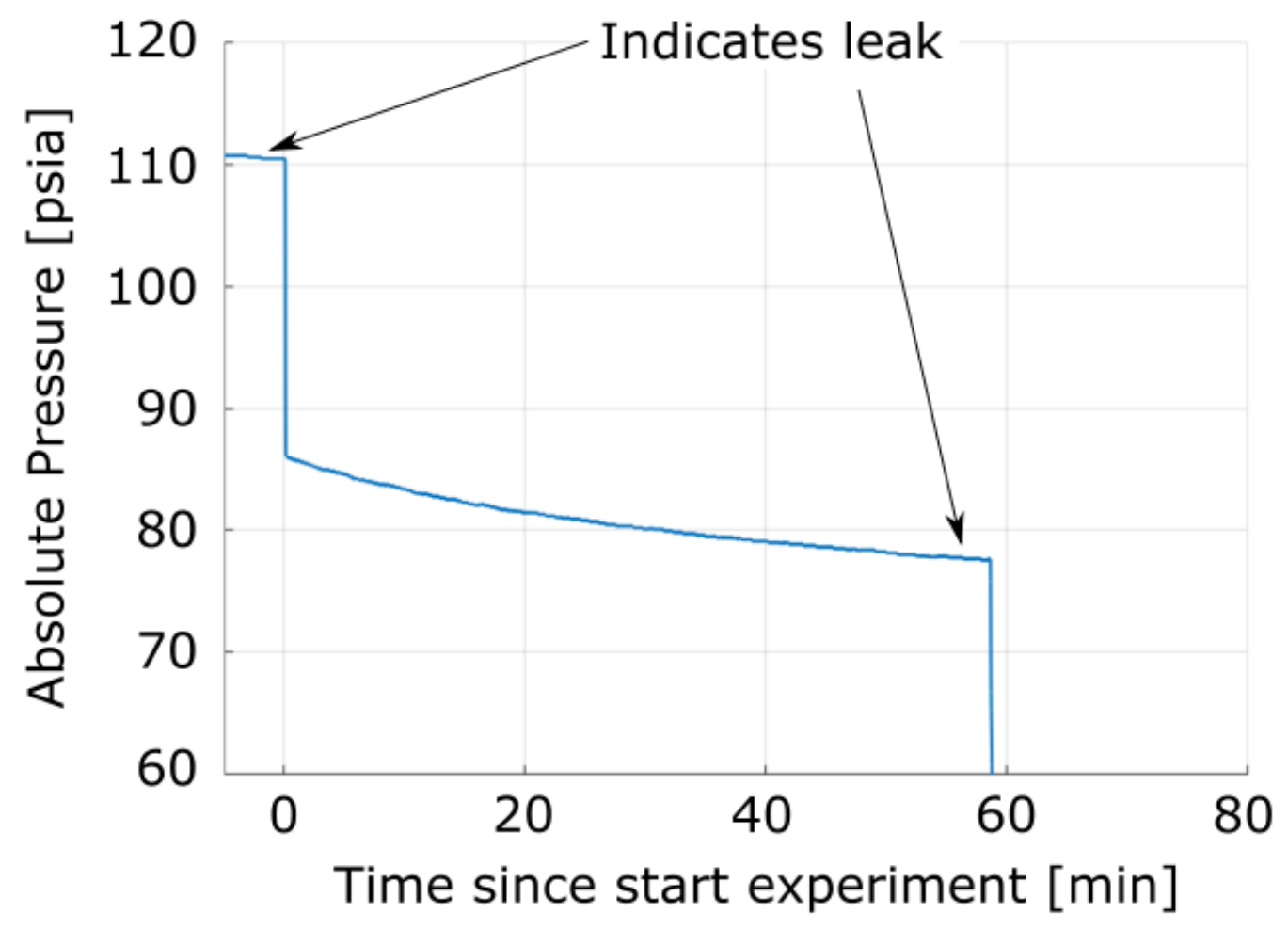

Figure 34. Transient pressure profile measured during unsuccessful experiment decreasing pressure indicates leaks. 


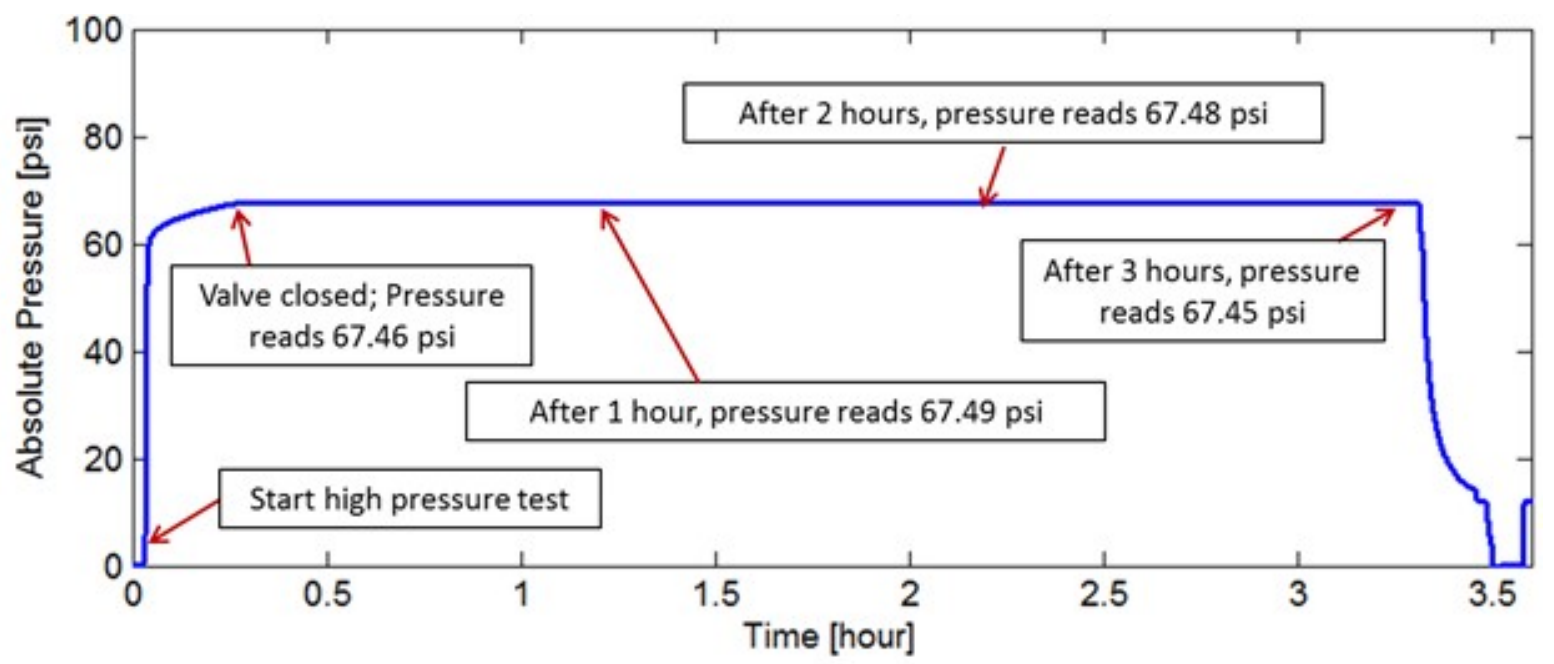

Figure 35. High-pressure hydrogen leak test shows no sign of leaks.

Hydrogen/HTF interface properties measurements - measurement results

Measurements for Henry's Law constant as a function of temperature are shown in Figure 36. Range and temperature dependency are comparable to correlations found in literature.

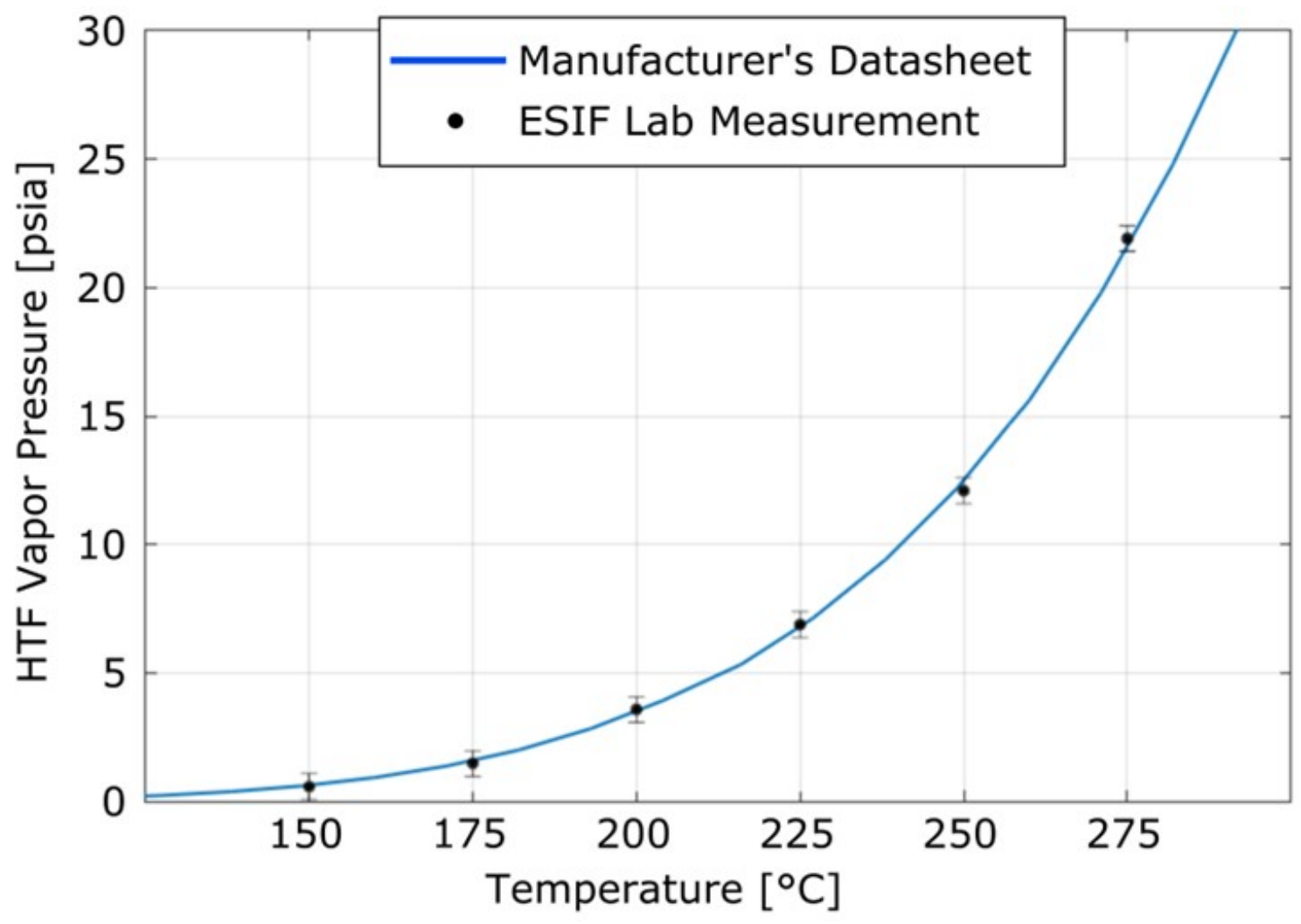

Figure 36. HTF vapor pressure as reported by manufacturer and measured with pressure transducer in lab. 
At higher temperatures, HTF vapor pressure significantly increases to the point where HTF vapor occupying the top vessel impacts the calculation at equilibrium for determining the amount of hydrogen absorbed in the HTF. No sensors are in place to measure independently HTF vapor and hydrogen pressure, only total pressure is measured. As a result, Henry's Law Constant cannot directly be measured, rather, it can be estimated for higher temperatures using an Arrhenius best fit equation (solid black line).

The mass transfer coefficient for pure hydrogen as a function of temperature is shown in Figure 37. Values obtained fall in the range predicted with the dual film layer theory model for an expected liquid film layer thickness between $0.001 \mathrm{~cm}$ and $0.01 \mathrm{~cm}$ (35). A higher hydrogen molar flux at higher temperatures may cause the mass transfer coefficient to slightly fall underneath a trend line extrapolated from values measured at lower temperatures. Additional experiments with low vs. high starting pressure for a set temperature confirmed that lower pressures (and corresponding lower fluxes) are associated with a slightly higher mass transfer coefficient (see Table 8).

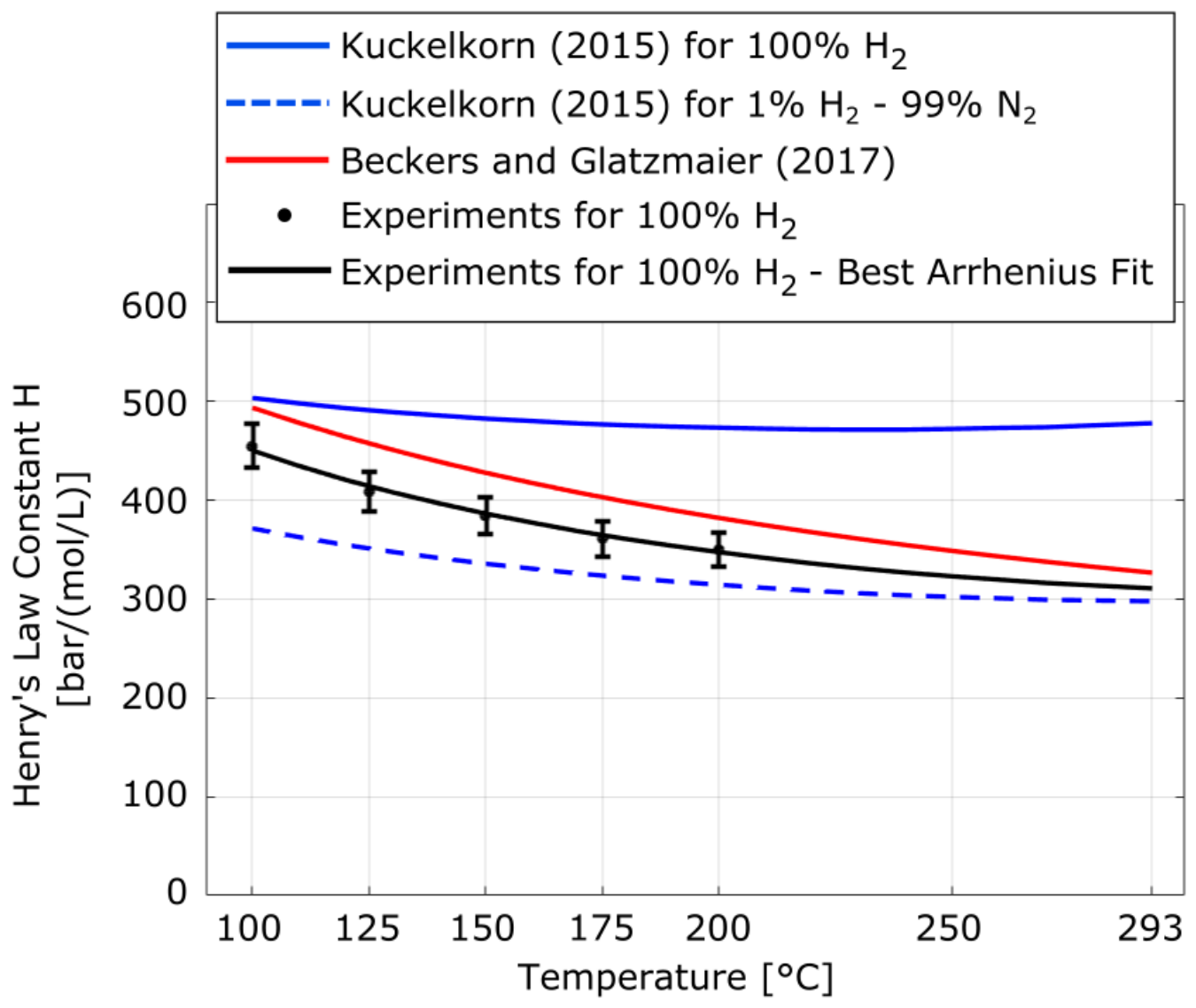

Figure 37. Measurements and literature correlations for Henry's Law Constant 
Table 3 lists all experiments conducted for calculating the hydrogen mass transfer coefficient as a function of temperature, mixing rate, HSG starting pressure and HSG compositions. The mass transfer coefficient $\left(K_{g}\right)$ as a function of temperature (experiments 1 through 7 ) was plotted in Figure 38. The results show the mixing rate (see experiments 5, 8 and 9) has negligible impact on the mass transfer coefficient. A lower starting HSG pressure (and corresponding lower molar flux) appears to slightly increase the mass transfer coefficient (see experiment 6 vs. 10, and 7 vs. 11).

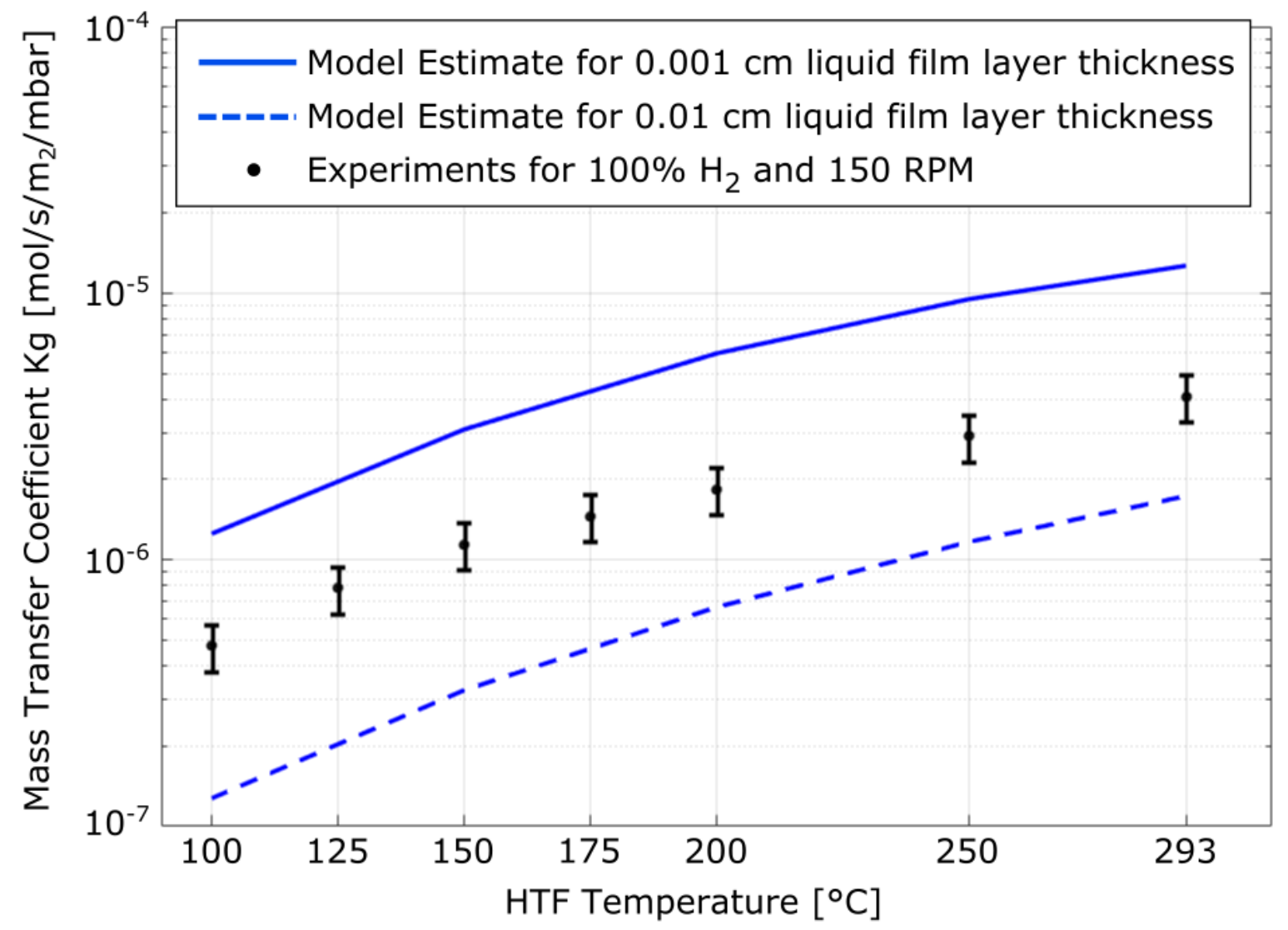

Figure 38. Measurements and theoretical model predictions for hydrogen mass transfer coefficient

The presence of nitrogen significantly increases the mass transfer coefficient (see experiments 12,13 and 14 vs. 7 , and 15 vs. 5). Lowering the hydrogen fraction increased the mass transfer coefficient up to $1 \times 10^{-5} \mathrm{~mol} /\left(\mathrm{s} \cdot \mathrm{mbar} \cdot \mathrm{m}^{2}\right)$ for $1 / 4$ hydrogen $3 / 4$ nitrogen as HSG (experiment 14). This value was our target the mass transfer coefficient. Considering that the mass transfer coefficient increases with increasing nitrogen/hydrogen molar ratio, the mass transfer coefficient within the expansion tanks where the nitrogen/hydrogen ration is greater than 0.99 - is likely much higher than this value. 
Table 3. List of experiments conducted for measuring hydrogen transfer coefficient $\left(K_{g}\right)$

\begin{tabular}{|c|c|c|c|c|c|c|}
\hline $\begin{array}{l}\text { Experiment } \\
\text { Number }\end{array}$ & $\begin{array}{c}\text { HTF Temperature } \\
{\left[{ }^{\circ} \mathrm{C}\right]}\end{array}$ & $\begin{array}{l}\text { HTF mass } \\
\text { [gram] }\end{array}$ & $\begin{array}{l}\text { HTF Stirring } \\
\text { (RPM) }\end{array}$ & $\begin{array}{c}\text { HSG } \\
\text { Composition }\end{array}$ & $\begin{array}{c}\text { HSG Starting } \\
\text { pressure [psi] }\end{array}$ & $\begin{array}{c}K_{g} \\
{\left[\mathrm{~mol} / \mathrm{s} / \mathrm{mbar} / \mathrm{m}^{2}\right]}\end{array}$ \\
\hline \multicolumn{7}{|c|}{ Effect of Temperature } \\
\hline 1 & 100.4 & 154.0 & 150 & $100 \% \mathrm{H}_{2}$ & 79.1 & $4.75 \times 10^{-7}$ \\
\hline 2 & 125.1 & 154.0 & 150 & $100 \% \mathrm{H}_{2}$ & 80.2 & $7.82 \times 10^{-7}$ \\
\hline 3 & 151.2 & 154.0 & 150 & $100 \% \mathrm{H}_{2}$ & 83.3 & $1.14 \times 10^{-6}$ \\
\hline 4 & 176.8 & 154.2 & 150 & $100 \% \mathrm{H}_{2}$ & 86.1 & $1.46 \times 10^{-6}$ \\
\hline 5 & 200.5 & 154.1 & 150 & $100 \% \mathrm{H}_{2}$ & 88.0 & $1.82 \times 10^{-6}$ \\
\hline 6 & 250.1 & 154.2 & 150 & $100 \% \mathrm{H}_{2}$ & 90.5 & $2.89 \times 10^{-6}$ \\
\hline 7 & 293.0 & 154.2 & 150 & $100 \% \mathrm{H}_{2}$ & 97.1 & $4.10 \times 10^{-6}$ \\
\hline \multicolumn{7}{|c|}{ Effect of Stirring } \\
\hline 8 & 200.2 & 154.1 & $\mathbf{0}$ & $100 \% \mathrm{H}_{2}$ & 78.4 & $1.98 \times 10^{-6}$ \\
\hline 5 & 200.5 & 154.1 & 150 & $100 \% \mathrm{H}_{2}$ & 88.0 & $1.82 \times 10^{-6}$ \\
\hline 9 & 201.9 & 154.1 & 600 & $100 \% \mathrm{H}_{2}$ & 78.5 & $1.84 \times 10^{-6}$ \\
\hline \multicolumn{7}{|c|}{ Effect of HSG Starting Pressure } \\
\hline 6 & 250.1 & 154.2 & 150 & $100 \% \mathrm{H}_{2}$ & 90.5 & $2.89 \times 10^{-6}$ \\
\hline 10 & 250.6 & 154.1 & 150 & $100 \% \mathrm{H}_{2}$ & 138.5 & $2.64 \times 10^{-6}$ \\
\hline 7 & 293.0 & 154.2 & 150 & $100 \% \mathrm{H}_{2}$ & 97.1 & $4.10 \times 10^{-6}$ \\
\hline 11 & 293.7 & 154.1 & 150 & $100 \% \mathrm{H}_{2}$ & 163 & $3.43 \times 10^{-6}$ \\
\hline \multicolumn{7}{|c|}{ Effect of Nitrogen } \\
\hline 7 & 293.0 & 154.2 & 150 & $100 \% \mathrm{H}_{2}$ & $\begin{array}{c}97.1 \\
\left(97.1 \mathrm{psi} \mathrm{H}_{2}\right) \\
\end{array}$ & $4.10 \times 10^{-6}$ \\
\hline 12 & 292.8 & 153.9 & 150 & $\begin{array}{c}49 \% \mathrm{H}_{2}- \\
51 \% \mathrm{~N}_{2}\end{array}$ & $\begin{array}{c}89.8 \\
\left(44.3 \mathrm{psi} \mathrm{H}_{2}\right) \\
\end{array}$ & $5.6 \times 10^{-6}$ \\
\hline 13 & 293.1 & 154.2 & 150 & $\begin{array}{c}33 \% \mathrm{H}_{2}- \\
67 \% \mathrm{~N}_{2}\end{array}$ & $\begin{array}{c}66.0 \\
(22.1 \mathrm{psi} \mathrm{H})\end{array}$ & $9.0 \times 10^{-6}$ \\
\hline 14 & 292.6 & 154.2 & 150 & $\begin{array}{c}26 \% \mathrm{H}_{2}- \\
74 \% \mathrm{~N}_{2} \\
\end{array}$ & $\begin{array}{c}67.8 \\
\left(17.4 \mathrm{psi} \mathrm{H}_{2}\right) \\
\end{array}$ & $1.0 \times 10^{-5}$ \\
\hline 5 & 200.5 & 154.1 & 150 & $100 \% \mathrm{H}_{2}$ & $\begin{array}{c}88.0 \\
\left(88.0 \mathrm{psi} \mathrm{H}_{2}\right) \\
\end{array}$ & $1.82 \times 10^{-6}$ \\
\hline 15 & 199.8 & 154.2 & 150 & $\begin{array}{c}54 \% \mathrm{H}_{2}- \\
46 \% \mathrm{~N}_{2}\end{array}$ & $\begin{array}{c}80.3 \\
(43.6 \mathrm{psi} \mathrm{H}) \\
\end{array}$ & $2.6 \times 10^{-6}$ \\
\hline
\end{tabular}

Mitigation process - development of the integrated module

The core effort of this project with respect to hydrogen mitigation was designing a process that would separate hydrogen from the headspace gas a rate that the power plant model predicted would be sufficient to reduce and maintain dissolved hydrogen concentration in the HTF at an acceptable level. Maintaining this level extends the time that the collector field receivers perform at their original performance.

One of the issues relating to the design of the hydrogen separation process was how to incorporate and use the sensor to measure hydrogen partial pressure in the headspace gas that is being treated by the separation module. After considering several configurations for the separator and sensor as separate modules, we conceived the integrated design in which the sensor and separator are combined into the single module that is shown in Figure 39. The module has two operating modes - separator and sensor. The separator mode uses the $\mathrm{Pd} / \mathrm{Ag}$ membrane to separate hydrogen from the (headspace) gas mixture. Figure 39 shows a cylindrical configuration for the 
integrated module. Major components are the membrane, headspace gas volume, and permeate volume. As with the sensor, the membrane is permeable exclusively to hydrogen, and forms a boundary between the flowing headspace gas mixture and permeate volumes.

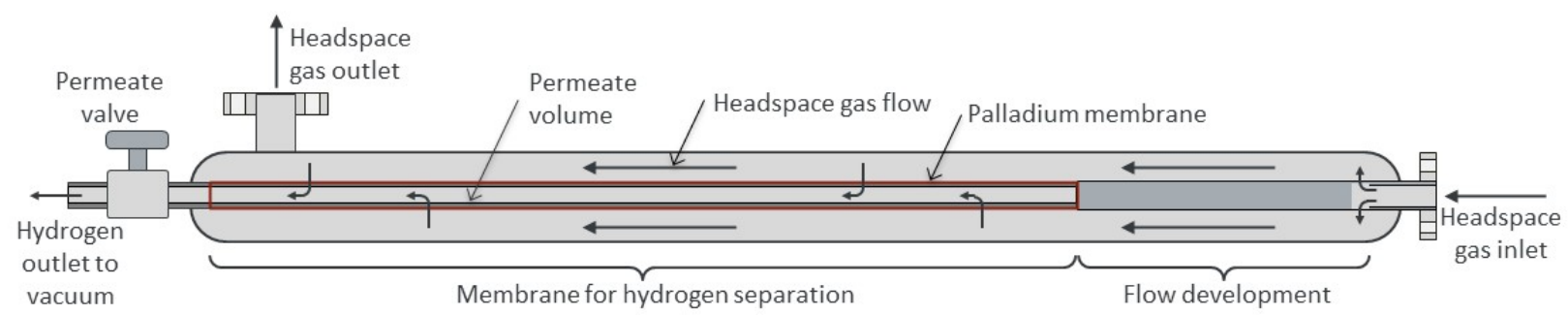

Figure 39. Integrated hydrogen sensor and separation module.

A vacuum pump connects to the permeate outlet, removes hydrogen from the permeate volume, and maintains hydrogen at low pressure in the permeate volume when the module is operating as a separator. A valve and pressure gage are located on the permeate outlet. The valve is closed and isolates the permeate volume from the vacuum pump when the module is operating as a sensor. The pressure gage measures permeate pressure when the module is operating as a sensor or separator. The boundary between the headspace gas and permeate volumes must seal absolutely so the only transfer of gas between the two volumes is hydrogen via membrane permeation. The membrane has a structural support on its low-pressure side that is gas permeable but provides support to the membrane, so it can withstand the pressure difference across the membrane during operation.

The module shown in Figure 39 operates as a separator and sensor. When operating as a separator, the permeate valve is open and the vacuum pump draws on the permeate volume. The headspace gas containing hydrogen flows through the annulus and hydrogen permeates from the headspace gas across the membrane and into the permeate volume. Hydrogen that enters the permeate volume is quickly removed via the vacuum pump, and is treated by thermal or catalytic oxidation.

When operating as a sensor, the permeate valve is closed, allowing hydrogen to accumulate in the permeate volume until its pressure equals the partial pressure of hydrogen in the gas mixture volume. Permeate pressure is measured with the pressure gage at the outlet of the permeate volume. The sensor function of the module is the same as that of the sensor that was developed initially in the project.

Additionally, the sensor measures the steady-state hydrogen transfer rate across the membrane when the module operates as a separator. This measurement is obtained from the permeate pressure versus time response shown in Figure 40. 


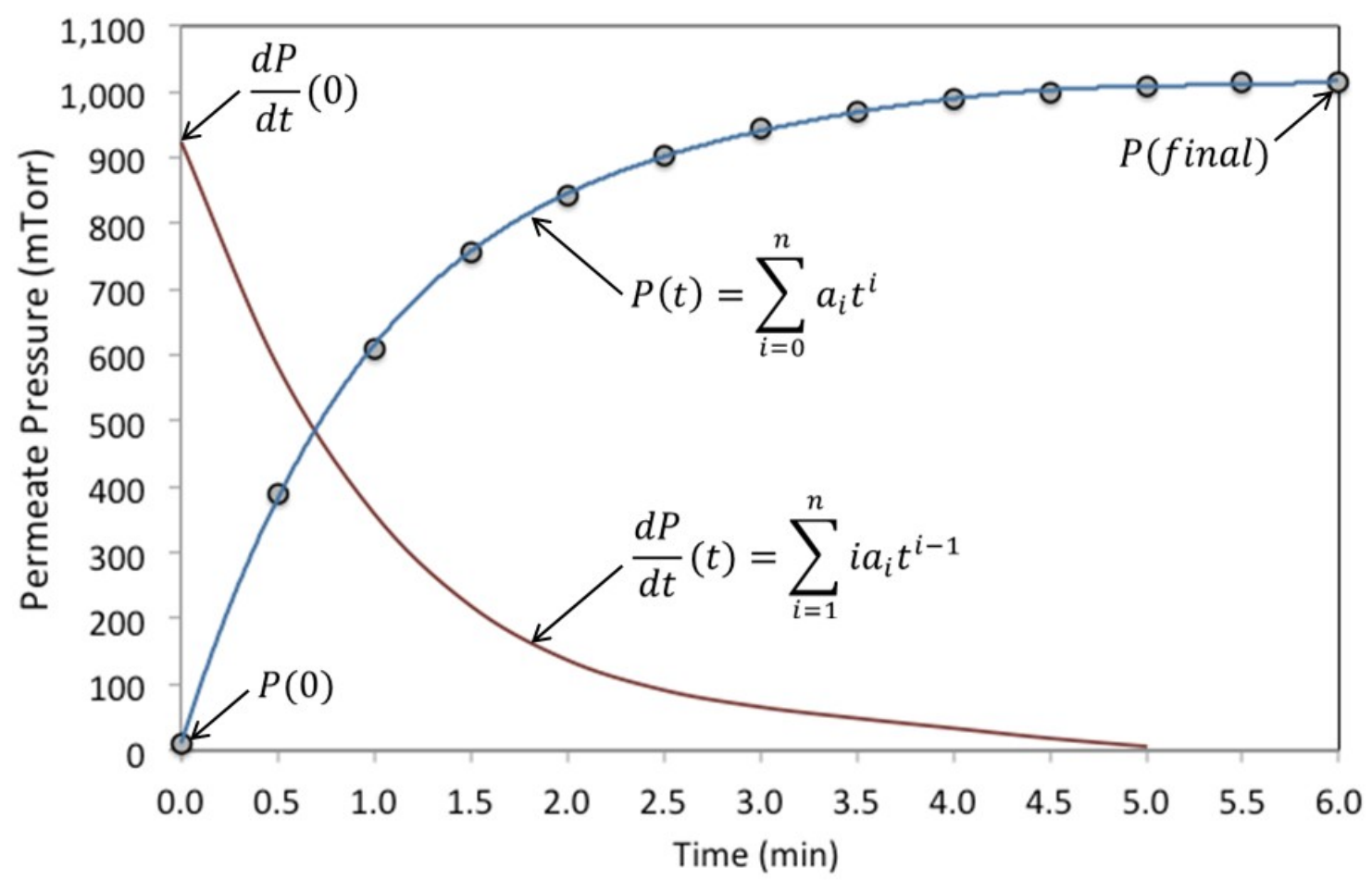

Figure 40. Permeate pressure response when valve is closed at $\boldsymbol{t}=\boldsymbol{0}$.

To obtain the molar transfer rate, the pressure response is fit to an $\mathrm{n}^{\text {th }}$ order polynomial:

$$
P(t)=\sum_{i=0}^{n} a_{i} t^{i}
$$

Taking the time derivative of the pressure response gives:

$$
\frac{d P}{d t}(t)=\sum_{i=1}^{n} i a_{i} t^{i-1}
$$

The value of the derivative at $t=0$ gives the initial change in permeate pressure, $d P / d t(0)$, when the permeate outlet valve is first closed. The hydrogen molar transfer rate into the permeate volume at $t=0$ relates to the change in permeate pressure at by:

$$
\frac{d n}{d t}(0)=\frac{V_{p}}{R T_{p}} \frac{d P}{d t}(0)
$$

$V_{p}$ is permeate volume, $T_{p}$ is permeate gas absolute temperature, and $R$ is the gas constant. Because the permeate pressure at $t=0, P(0)$, equals the steady state permeate pressure when the module is operating in separator mode, the hydrogen 
molar transfer rate at $t=0$ equals the steady-state hydrogen molar transfer rate into the permeate volume. Integrating the sensor with the separator simplifies the module design and allows the sensor to measure both the headspace gas hydrogen partial pressure and the hydrogen transfer rate across the membrane when the module is operating in separator mode.

The first measurement is needed to ensure that the separator module is reducing the hydrogen partial pressure in the headspace gas to the target level. The second measurement is needed to ensure that the hydrogen removal rate from the expansion tank agrees with the modeled rate that reduces hydrogen in the collector field to acceptable levels. NREL submitted a US patent application for this invention in 2017 [7].

\section{Mitigation process - integrated module model development}

Figure 41 shows details of the integrated module section (along its centerline) that were used to develop the mass transfer models for the module. The inner permeate volume and the annular gas mixture volume are separated by the membrane, which is $127 \mu \mathrm{m}$ thick. The laminar diffusion layer surrounds the membrane adjacent to its outside surface, and has an estimated thickness of $25 \mu \mathrm{m}-100 \mu \mathrm{m}$. $P_{\text {gas }}, P_{\text {mem }}$, and $P_{\text {perm }}$ are the hydrogen partial pressures in the turbulent gas mixture flow, at the outside membrane surface, and in the permeate volume.

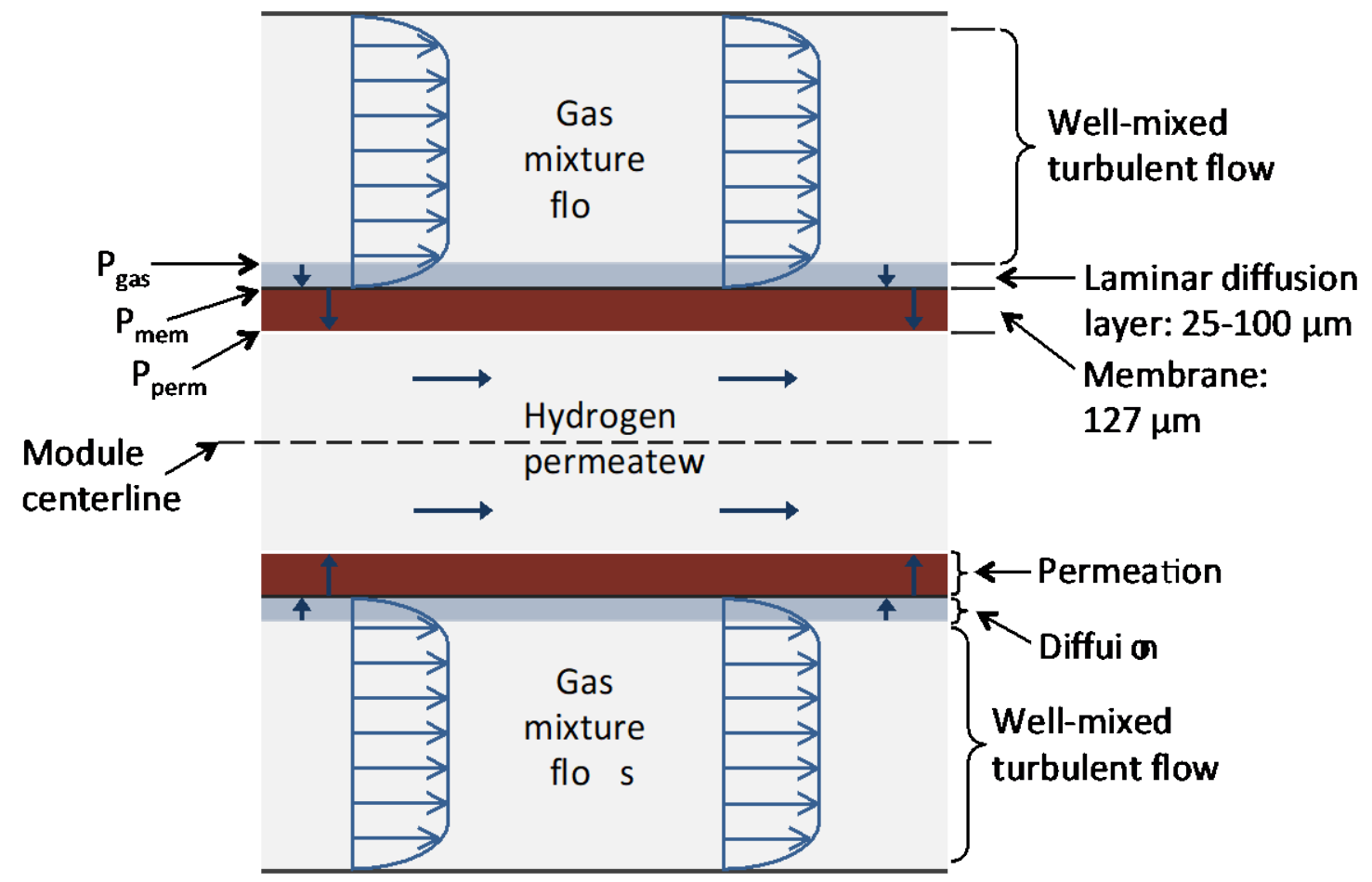

Figure 41. Integrated module detailed cross section. 
We modeled hydrogen transport in the integrated module under two operating conditions. We developed a steady-state model that predicts hydrogen transfer when the module is operating in separation mode, and a dynamic model that predicts hydrogen transfer when the module is operating in sensor mode.

Mitigation process - steady-state model

When in separation (steady state) mode, the vacuum pump removes hydrogen from the permeate volume so $P_{\text {perm }}=0$, but $P_{\text {gas }}$ and $P_{\text {mem }}$ vary with membrane axial position, $L$. Hydrogen transfer due to permeation causes the gas mixture partial pressure, $P_{\text {gas }}$, to decrease as the gas flows along the length of the membrane. We modeled $P_{\text {gas }}$ and $P_{m e m}$ by defining hydrogen flux through the diffusion boundary layer as:

$$
J=\frac{D_{f}}{R T_{g a s} \delta_{B L}}\left(P_{g a s}-P_{m e m}\right)
$$

Here $D_{f}$ is the hydrogen diffusion coefficient, $R$ is the gas constant, $T_{\text {gas }}$ is the gas mixture absolute temperature, and $\delta_{B L}$ is the boundary layer thickness. $J$ is a function of membrane axial position, $L$. Because $P_{\text {perm }}=0$ in separation mode, we defined hydrogen permeation flux as:

$$
J=\frac{\phi_{\text {mem }}}{\delta_{\text {mem }}} \sqrt{P_{\text {mem }}}
$$

where $\phi_{m e m}$ and $\delta_{m e m}$ are the membrane permeation coefficient and thickness. The decrease in gas mixture hydrogen pressure, $P_{\text {gas }}$, as the gas flows along the length of the membrane is given by:

$$
\frac{d P_{\text {gas }}}{d L}=-J \frac{R T_{\text {gas }} P e r_{m e m}}{v_{\text {gas }}}
$$

where $\mathrm{Per}_{\mathrm{mem}}$ is the membrane perimeter, $v_{\text {gas }}$ is the gas mixture volumetric flow rate, and $d L$ is the axial length increment along membrane. Finally, the rate of hydrogen transfer across the total membrane of length, $L_{m}$ is:

$$
r_{\text {mem }}=\operatorname{Per}_{\text {mem }} \int_{0}^{L_{m}} J d L
$$

These equations were solved numerically to determine the steady-state gas mixture hydrogen pressure, $P_{\text {gas }}$, hydrogen pressure at the membrane surface, $P_{m e m}$, as functions of axial position, and the total rate of hydrogen transfer, $r_{\text {mem }}$. 
We solved the set of equations for the steady-state model numerically to predict hydrogen partial pressure profiles and removal rates for a laboratory-scale module. All module characteristics, fluid properties, and flow properties were known or could be specified except the boundary layer thickness, $\delta_{B L}$. Incropera et al (2011) [48] defined the boundary layer thickness for internal turbulent flow as:

$$
\delta_{B L}=\frac{25 \mu_{\text {gas }}}{\rho_{\text {gas }} r_{B L M} v_{M}}
$$

where $\mu_{\text {gas }}$ and $\rho_{\text {gas }}$ are the gas viscosity and density, $v_{M}$ is the mean gas velocity, and $r_{B L M}$ is:

$$
r_{B L M}=\frac{v_{B L}}{v_{M}}
$$

Here $v_{B L}$ is the gas velocity at the outer edge of the boundary layer. This ratio is not known exactly but is approximately: $r_{B L M}=0.5-0.8$. The goal of our experiments is to determine the value of $r_{B L M}$ for our laboratory-scale module, and use these results to design the full-scale module for NSO. For our current modeling, we chose a value of 0.5 for $r_{B L M}$. We modeled the laboratory-scale module with dimensions listed in Table 4 . We solved the steady-state model for two cases defined by gas flow rate: $0.75 \mathrm{~L} / \mathrm{s}$ and1.5 L/s. Key results for the two flow rates are listed in Table 2.

Table 4: Laboratory-scale integrated module dimensions.

\begin{tabular}{|c|c|c|c|c|}
\hline Membrane Dia. & Membrane Length & Membrane Thickness & Annulus Gap & Outer Diameter \\
\hline 0.5 in $(1.27 \mathrm{~cm})$ & 8 in $(20.3 \mathrm{~cm})$ & 0.005 in $(127 \mu \mathrm{m})$ & 0.2 in $(0.508 \mathrm{~cm})$ & 0.9 in $(2.286 \mathrm{~cm})$ \\
\hline
\end{tabular}

Table 5 shows that the lower flow rate generates a lower Reynolds number and thicker boundary layer as expected, and higher hydrogen removal percentage due to the longer gas residence time in the module. The removal rate is lower due to the thicker boundary layer and the lower average hydrogen partial pressure along the membrane.

Table 5. Modeled gas mixture flow and hydrogen removal rate for laboratory testing.

\begin{tabular}{|c|c|c|c|c|c|}
\hline Test No. & Gas Flow & Reynolds No. & Boundary Layer & $\mathrm{H}_{2}$ Removed & $\mathrm{H}_{2}$ Rate \\
\hline 1 & $0.75 \mathrm{~L} / \mathrm{s}$ & 5,527 & 0.0036 in $(91 \mu \mathrm{m})$ & $82 \%$ & $1.94(\mu \mathrm{mole} / \mathrm{s})$ \\
\hline 2 & $1.5 \mathrm{~L} / \mathrm{s}$ & 11,054 & 0.0018 in $(46 \mu \mathrm{m})$ & $64 \%$ & $3.00(\mu \mathrm{mole} / \mathrm{s})$ \\
\hline
\end{tabular}

Figures $42 \mathrm{~A}, 42 \mathrm{~B}$ show the partial pressure profile for hydrogen along the membrane length. The height of the two profiles show the pressure drops needed for diffusion and permeation. The higher flow velocity and thinner boundary layer in 42B allow the diffusion pressure drop to be less than that in 42A. In both cases, the driving 
forces for diffusion and permeation are about the same, which says we are in the correct flow regime.
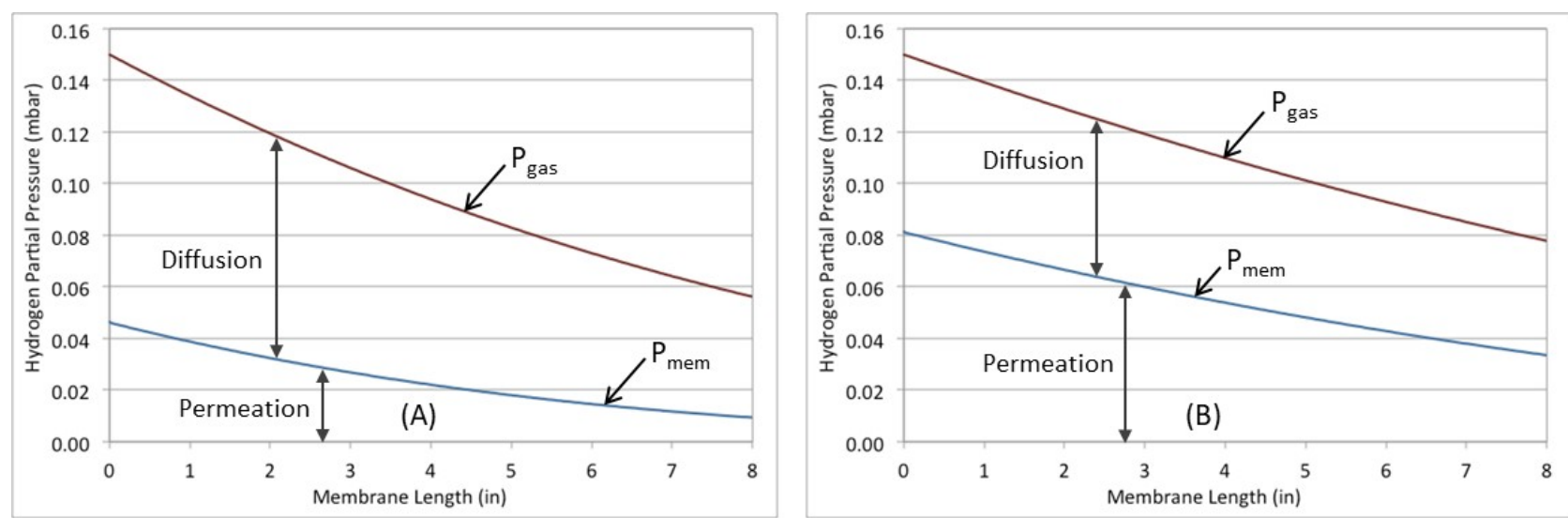

Figure 42. Modeled gas mixture and membrane outside wall hydrogen partial pressures versus axial position along membrane. (A): Gas flow = $0.75 \mathrm{~L} / \mathrm{s}$; (B): Gas flow = $1.5 \mathrm{~L} / \mathrm{s}$.

Mitigation process - dynamic model

When the module is operating in sensor mode, the valve that isolates the permeate volume from the vacuum pump is closed and the permeate pressure, $P_{\text {perm }}$, increases with time as shown in Figure 2 . We modeled the dynamic response by solving a set of equations to determine the gas mixture hydrogen pressure, $P_{\text {gas }}$, versus membrane position, $L$, for each time step as the permeate volume fills with hydrogen. For the dynamic model, hydrogen permeation flux is now:

$$
J=\frac{\phi_{\text {mem }}}{\delta_{\text {mem }}}\left(\sqrt{P_{\text {mem }}}-\sqrt{P_{\text {perm }}}\right)
$$

where $P_{\text {perm }} \neq 0$, (except for $t=0$ ) due to the permeate volume filling with hydrogen. All the other steady-state equations still account for boundary layer diffusion, the change in hydrogen gas mixture pressure with axial length, and the rate of hydrogen transfer for the total membrane area. For the dynamic model, these equations were solved together to generate a solution for each time step. For the first time step, $P_{\text {perm }}=$ 0 . For each subsequent time step, the increase in $P_{\text {perm }}$ was calculated from the rate of hydrogen transfer into the permeate volume during the previous time step:

$$
d P_{\text {perm }}=\frac{R T_{\text {perm }}}{V_{\text {perm }}} r_{\text {mem }} d t
$$

where $d t$ is the length of the time step. 
Mitigation process - dynamic model results

Figures 43A, 43B show the results for the module operating in sensor mode with a gas mixture flow rate of $1.5 \mathrm{~L} / \mathrm{s}$. Both graphs show responses after the valve is closed at $t=0 \mathrm{~s}$. Figure $9 \mathrm{~A}$ shows the gas mixture hydrogen pressure versus membrane length for $t$ $=0,2,4,6$, and 10 seconds. The pressure at the start of the membrane (inlet) is always 0.15 mbar. At $t=0 \mathrm{~s}$, the partial pressure profile versus membrane length is the same as the steady-state profile shown for $P_{\text {gas }}$ in Figure 42B. When the valve is closed, the gas mixture profiles increase with time and reach the inlet pressure $(0.15 \mathrm{mbar})$ at 10 seconds. Figure 43B shows the corresponding permeate pressure response with time. The permeate pressure also reaches the inlet pressure at 10 seconds.
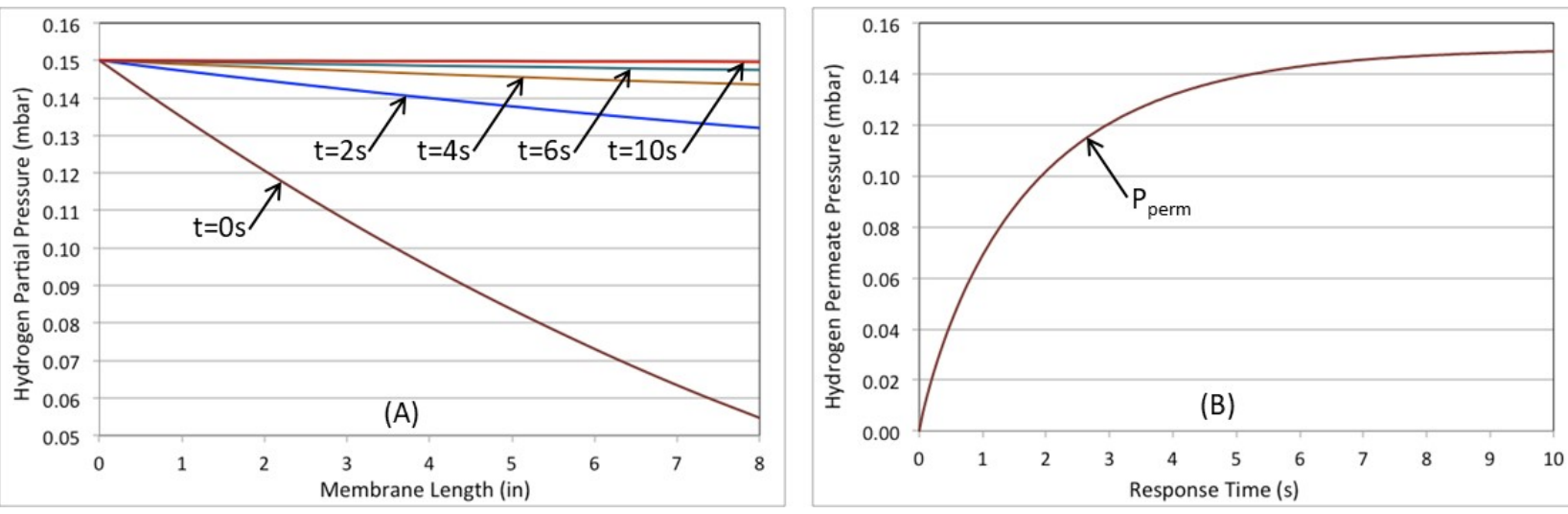

Figure 43. Modeled dynamic responses for hydrogen pressures when valve is closed. (A): Gas mixture hydrogen partial pressure versus membrane length at $t=0,2,4,6,10$ seconds; (B): Permeate volume pressure response versus time after valve is closed.

Mitigation process - laboratory testing

During Quarter 3 we completed fabrication of the integrated module, the membrane insert, and the complete system layout. Figure 44 shows a schematic of the system hardware including temperature and pressure sensors, and controls. Temperature controllers for the three gas mixture preheaters and for the heat tapes at the module inlet and outlet were tuned and tested with nitrogen gas flow through module. The cooling coil and fan were tested at test flow rates to ensure that the gas flow cooled to ambient temperature before passing through the volumetric gas flowmeter. The cooling coil and fan were able to maintain the exist gas at $22^{\circ} \mathrm{C}$ when the flow rate was $10 \mathrm{CFM}$ through the flowmeter.

Figure 45 shows the laboratory system layout. The center table holds the three preheaters inside the enclosure, the sensor/separation module in the tube furnace, and the heat rejection coil and fan. The stand to the left of the center table holds the tube furnace controller and data acquisition logger. The scroll and turbo pumps sit on the 
base of the stand. The desk to the right has the laptop computer that records temperature and pressure data that are acquired by the data logger. Compressed gas cylinders that contain test gas mixtures are mounted to the wall behind the test system.

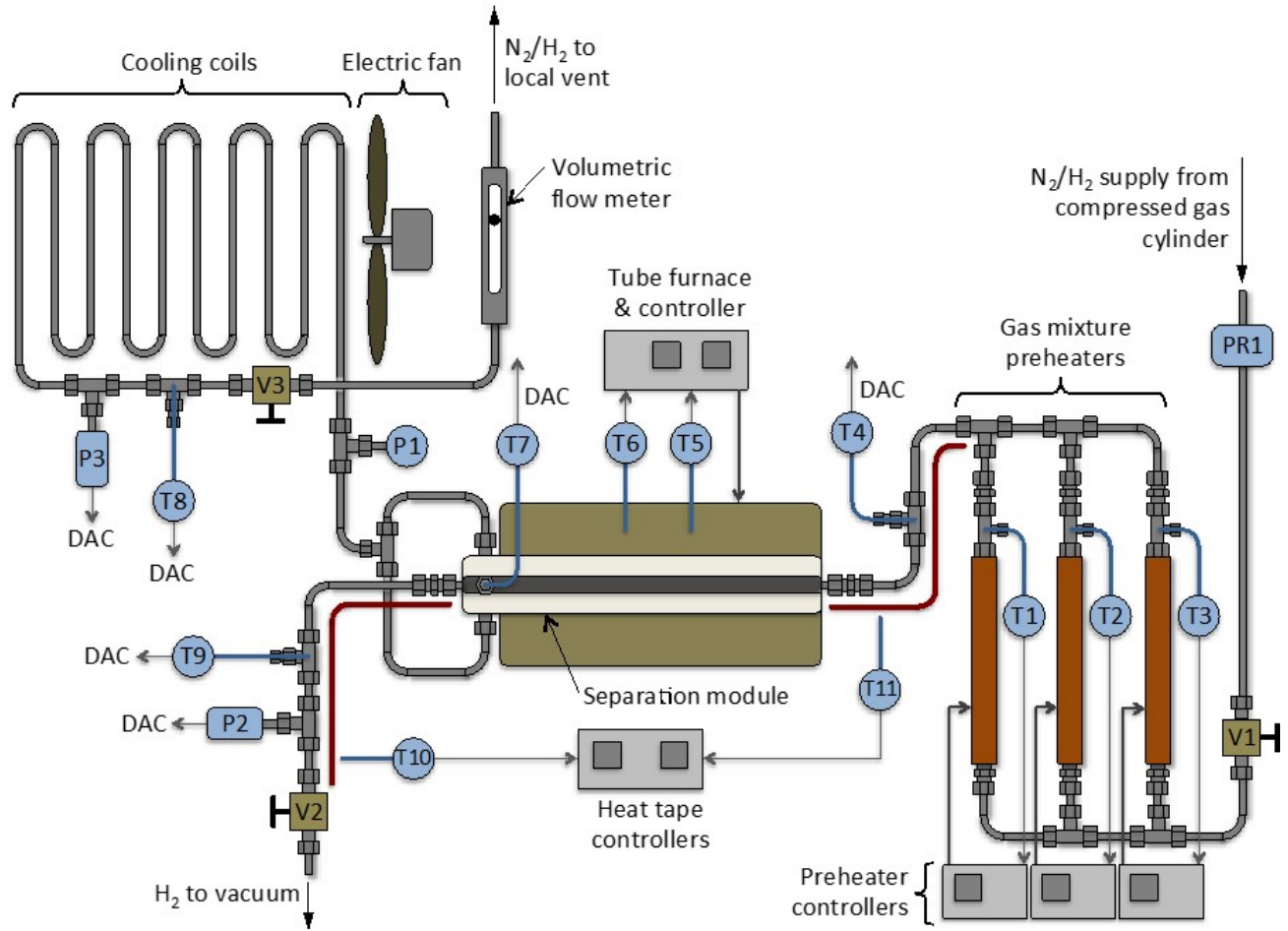

Figure 44. Schematic of laboratory test layout for testing the integrated hydrogen sensor and separation module.

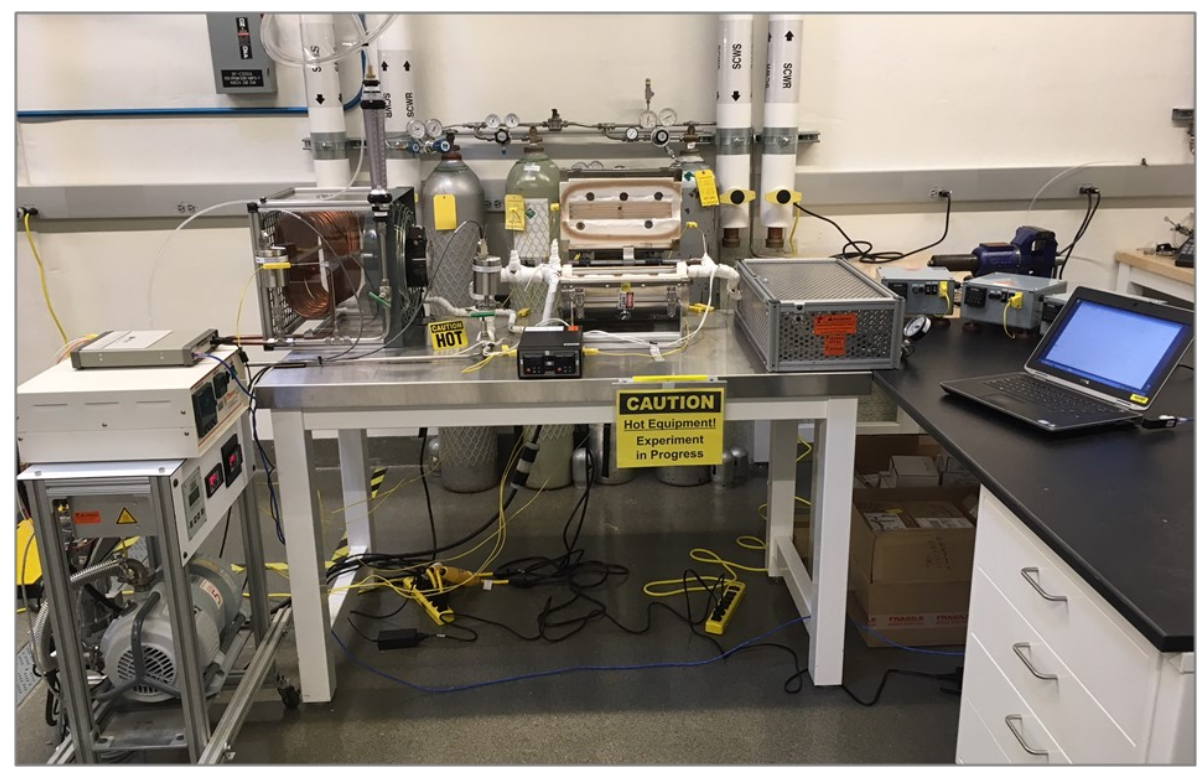

Figure 45. Laboratory test layout for testing the integrated hydrogen sensor and separation module. 
After checking the function of all system components, we performed baseline measurements to determine the permeate volume pressure increase due to leakage and gas desorption from the internal permeate volume surfaces. We brought the nominal tube furnace/module temperature to $350^{\circ} \mathrm{C}$, and flowed pure nitrogen through the module at 3 SCFM at pressures of $5 \mathrm{bar}, 7.5 \mathrm{bar}$, and $10 \mathrm{bar}$. The gas temperature at the module inlet ( $\mathrm{T} 4$ in Fig. 43 ) was $320^{\circ} \mathrm{C}$. At time $=0$ seconds, we closed the permeate valve and measured the permeate pressure increase. Figure 46 shows the pressure increase for pure nitrogen flow through the module annulus at 10 bar. The pressure increase after 3 minutes was $0.2 \%$ of the pressure increase that occurs when hydrogen is present in the gas mixture. The partial pressure measurement takes 2 minutes to come to steady state.

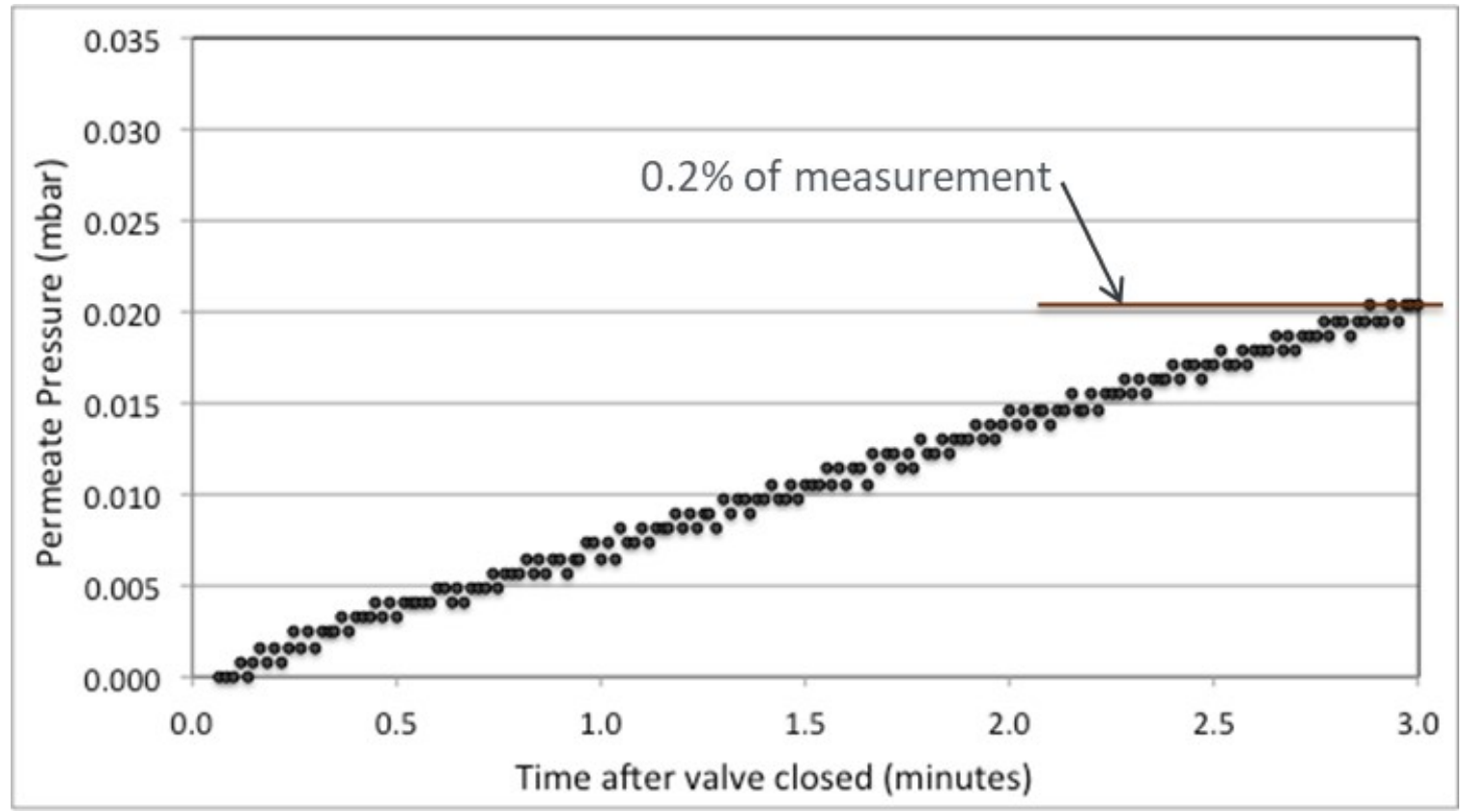

Figure 46. Permeate volume pressure increase due to leakage and surface desorption for pure nitrogen at 10 bar pressure. Total increase is $0.2 \%$ of hydrogen partial pressure measurement.

We devised a test plan that determined the accuracy of the hydrogen partial pressure measurement and the molar transfer rate across the membrane as functions of test flow conditions. Our test plan consisted of a set of tests in which we varied hydrogen concentration, module pressure, module flow rate, and module temperature one at a time while keeping the other variables constant. For each test condition, we made multiple measurements. Our original plan was to make five measurements for each condition. However, the high gas flow rates consumed our gas mixture supply quickly, so we were limited in the number of runs we could make for each condition. We were always able to make at least two runs for each test condition. 
For each test condition, we recorded the transient pressure response for multiple runs. Figures $47 \& 48$ show two sets of pressure transients. Figure 47 shows the responses for 1,000 ppmv hydrogen concentration, 7.55 bar module pressure, $325^{\circ} \mathrm{C}$ module temperature, and $1.0 \mathrm{~L} / \mathrm{s}$ module flow rate. During the test, the permeate valve was alternately open and closed. When open, hydrogen pressure was constant near 0 mbar. When closed, the hydrogen pressure increased to reach the partial pressure of hydrogen in the gas mixture. The horizontal line shows the target pressure of 7.55 mbar. Figure 48 shows the same responses for 1,000 ppmv hydrogen concentration, 7.55 bar module pressure, $325^{\circ} \mathrm{C}$ module temperature, but with $1.25 \mathrm{~L} / \mathrm{s}$ module flow rate. The target pressure for this set of measurements was again 7.55 mbar.

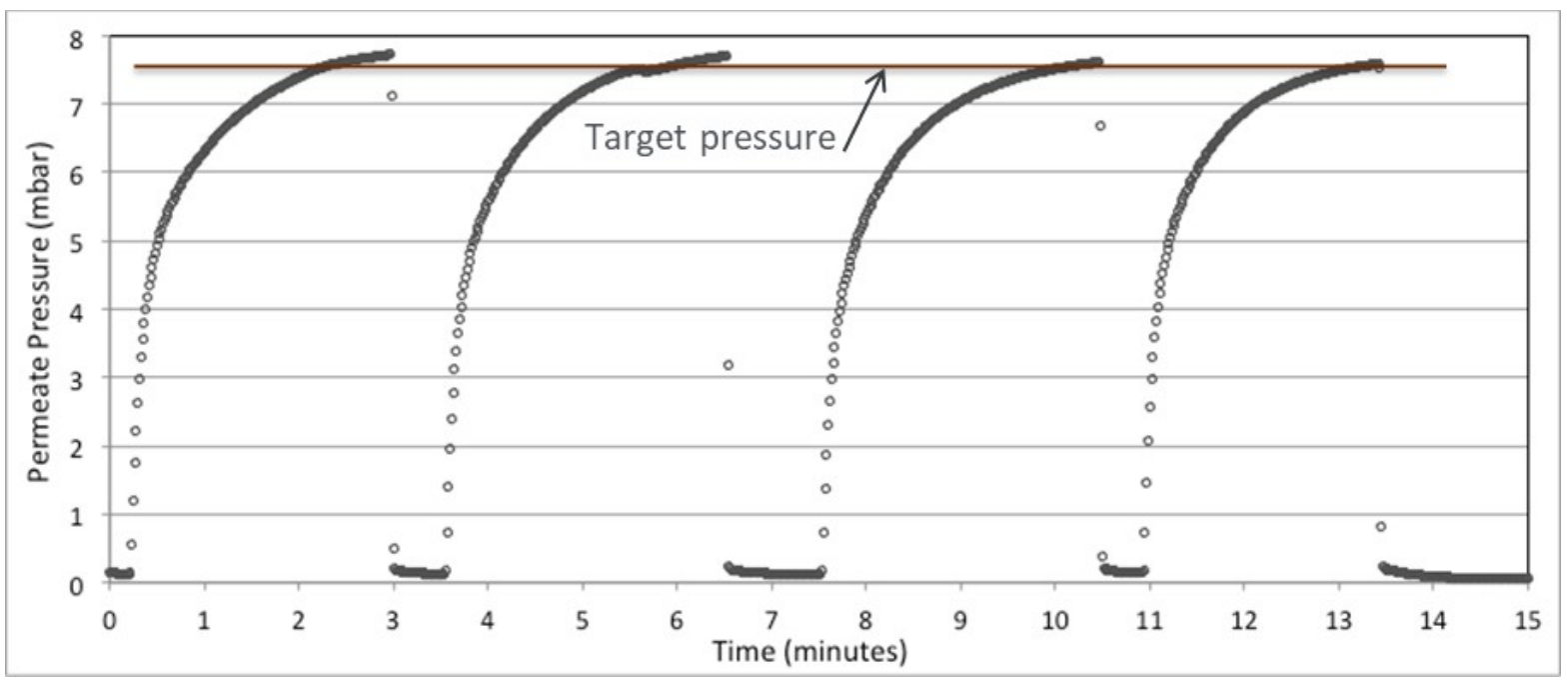

Figure 47. Hydrogen pressure responses for $1,000 \mathrm{ppmv}$ hydrogen concentration, 7.55 bar module pressure, $325^{\circ} \mathrm{C}$ module temperature, and $1.0 \mathrm{~L} / \mathrm{s}$ module flow rate.

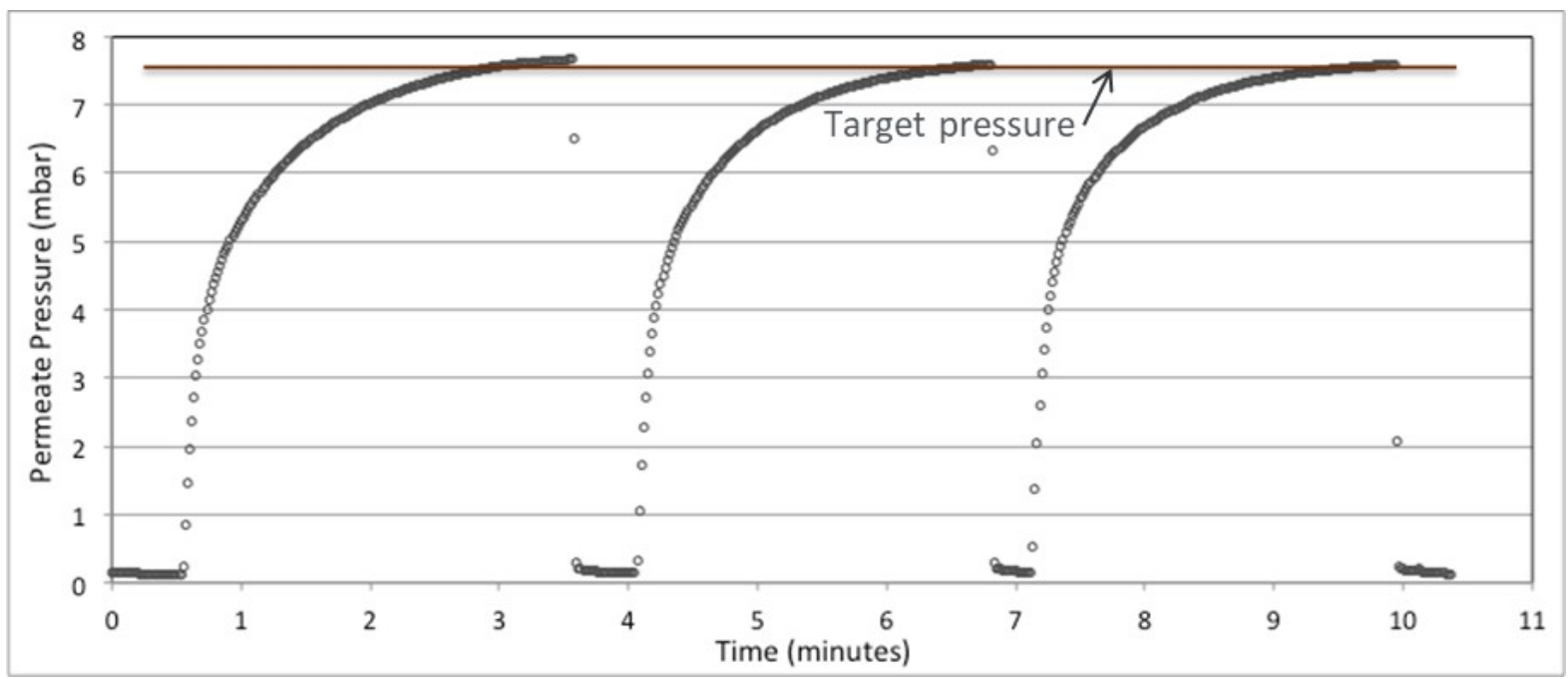

Figure 48. Hydrogen pressure responses for $1,000 \mathrm{ppmv}$ hydrogen concentration, 7.55 bar module pressure, $325^{\circ} \mathrm{C}$ module temperature, and $1.25 \mathrm{~L} / \mathrm{s}$ module flow rate. 
Table 6 lists the test conditions and results for all hydrogen partial pressure measurements. Within this set of measurements, 1) the hydrogen concentration had two values $-1,000$ ppmv and 2,000 ppmv, 2) module pressure was set to 5 bar, 7.5 bar, and 10 bar nominally, 3) module inlet temperature was set to $310^{\circ} \mathrm{C}, 325^{\circ} \mathrm{C}$, and $340^{\circ} \mathrm{C}$, and 4 ) module flow rate was set to $1.0 \mathrm{~L} / \mathrm{s}, 1.25 \mathrm{~L} / \mathrm{s}$, and $1.5 \mathrm{~L} / \mathrm{s}$ accounting for module temperature and pressure. Table 1 lists the percent error of the average measured partial pressure compared to the known value based on the hydrogen concentration, and the module total pressure. The greatest error was $10 \%$ while most of the measurement errors were within $5 \%$ of the known value. This error range is a significant improvement over the measurement error observed for the first version of the sensor (Figure 5). The improvement is likely due to the larger membrane area to permeate volume ratio, which generates a faster response that minimizes errors due to leakage and outgassing.

Table 6. Summary of hydrogen partial pressure measurement conditions and results.

\begin{tabular}{|c|c|c|c|c|c|c|c|c|c}
\hline $\begin{array}{c}\text { Test } \\
\text { No. }\end{array}$ & $\begin{array}{c}\text { Hydrogen } \\
\text { Conc } \\
\text { (ppmv) }\end{array}$ & $\begin{array}{c}\text { Flow } \\
\text { Rate } \\
(\text { SCFM) }\end{array}$ & $\begin{array}{c}\text { Module } \\
\text { Flow } \\
(\text { L/s) }\end{array}$ & $\begin{array}{c}\text { Module } \\
\text { Pressure } \\
\text { (bar) }\end{array}$ & $\begin{array}{c}\text { Module } \\
\text { Temp } \\
\left({ }^{\circ} \mathrm{C}\right)\end{array}$ & $\begin{array}{c}\text { No. } \\
\text { of } \\
\text { Runs }\end{array}$ & $\begin{array}{c}\text { Average } \\
\text { Measured } \\
(\mathrm{mbar})\end{array}$ & $\begin{array}{c}\text { Target } \\
\text { Pressure } \\
(\mathrm{mbar})\end{array}$ & $\begin{array}{c}\text { Percent } \\
\text { Error }\end{array}$ \\
\hline $11-11-1$ & 2,000 & 3.0 & 1.25 & 3.1 & 325 & 3 & 6.5 & 6.2 & $5 \%$ \\
\hline $11-11-2$ & 2,000 & 5.0 & 1.25 & 5.5 & 325 & 5 & 11.2 & 11.0 & $\mathbf{2 \%}$ \\
\hline $11-11-3$ & 1,000 & 6.5 & 1.00 & 7.55 & 325 & 4 & 7.7 & 7.55 & $\mathbf{1 \%}$ \\
\hline $11-11-4$ & 1,000 & 8.1 & 1.25 & 7.55 & 325 & 3 & 7.6 & 7.55 & $\mathbf{1 \%}$ \\
\hline $11-12-1$ & 1,000 & 5.4 & 1.25 & 5.1 & 325 & 4 & 5.6 & 5.1 & $10 \%$ \\
\hline $11-12-2$ & 1,000 & 9.7 & 1.50 & 7.55 & 325 & 2 & 8.0 & 7.55 & $5 \%$ \\
\hline $11-12-3$ & 1,000 & 7.9 & 1.25 & 7.5 & 340 & 2 & 8.2 & 7.5 & $9 \%$ \\
\hline $11-12-4$ & 1,000 & 8.2 & 1.25 & 7.55 & 310 & 2 & 7.6 & 7.55 & $1 \%$ \\
\hline $11-12-5$ & 1,000 & 10.8 & 1.25 & 10.0 & 325 & 2 & 10.4 & 10.0 & $4 \%$ \\
\hline
\end{tabular}

Tables 7-10 show summaries of the initial pressure rate increase according to the test parameter that were varied within the measurement sets. Table 7 shows the variation of initial pressure rate versus hydrogen concentration in the feed gas mixture. Table 8 shows the variation of initial pressure rate versus module pressure. Table 9 shows the variation of initial pressure rate versus module temperature. Table 10 shows the variation of initial pressure rate versus module flow rate.

Table 7. Initial pressure rate increase versus hydrogen concentration.

\begin{tabular}{|c|c|c|c|c|c|c|c|}
\hline $\begin{array}{c}\text { Test } \\
\text { No. }\end{array}$ & $\begin{array}{c}\text { Hydrogen } \\
\text { Conc } \\
(\mathrm{ppmv})\end{array}$ & $\begin{array}{c}\text { Flow } \\
\text { Rate } \\
(\text { SCFM) }\end{array}$ & $\begin{array}{c}\text { Module } \\
\text { Flow } \\
(\mathrm{L} / \mathrm{s})\end{array}$ & $\begin{array}{c}\text { Module } \\
\text { Pressure } \\
(\text { bar })\end{array}$ & $\begin{array}{c}\text { Module } \\
\text { Temp } \\
\left({ }^{\circ} \mathrm{C}\right)\end{array}$ & $\begin{array}{c}\text { No. } \\
\text { of } \\
\text { Runs }\end{array}$ & $\begin{array}{c}\text { Initial Press } \\
\text { Rate } \\
(\mathrm{mbar} / \mathrm{s})\end{array}$ \\
\hline $11-12-1$ & 1,000 & 5.4 & 1.25 & 5.1 & 325 & 4 & 0.415 \\
\hline $11-11-2$ & $\mathbf{2 , 0 0 0}$ & 5.0 & 1.25 & 5.5 & 325 & 5 & 0.799 \\
\hline
\end{tabular}


Table 7 shows that the initial pressure increase rate almost doubles when the hydrogen concentration doubles from 1,000 ppmv to 2,000 ppmv in the feed gas mixture as expected due to the increased hydrogen partial pressure in the gas mixture.

Table 8. Initial pressure rate increase versus module pressure.

\begin{tabular}{|c|c|c|c|c|c|c|c|}
\hline $\begin{array}{c}\text { Test } \\
\text { No. }\end{array}$ & $\begin{array}{c}\text { Hydrogen } \\
\text { Conc } \\
\text { (ppmv) }\end{array}$ & $\begin{array}{c}\text { Flow } \\
\text { Rate } \\
(\text { SCFM) }\end{array}$ & $\begin{array}{c}\text { Module } \\
\text { Flow } \\
(\mathrm{L} / \mathrm{s})\end{array}$ & $\begin{array}{c}\text { Module } \\
\text { Pressure } \\
\text { (bar) }\end{array}$ & $\begin{array}{c}\text { Module } \\
\text { Temp } \\
\left({ }^{\circ} \mathrm{C}\right)\end{array}$ & $\begin{array}{c}\text { No. } \\
\text { of } \\
\text { Runs }\end{array}$ & $\begin{array}{c}\text { Initial Press } \\
\text { Rate Est } \\
(\mathrm{mbar} / \mathrm{s})\end{array}$ \\
\hline $11-12-1$ & 1,000 & 5.4 & 1.25 & 5.1 & 325 & 4 & $\mathbf{0 . 4 1 5}$ \\
\hline $11-11-4$ & 1,000 & 8.1 & 1.25 & 7.55 & 325 & 3 & $\mathbf{0 . 6 3 9}$ \\
\hline $11-12-5$ & 1,000 & 10.8 & 1.25 & 10.0 & 325 & 2 & $\mathbf{0 . 7 1 0}$ \\
\hline
\end{tabular}

Table 8 shows the initial pressure increase rate increases with increasing module pressure when module flow rate and temperature are constant. This trend is expected because the increased total pressure increases the hydrogen partial pressure in the feed gas, which provides a higher driving force for hydrogen to cross the membrane.

Table 9. Initial pressure rate increase versus module temperature.

\begin{tabular}{|c|c|c|c|c|c|c|c|}
\hline $\begin{array}{c}\text { Test } \\
\text { No. }\end{array}$ & $\begin{array}{c}\text { Hydrogen } \\
\text { Conc } \\
(\mathrm{ppmv})\end{array}$ & $\begin{array}{c}\text { Flow } \\
\text { Rate } \\
(\text { SCFM) }\end{array}$ & $\begin{array}{c}\text { Module } \\
\text { Flow } \\
(\mathrm{L} / \mathrm{s})\end{array}$ & $\begin{array}{c}\text { Module } \\
\text { Pressure } \\
(\text { bar })\end{array}$ & $\begin{array}{c}\text { Module } \\
\text { Temp } \\
\left({ }^{\circ} \mathrm{C}\right)\end{array}$ & $\begin{array}{c}\text { No. } \\
\text { of } \\
\text { Runs }\end{array}$ & $\begin{array}{c}\text { Initial Press } \\
\text { Rate Est } \\
(\mathrm{mbar} / \mathrm{s})\end{array}$ \\
\hline $11-12-4$ & 1,000 & 8.2 & 1.25 & 7.55 & 310 & 2 & $\mathbf{0 . 6 2 2}$ \\
\hline $11-11-4$ & 1,000 & 8.1 & 1.25 & 7.55 & 325 & 3 & $\mathbf{0 . 6 3 9}$ \\
\hline $11-12-3$ & 1,000 & 7.9 & 1.25 & 7.5 & 340 & 2 & $\mathbf{0 . 6 5 7}$ \\
\hline
\end{tabular}

Table 9 shows the initial pressure increase rate increases with increasing module temperature when module flow rate and pressure are constant. This trend is expected primarily because membrane permeability increases with increasing module temperature.

Table 10. Initial pressure rate increase versus module flow rate.

\begin{tabular}{|c|c|c|c|c|c|c|c|}
\hline $\begin{array}{c}\text { Test } \\
\text { No. }\end{array}$ & $\begin{array}{c}\text { Hydrogen } \\
\text { Conc } \\
\text { (ppmv) }\end{array}$ & $\begin{array}{c}\text { Flow } \\
\text { Rate } \\
(\text { SCFM) }\end{array}$ & $\begin{array}{c}\text { Module } \\
\text { Flow } \\
(\mathrm{L} / \mathrm{s})\end{array}$ & $\begin{array}{c}\text { Module } \\
\text { Pressure } \\
\text { (bar) }\end{array}$ & $\begin{array}{c}\text { Module } \\
\text { Temp } \\
\left({ }^{\circ} \mathrm{C}\right)\end{array}$ & $\begin{array}{c}\text { No. } \\
\text { of } \\
\text { Runs }\end{array}$ & $\begin{array}{c}\text { Initial Press } \\
\text { Rate Est } \\
(\mathrm{mbar} / \mathrm{s})\end{array}$ \\
\hline $11-11-3$ & 1,000 & 6.5 & 1.00 & 7.55 & 325 & 4 & 0.594 \\
\hline $11-11-4$ & 1,000 & 8.1 & 1.25 & 7.55 & 325 & 3 & 0.639 \\
\hline $11-12-2$ & 1,000 & 9.7 & 1.50 & 7.55 & 325 & 2 & 0.696 \\
\hline
\end{tabular}

Table 10 shows the initial pressure increase rate increases with increasing module flow rate when module temperature and pressure are constant. Again, this trend is 
expected because the transfer of hydrogen from the bulk gas to the boundary layer adjacent to the membrane surface increases with increasing gas flow rates. All trends that are shown in Tables 7-10 are consistent with our physical transport model for hydrogen transfer in the gas mixture flow and across the membrane.

We used the initial pressure increases listed in Tables 7-10 to calculate the initial molar transfer rate across the membrane. This rate equals the steady-state molar transfer rate when the permeate valve is open. The molar transfer rates were calculated using the expression:

$$
\frac{d n}{d t}(0)=\frac{V_{p}}{R T_{p}} \frac{d P_{p}}{d t}(0)
$$

This expression relates the molar transfer rate at time $=0$ seconds to the initial pressure increase using the ideal gas law. Here, $V_{p}$ is the permeate volume, $T_{p}$ is the permeate volume temperature, and $R$ is the ideal gas constant. Table 11 lists the test measurement conditions along with the initial pressure increase rates and corresponding initial transfer rates.

Table 11. Summary of initial pressure rate increase and corresponding hydrogen molar transfer rates.

\begin{tabular}{|c|c|c|c|c|c|c|c|c|}
\hline $\begin{array}{c}\text { Test } \\
\text { No. }\end{array}$ & $\begin{array}{c}\text { No. } \\
\text { of } \\
\text { Runs }\end{array}$ & $\begin{array}{c}\text { Hydrogen } \\
\text { Conc } \\
(\mathrm{ppmv})\end{array}$ & $\begin{array}{c}\text { Module } \\
\text { Flow } \\
(\mathrm{L} / \mathrm{s})\end{array}$ & $\begin{array}{c}\text { Module } \\
\text { Pressure } \\
(\mathrm{bar})\end{array}$ & $\begin{array}{c}\text { Module } \\
\text { Temp } \\
\left({ }^{\circ} \mathrm{C}\right)\end{array}$ & $\begin{array}{c}\text { Initial } \\
\text { Rate } \\
(\mathrm{mbar} / \mathrm{s})\end{array}$ & $\begin{array}{c}\text { Transfer } \\
\text { Rate } \\
(\mu \mathrm{mol} / \mathrm{s})\end{array}$ & $\begin{array}{c}\text { Reynolds } \\
\text { No. }\end{array}$ \\
\hline $11-11-1$ & 3 & 2,000 & 1.25 & 3.1 & 325 & 0.467 & $\mathbf{0 . 6 2}$ & 2,010 \\
\hline $11-11-2$ & 5 & 2,000 & 1.25 & 5.5 & 325 & 0.799 & 1.06 & 3,184 \\
\hline $11-11-3$ & 4 & 1,000 & 1.00 & 7.55 & 325 & 0.594 & 0.79 & 4,072 \\
\hline $11-11-4$ & 3 & 1,000 & 1.25 & 7.55 & 325 & 0.639 & 0.84 & 4,767 \\
\hline $11-12-1$ & 4 & 1,000 & 1.25 & 5.1 & 325 & 0.386 & 0.52 & 3,438 \\
\hline $11-12-2$ & 2 & 1,000 & 1.50 & 7.55 & 325 & 0.696 & 0.92 & 5,617 \\
\hline $11-12-3$ & 2 & 1,000 & 1.25 & 7.5 & 340 & 0.657 & 0.84 & 5,154 \\
\hline $11-12-4$ & 2 & 1,000 & 1.25 & 7.55 & 310 & 0.622 & 0.80 & 5,598 \\
\hline $11-12-5$ & 2 & 1,000 & 1.25 & 10.0 & 325 & 0.710 & 0.91 & 7,130 \\
\hline
\end{tabular}

The transfer rates listed in Table 11 were significantly less than the rates that were predicted assuming fully developed turbulent flow in the module annulus and corresponding thin laminar boundary layer that is adjacent to the outer surface of the membrane. Table 6 shows the corresponding Reynold's number for each of the test conditions. All but the first are well above the nominal value of 2,600 that sets the boundary between laminar and turbulent flow. However, Incropera et al (2011) [48] 
states that the Reynold's number must be greater than 10,000 to ensure fully developed turbulent flow. Values between 2,600 and 10,000 are considered to correspond to the transition region between laminar and turbulent.

Considering this limitation, the set of tests listed in Table 11 may have had flows within the module annulus that were not fully turbulent resulting in lower molar transfer rates. We completed modifications to the system layout that is shown in Figures $44 \& 45$ that allow us to operate at higher flow rates and higher Reynold's numbers. We performed a set of tests at Reynold's numbers greater than 10,000 to determine molar transfer rates when the gas mixture flow is fully turbulent.

\section{Power plant mitigation process installation}

In early 2018, NREL and Acciona met to discuss findings for all experimental and modeling work, along with the initial design, performance, and cost estimates for testand full-scale installations at their NSO power plant. After evaluating the results, Acciona decided to proceed with the test- and full-scale installations at the plant.

Most of the process specification and design information for the installation at the NSO power plant is proprietary, so this information was not included in this report. This section does include some general process and module design information to provide a sense of the installation process.

The first step was to identify a location for the process in the central part of the power plants. Once the location was selected, we determined piping lengths for the headspace supply and return lines. Figure 49 shows piping for the headspace gas supply and return lines. Two tanks supply headspace gas to the process, which is returned to the other two tanks. Existing piping maintains equal pressure in the four tanks. With this information, we could specify final headspace gas flow rates and pressure drops, which allowed us to size the headspace gas compressor and membrane area. These specifications provided the final design for the separation module and other equipment.

The target hydrogen partial pressure in the headspace gas for the test scale was 2.3 mbar. Our target for the full-scale unit was 0.35 mbar. This level was chosen because we believe that it will allow existing receivers to maintain their performance for the remaining operating years of the power plant. In addition, this level can be reached using just one additional sensor/separator module of the same size as the test-scale module, and so allows a relatively easy transition from test scale to full scale. 


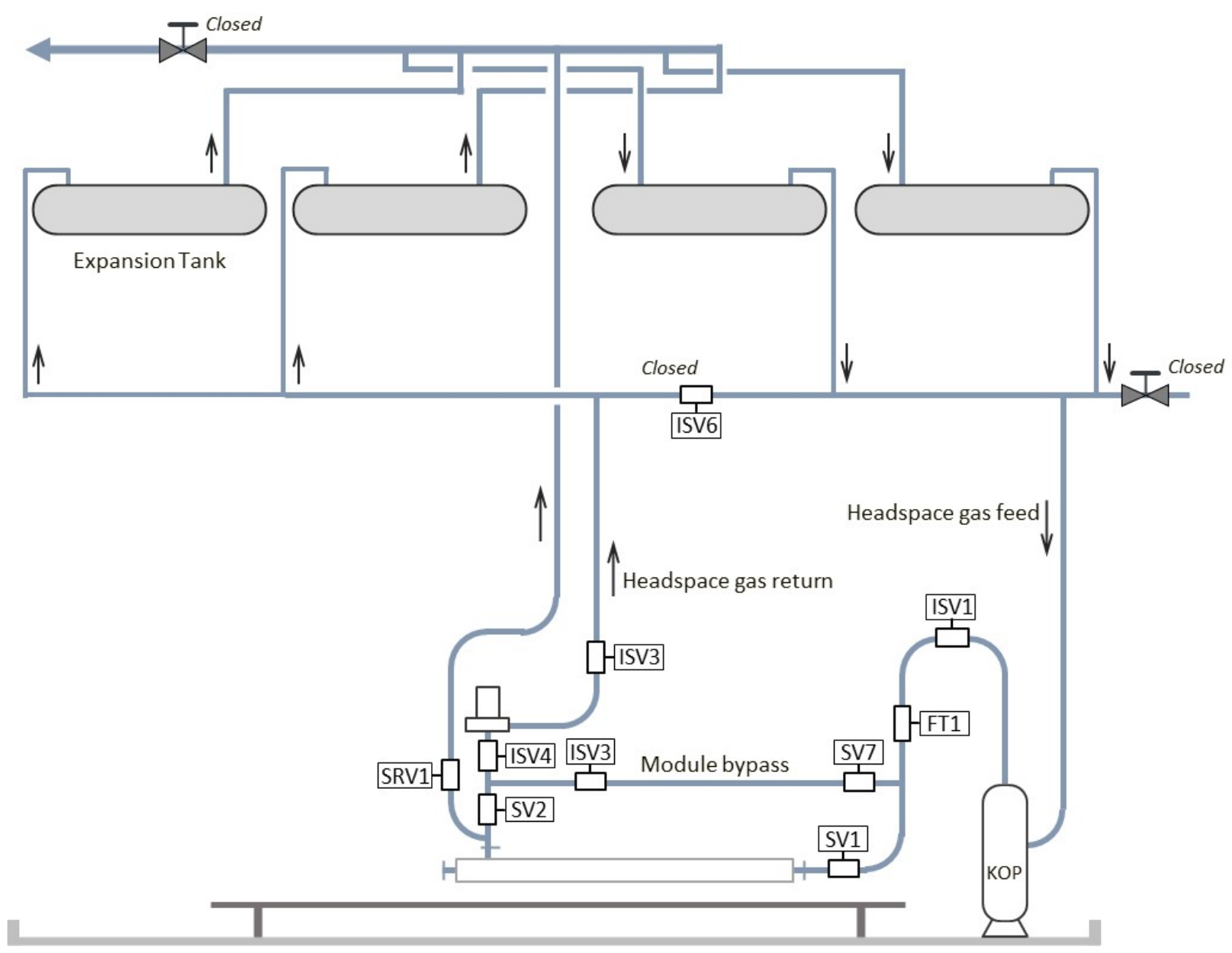

Figure 49. Piping layout for hydrogen mitigation process installation at NSO.

Figure 50 shows the general module design. As with the laboratory-scale version, headspace gas enters the right end through the insert and distributes into the annulus. The right insert is a flow straightener that allows the headspace gas to establish fullydeveloped flow before reaching the membrane.

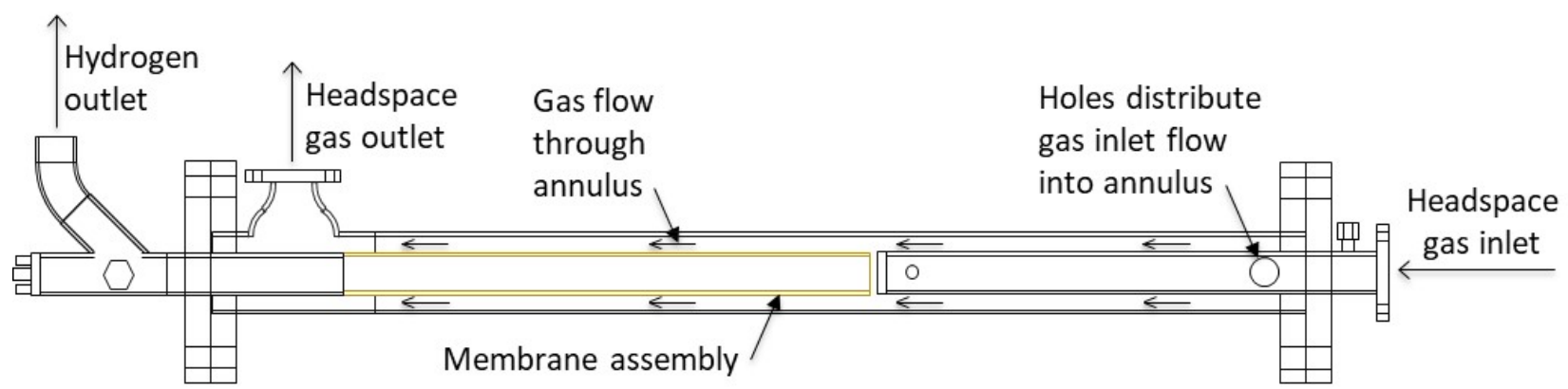

Figure 50. Integrated hydrogen sensor/separation module design.

Figures 51 and 52 show the fabricated module and two module inserts respectively in a workshop at NREL. 


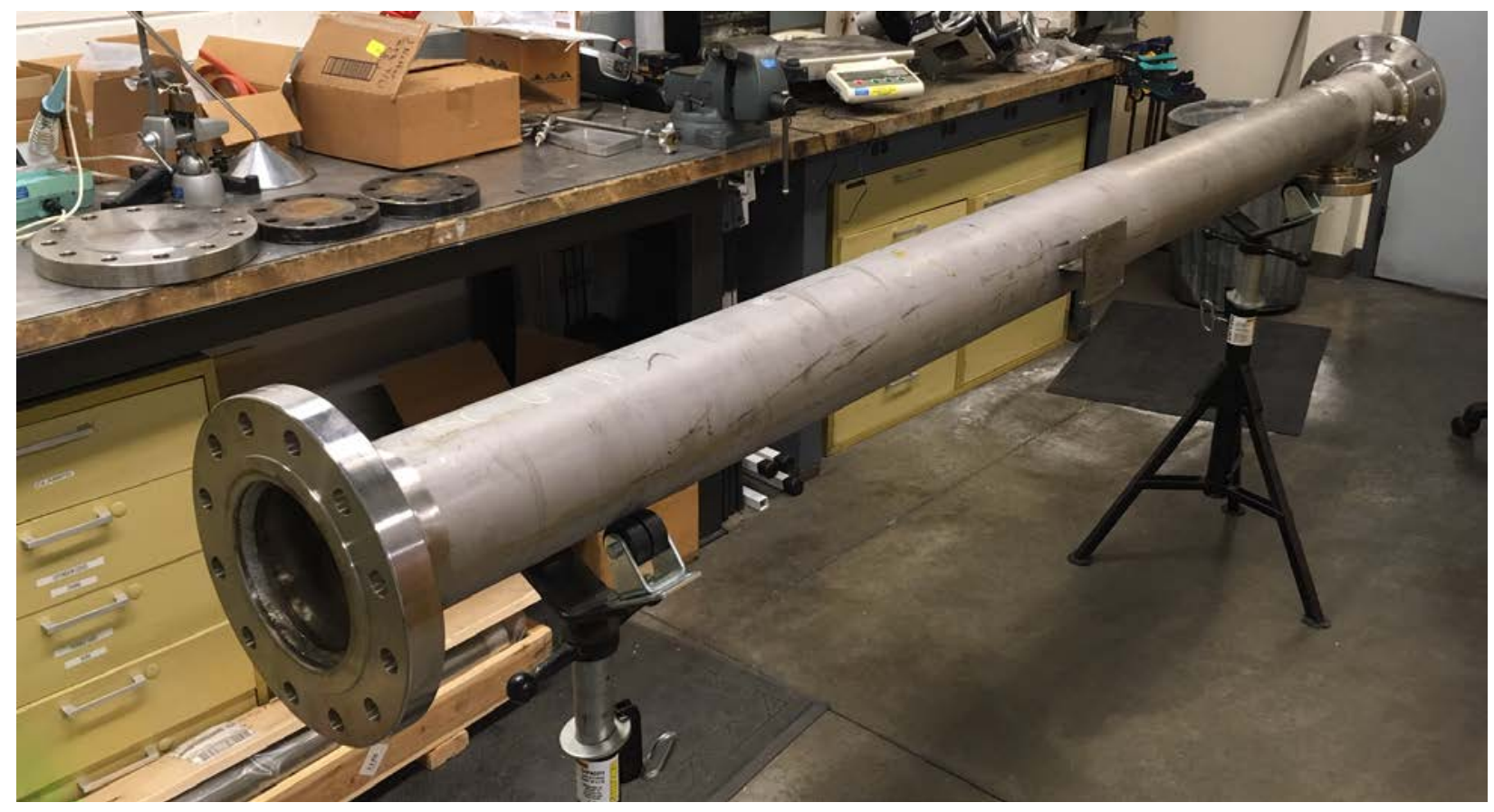

Figure 51. Integrated hydrogen sensor/separation module.

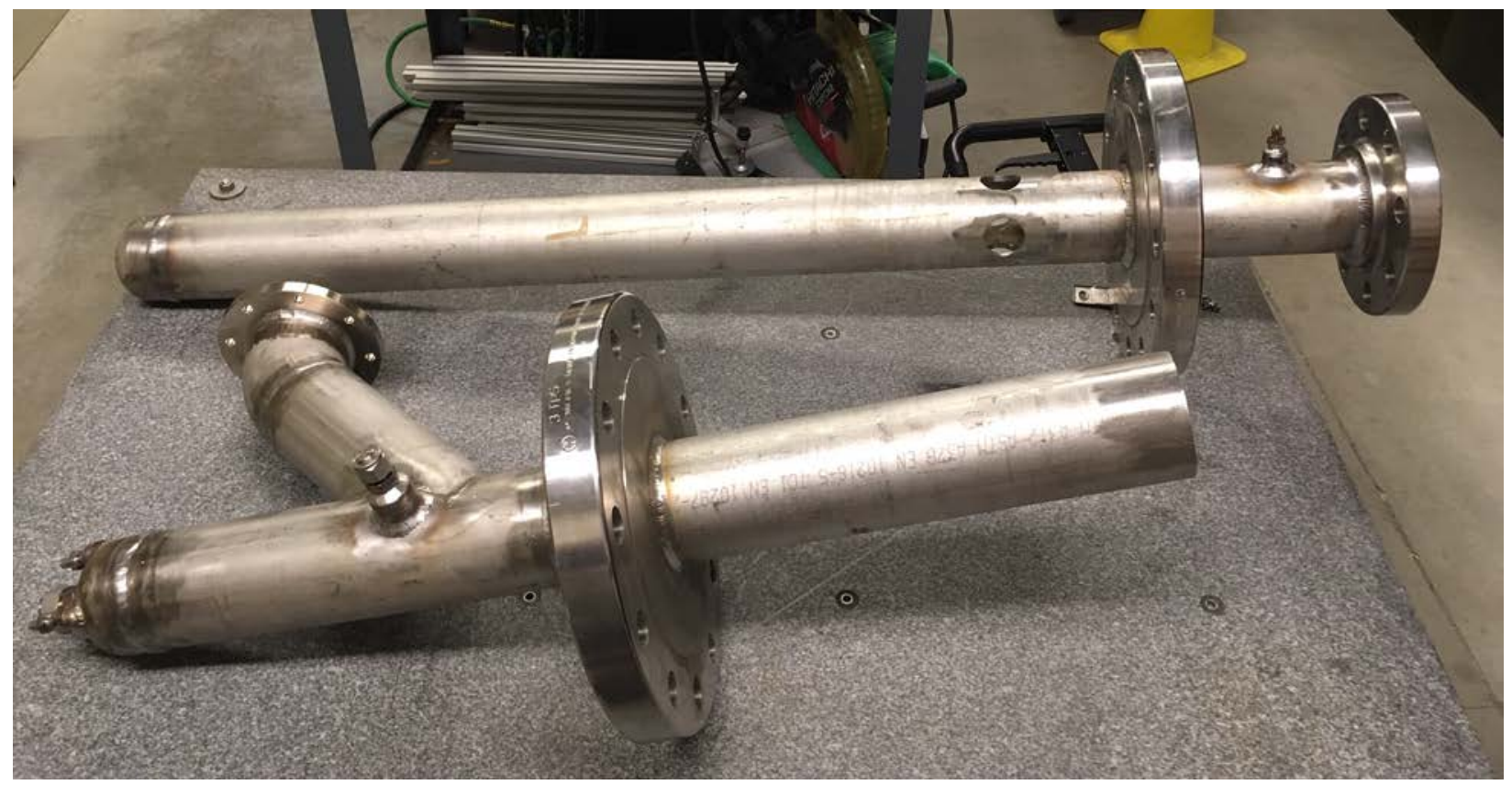

Figure 52: Photo of completed module with its two inserts.

At the conclusion of the period of performance for this project, NREL and Acciona were in the process of procuring, fabricating, and installing equipment for the test-scale module and process at the NSO power plant. Earlier in 2018, NREL applied for and was awarded funding from the Technology Commercialization Fund (TCF) FOA. The 
resulting CRADA is a 50:50 cost share between Acciona and DOE. Acciona has committed funds to complete installation of the test- and full-scale processes. With the TCF funds, NREL will continue to participate as a partner in the installations and commercialization of this new technology.

\section{Continuing Work}

\section{TCF award work plan}

NREL received a Technology Commercialization Fund (TCF) award in August 2018 from the DOE Office of Technology Transitions (OTT), and began performing the workplan November 1, 2018. The workplan includes 1) completing the test-scale installation, 2) evaluating the performance of the test-scale process, 3) designing and installing the full-scale process, and 4) evaluating the full-scale process performance. The period of performance runs through March 2020. With this award, NREL and Acciona will be able to complete technology transfer from laboratory-scale at NREL to full-scale commercial implementation at NSO.

\section{Summary}

\section{Fundamental advances}

Technical progress during the project period of performance included several fundamental advances - all of which were needed to meet the overall technical objectives for this project. These advances were achieved using a combination of process modeling and analysis, and extensive experimental work that validated modeling results and provided the performance data necessary to specify the full-scale mitigation system. Fundamental advances during the first 2 years included:

- A simple hydrogen sensor that measures hydrogen partial pressure in the expansion tank headspace gas at expansion tank conditions;

- Extended receiver heating and heat loss measurements that provided the first evidence that hydrogen permeation in receivers is reversible and that receiver performance can be improved with extended receiver heating when no hydrogen is present in the absorber;

- A power plant hydrogen transport and generation model that showed that controlling hydrogen levels in the expansion tanks maintains the level of dissolved hydrogen in the HTF that is circulating in the collector field to target levels;

- A receiver lifetime model that estimated the years that a receiver would last in the collector field as a function of SCA position and dissolved hydrogen concentration in the circulating HTF. 
- Modeling and experimental testing that generated critical partitioning and mass transfer coefficients for hydrogen at the HTF liquid/gas interface within the expansion tanks;

- An integrated hydrogen separator and sensor module that separates hydrogen from the headspace gas, measures hydrogen partial pressure in the headspace gas, and measures the rate of hydrogen removal from the expansion tank headspace gas.

- One interesting feature of the integrated sensor and separation module is its use of a palladium membrane to remove hydrogen from the power plant. This general approach was used originally by Labaton [15] to remove hydrogen from individual receivers. However, the palladium membranes in the receivers cooled to below $300^{\circ} \mathrm{C}$ at night, embrittled, and failed. We addressed this problem by locating a single palladium membrane within the sensor/separation module. This membrane is always kept above $325^{\circ} \mathrm{C}$ using an electric heater, and so avoids embrittlement and failure.

\section{Key project result}

During the third year of this project, Acciona committed to proceed with test-scale and full-scale installations at their Nevada Solar One power plant. Since making this decision, Acciona has fully committed to making these installations technically and commercially successful. Their decision to proceed resulted in the transfer of process and plant knowledge - acquired as part of the fundamental advances generated during the first two years of this project - to commercial implementation and use at Acciona's NSO power plant in Boulder City, Nevada. 


\section{References}

1. G. C. Glatzmaier (2013) "Systems and methods for selective hydrogen transport and measurement." U.S. Patent 8,568,582.

2. G. C. Glatzmaier, D. A. Cooney (2017) "Sensor for measuring hydrogen partial pressure in parabolic trough power plant expansion tanks." AIP Conference Proceedings 1850, 020007: doi: 10.1063/1.4984331.

3. G. C. Glatzmaier (2018) "Hydrogen sensor for parabolic trough expansion tanks," AIP Conference Proceedings 2033, 030006; doi: 10.1063/1.5067022.

4. G. C. Glatzmaier, R. Cable, M. Newmarker (2017) "Long-term heating to improve receiver performance." AIP Conference Proceedings 1850, 020006: doi: 10.1063/1.4984330.

5. G. C. Glatzmaier, R. Cable, M. Newmarker (2017) "Steady-state plant model to predict hydrogen levels in power plant components." AIP Conference Proceedings 1850, 020008: doi: 10.1063/1.4984332.

6. K. F. Beckers, G. C. Glatzmaier (2018) "Modeling and simulating diffused aeration for hydrogen removal from expansion tanks of parabolic trough solar thermal power plants," AIP Conference Proceedings 2033, 030001; doi: 10.1063/1.5067017.

7. G. C. Glatzmaier (2017) "Hydrogen Sensing and Separation," U.S. Pat. App. No. 15/782,198; filed October 12, 2017.

8. G. C. Glatzmaier (2018) "Integrated hydrogen sensor and separator for parabolic trough expansion tanks," 2018 Solar PACES Conference, Casablanca, Morocco.

9. K. F. Beckers, G. C. Glatzmaier (2018) "Experimental measurements of Henry's law constant and mass transfer coefficient of hydrogen absorbing in eutectic BP/DPE heat transfer fluid," Solar Energy 173, 304-312.

10. http://www.nrel.gov/csp/solarpaces/

11. L. Moens, D. Blake (2008) "Mechanism of hydrogen formation in solar parabolic trough receivers," NREL/TP-510-42468.

12. I. B. Johns, E. A. McElhill, J. O. Smith (1962) "Thermal Stability of Some Organic Compounds,"J. of Chemical and Engineering Data 7(2) 277-281.

13. K. Horikawa, H. Okada, H. Kobayashi, W. Urushihara (2009) "Hydrogen Permeation Estimated by HMT in Carbon Steel Exposed to Gaseous Hydrogen," Materials Transactions 50(9), 2201-2206. 
14. V. L. Gadgeel, D. L. Johnson (1979) "Gas-Phase Hydrogen Permeation and Diffusion in Carbon Steels as a Function of Carbon Content from 500 to $900 \mathrm{~K}$," J. Materials for Energy Systems 1(2), 32-40.

15. I. J. Labaton, Y. Harats (1989) "Hydrogen Pump," U.S. Patent No. 4,886,048.

16. O. Sohr, M. Mollenhoff, T. Kuckelkorn (2013) "Laser induced release of encapsulated noble gas in Schott receiver," 2013 Solar PACES Conference.

17. F. Burkholder, M. Brandemuehl, C. Kutscher, E. Wolfrum (2008) "Heat conduction of inert gas-hydrogen mixtures in parabolic trough receivers," Proceedings of the ASME $2^{\text {nd }}$ International Conference on Energy Sustainability, ES2008-54176.

18. T. Mclntyre, "Low-cost, thick-film hydrogen sensors," Oak Ridge National Laboratory Fact Sheet.

19. G. Korotcenkov, S. D. Han, J. R. Stetter (2009) "Review of electrochemical hydrogen sensors," Chem. Rev. 109, 1402-1433.

20. C. Schwandt (2013) "Solid state electrochemical hydrogen sensor for aluminum and aluminum alloy melts," Sensors and Actuators B, 187, 227-233.

21. M. P. Hills, C. Schwandt, R. V. Kumar (2011) "The zirconium/hydrogen system as the solid-state reference of a high-temperature proton conductor-based hydrogen sensor," J. Appl. Electrochem. 41, 499-506.

22. C. Schwandt, D. J. Fray (2006) "The titanium/hydrogen system as the solid-state reference in high-temperature proton conductor-based hydrogen sensors," ," $J$. Appl. Electrochem. 36, 557-565.

23. O. Hatlevik, S. K. Gade, M. K. Keeling, P. M. Thoen, A. P. Davidson, J. D. Way (2010) "Palladium and palladium alloy membranes for hydrogen separation and production: History, fabrication strategies, and current performance," Separation and Purification Technology, 73 (1) 59-64.

24. Y. S. Cheng, K. L. Yeung (1999) "Palladium-silver composite membranes by electroless plating technique," J. Membrane Science, 158 (1-2) 127-141.

25. R. Bhandari and Y. H. Ma (2009) "Pd-Ag membrane synthesis: the electroless and electro-plating conditions and their effect on the deposits morphology," J. Membrane Science, 334 (1-2) 50-63.

26. S. Adhikari, S. Fernando (2006) "Hydrogen membrane separation techniques," Industrial \& Engineering Chemistry Research, 45 (3) 875-881.

27. E. David, J. Kopac (2011) "Development of palladium/ceramic membranes for hydrogen separation," Int J Hydrogen Energy, 36 (7) 4498-4505. 
28. "MKS Type a-Baratron ${ }^{T M}$ Absolute Pressure Transducer," Pub. 1048990-001 Rev. 1 (2014).

29. https://www.mathesongas.com/pdfs/products/Mixture-Grades.pdf

30. "Therminol VP-1, Heat Transfer Fluid by Solutia," Tech. Bull. 7239115B (1999) www.therminol.com.

31. Crittenden, J. C., Howe, K. J., Hand, D. W., Tchobanoglous, G. \& Trussell, R. R. (2012) Principles of Water Treatment, John Wiley \& Sons.

32. F. Burkholder, C. Kutscher (2009) "Heat loss testing of Schott's 2008 PTR70 parabolic trough receiver," NREL/TP-550-45633.

33. F. Burkholder, C. Kutscher (2008) "Heat loss testing of Solel's UVAC3 parabolic trough receiver," NREL/TP-550-42394.

34. V. L. Gadgeel, D. L. Johnson (1979) "Gas-Phase Hydrogen Permeation and Diffusion in Carbon Steels as a Function of Carbon Content from 500 to $900 \mathrm{~K}$," J. Materials for Energy Systems 1(2), 32-40.

35. T. Kuckelkorn, C. Jung, T. Gnädig, C. Lang, C. Schall (2016) "Hydrogen Generation in CSP Plants and Maintenance of DPO/BP Heat Transfer Fluids - A Simulation Approach," AIP Conf. Proceedings 1734, 090002; doi: 10.1063/1.4949187.

36. J. R. Davis (2000) "Alloy Digest, Sourcebook, Stainless Steels," Materials Park, OH: ASM International.

37. S. Xiukui, X. Jian, L. Yiyi (1989) "Hydrogen permeation behaviour in austenitic stainless steels," Mater. Sci. Eng. A114, 179-187.

38. "Schott PTR70 Receiver - $4^{\text {th }}$ Generation," Schott Solar CSP, Germany; www.schott.com/csp

39. S. A. Klein (2002) "Engineering Equation Solver (EES) for Microsoft Windows Operating System: Commercial and Professional Versions," Madison, WI: F-Chart Software (http://www.fchart.com).

40. C. Yung (2018) "Hydrogen Monitoring in the Heat Transfer Fluid of Parabolic Trough Plants," $24^{\text {th }}$ Solar PACES Conference, Casablanca, Morocco.

41. G. C. Glatzmaier (2009) "Modeling Hydrogen Occurrence in Parabolic Trough Power Plants," 2009 Solar PACES Conference, Berlin, Germany.

42. Cussler, E. L. (2009). Diffusion: mass transfer in fluid systems, Cambridge University Press.

43. Hines, A. L., and Maddox, R. N. (1985) Mass transfer: fundamentals and applications, Vol. 434, Englewood Cliffs, NJ: Prentice-Hall. 
44. Wilke, C. R., and Chang, P. (1955) "Correlation of diffusion coefficients in dilute solutions," AIChE Journal 1, no. 2: 264-270.

45. Chern, J. M., \& Yu, C. F. (1995) "Volatile Organic Carbon Emission Rate from Diffused Aeration Systems, 1. Mass Transfer Modeling," Industrial \& engineering chemistry research, 34(8), 2634-2643.

46. MathWorks (2012). MATLAB Release 2012a, The Mathworks, Inc., Natick, Massachusetts, United States.

47. Dewulf, J., Drijvers, D., \& Van Langenhove, H. (1995) "Measurement of Henry's law constant as function of temperature and salinity for the low temperature range," Atmospheric Environment, 29(3), 323-331.

48. F. Incropera, D. DeWitt (1990) "Fundamentals of Heat and Mass Transfer," $3^{\text {rd }}$ Edition. New York, NY: John Wiley and Sons.

49. J. Li, Z. Wang, D. Lei, J. Li (2012) "Hydrogen permeation model of parabolic trough receiver tube," Solar Energy 86, 1187-1196. 